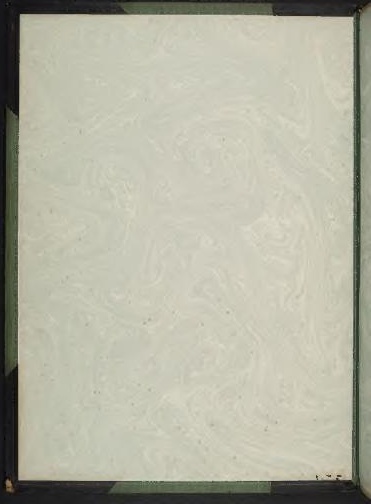




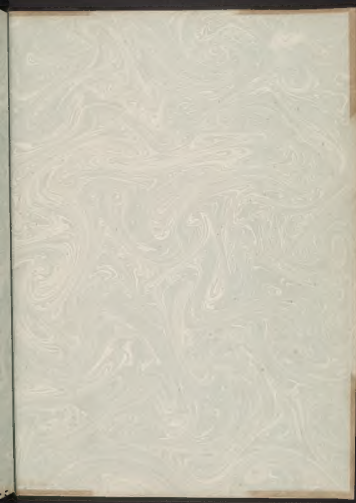




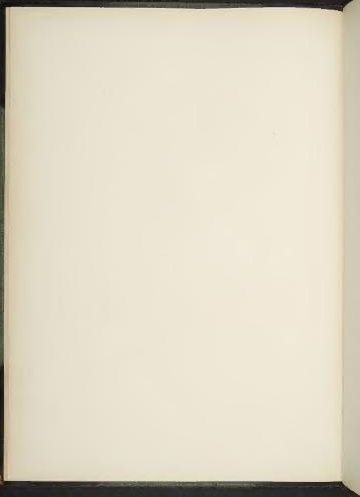




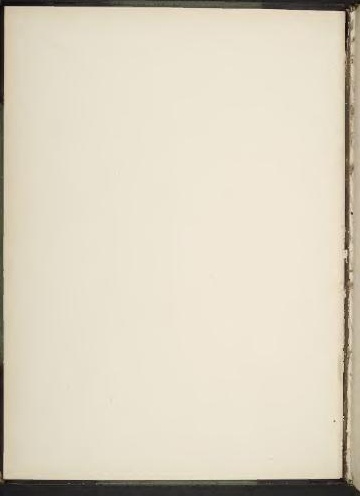


SPI, BCT

ORCHIDACEOES PIANTS 
6 
SELECT

\section{ORCHHDACEOLS PLANTS.}

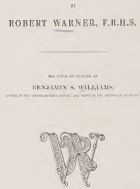

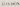

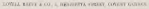
$1014=14$

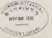




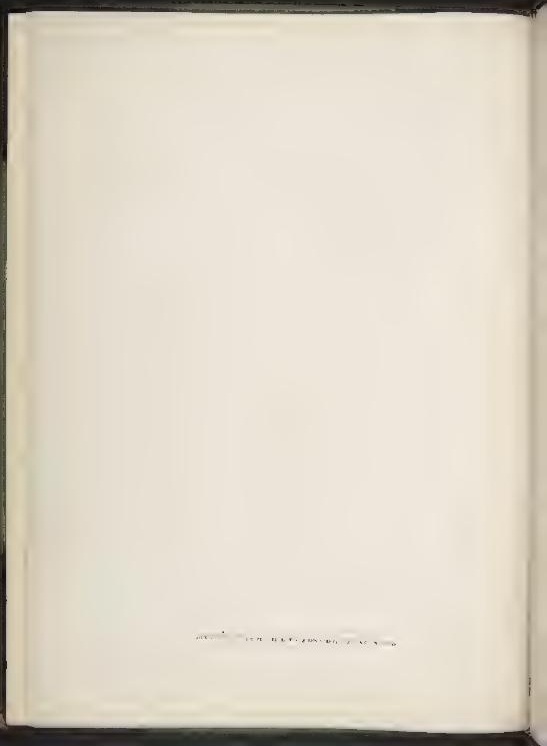




\title{
Mediated
}

\author{
cy Sustal yeroustam
}

\section{HER BOST (FACIOLS MAJEST}

\section{QUEEN VICTORIA.}

If Hat 4 sistry

JAYAL ASB NOST GE+THENT SETL SN?

MOBEBI WAHXY1 


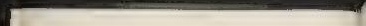




\section{INTRODLCTION.}

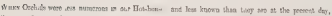

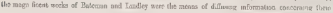

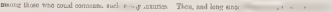

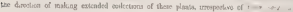

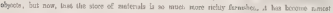

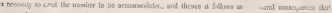

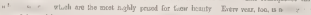

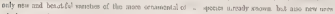

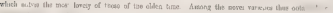

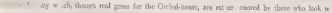

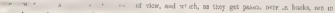

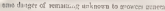

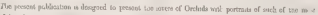

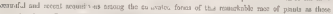

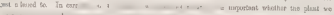

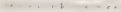

$Y=1$ isare

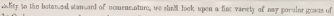

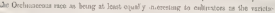

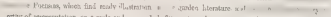

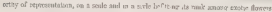

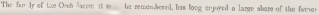

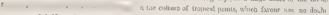

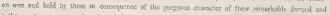

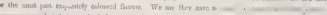

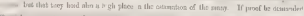

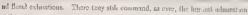

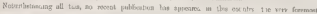

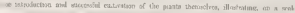

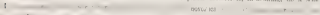

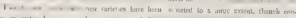

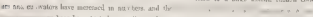

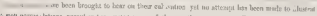

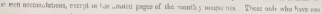

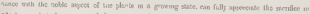

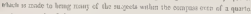

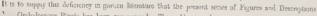

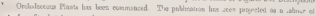

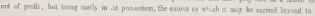




\section{$\sin x+\cos$}

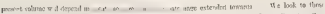

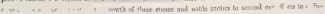

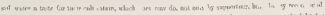

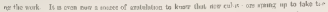

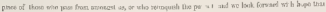

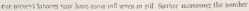

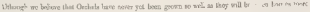

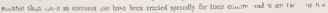

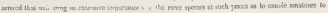

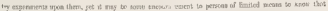

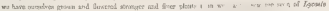

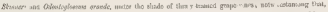

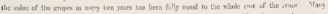

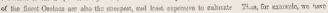

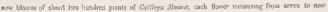

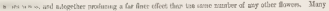

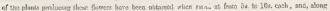

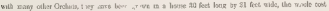

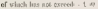

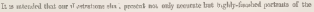

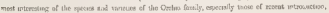

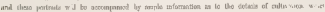

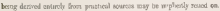

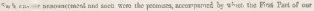

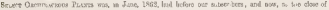

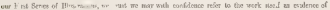

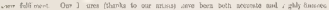

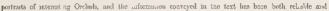

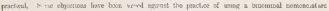

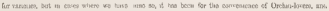

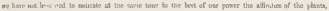

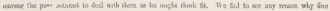

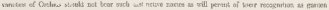

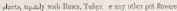

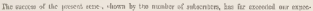

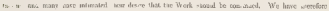

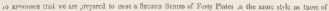

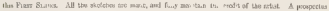
\$, ll ke Lew

IOT)

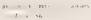


CONTENTS.

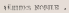

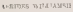

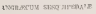

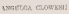

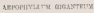

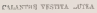

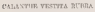

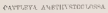

csprasya isawgosa.

EAmorks surenos.

ratuaks Finerar

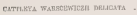

gursts 1 1

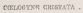

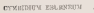

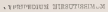

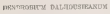

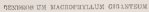

moxogome if vesmiasust

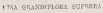

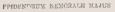

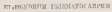

$\rightarrow$

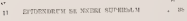

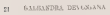

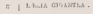

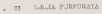

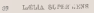

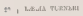

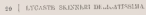

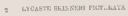

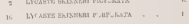

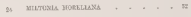

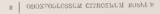

4

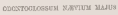

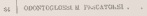

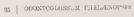

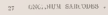

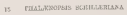

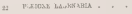

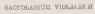

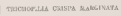

is.us batrata

11. verna thertixis: 


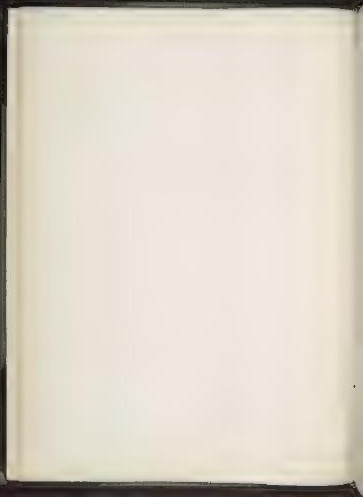





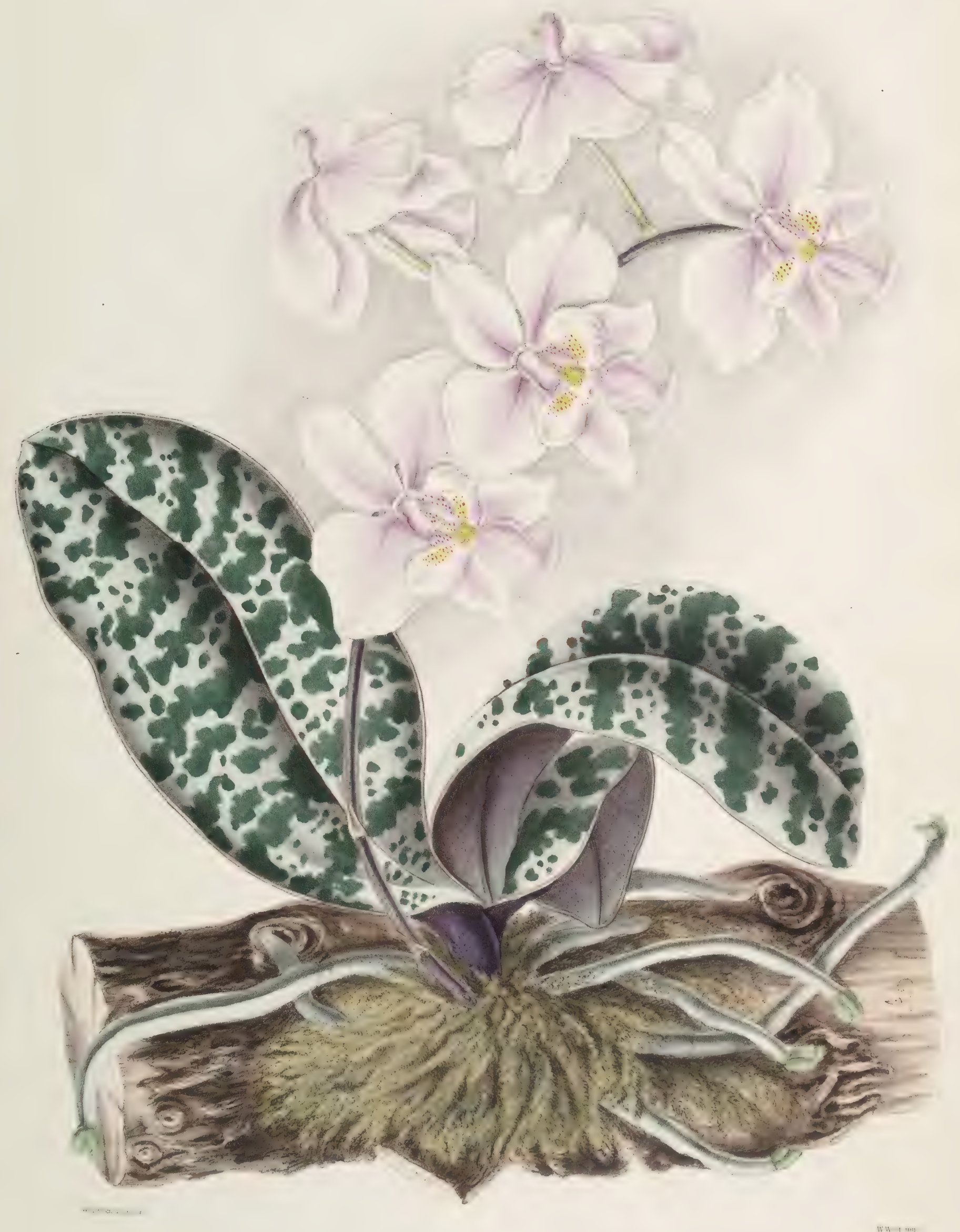




\section{PIIAT MONOPST GCIHLLERIANA}

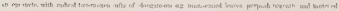

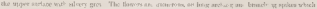

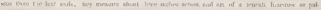

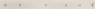

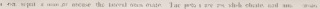

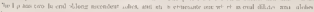

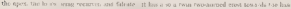

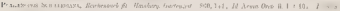

11. $+1 .+1$.

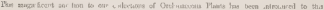

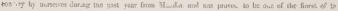

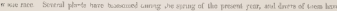

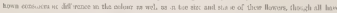

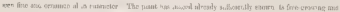

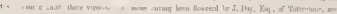

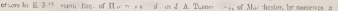

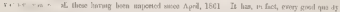

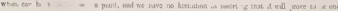

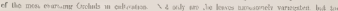

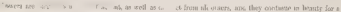

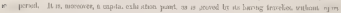

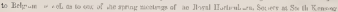

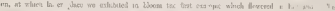

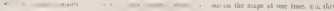

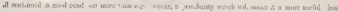

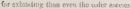

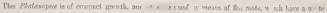

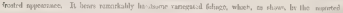

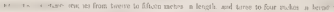

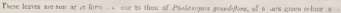

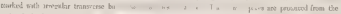

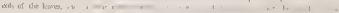

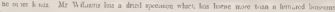

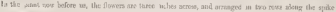

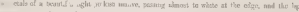

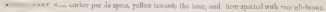

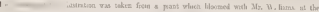

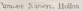

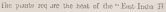

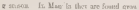




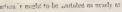

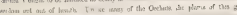

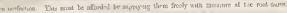

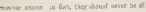

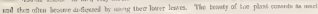

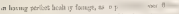

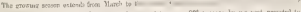

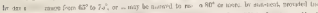

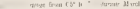

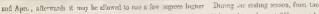

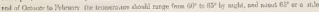

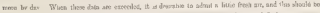

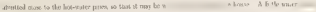

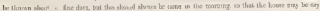

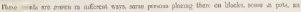

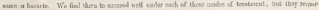

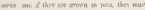

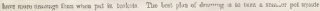

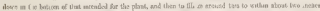

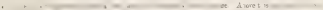

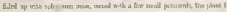

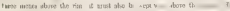

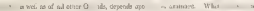

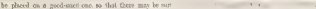

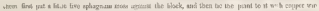

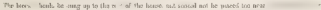

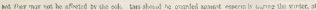

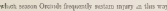

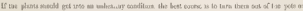

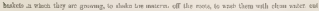

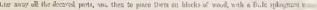

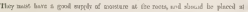

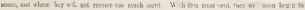

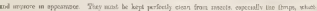

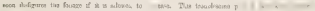

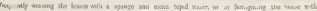

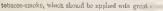

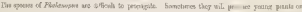

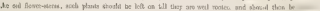

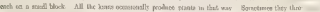

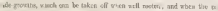

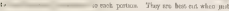

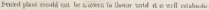





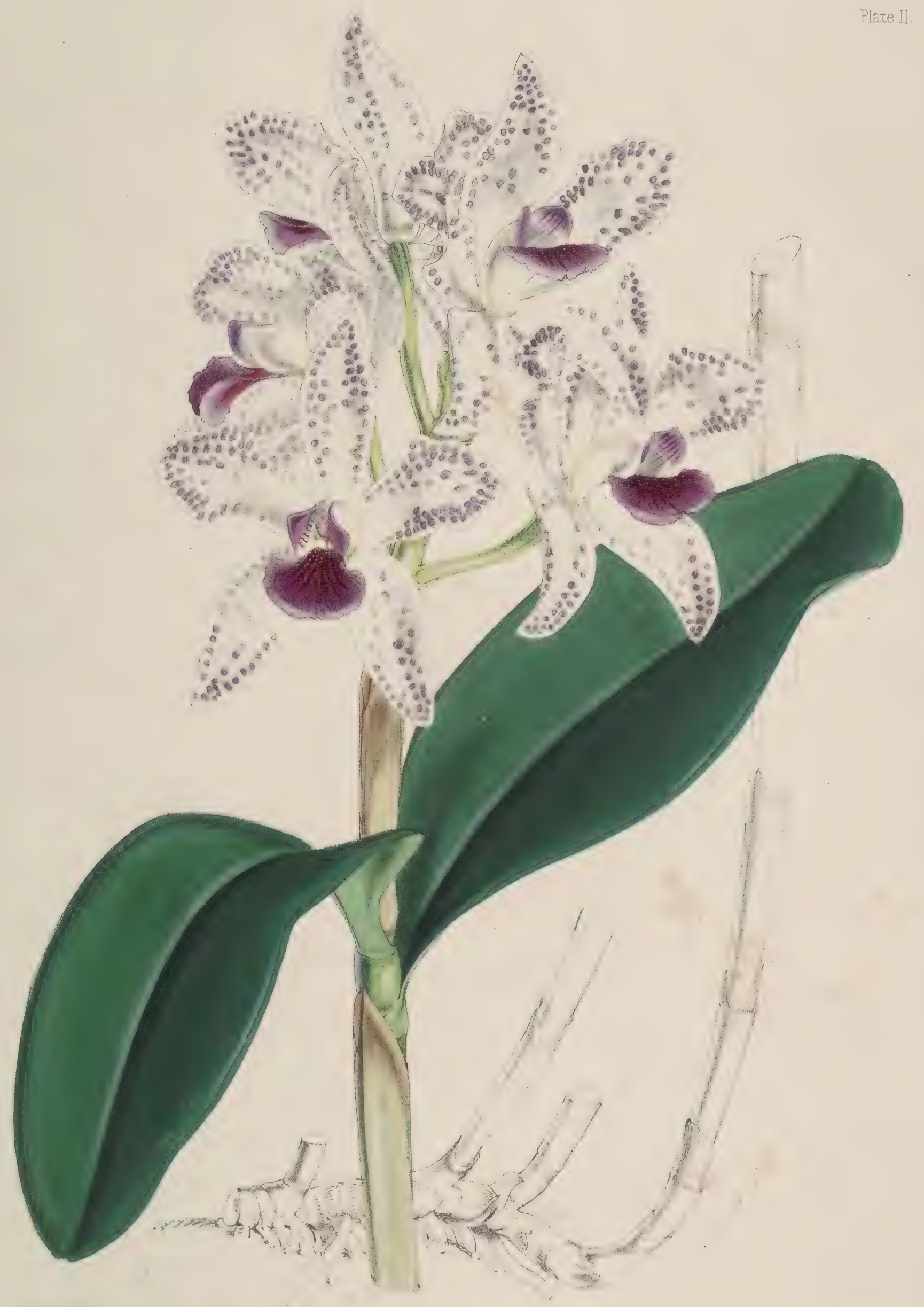




\section{Penrs il}

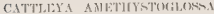
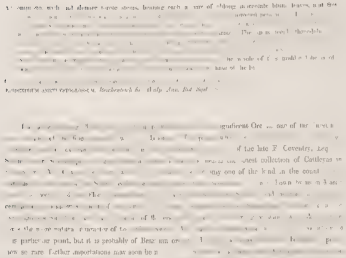

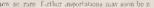

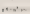

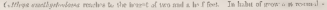

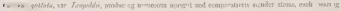

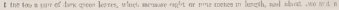

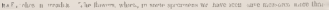

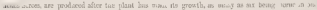

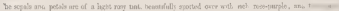

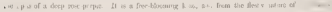

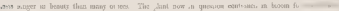

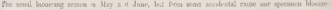

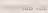

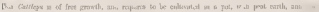

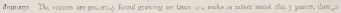

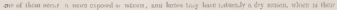

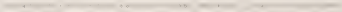






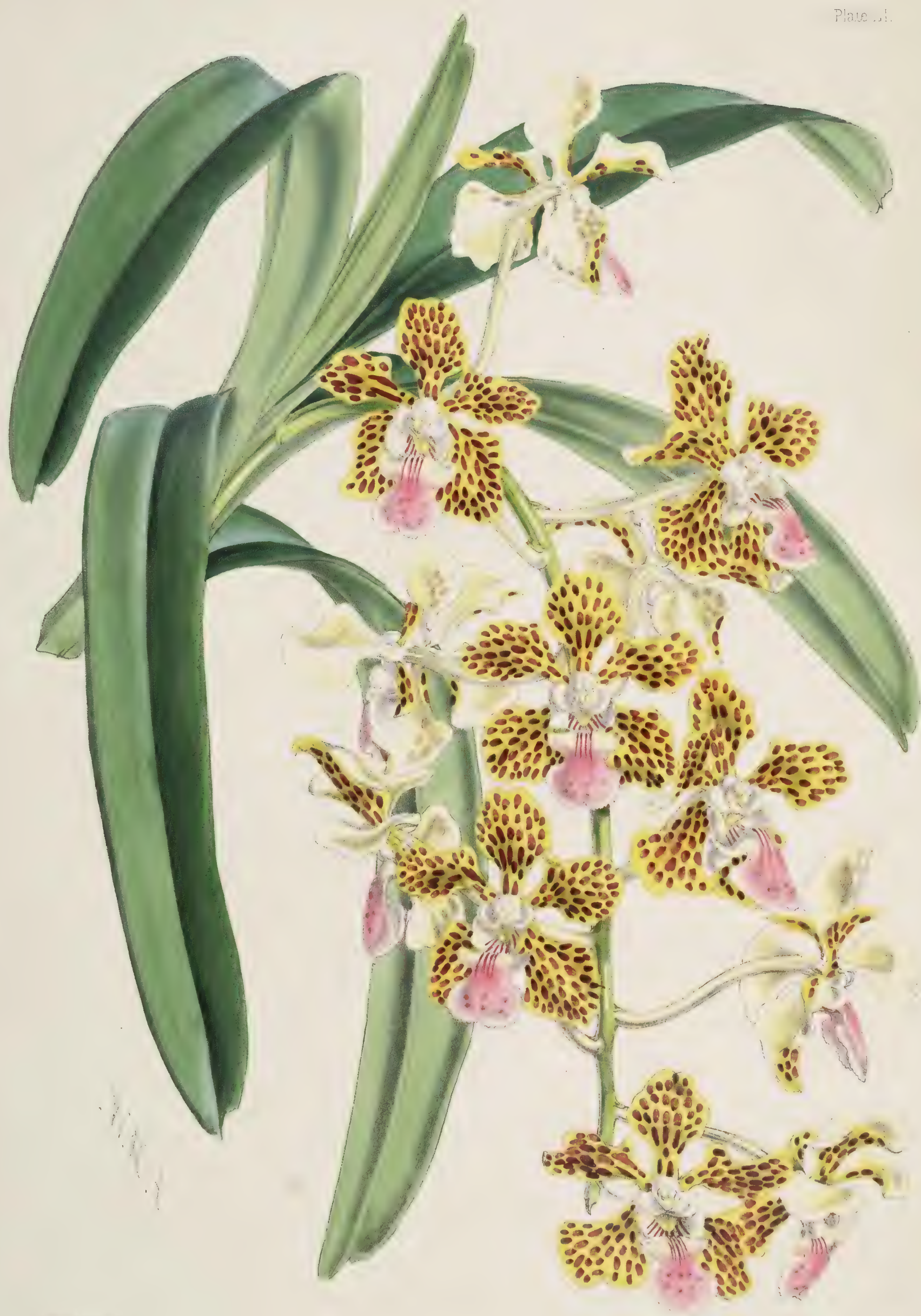




\section{PT.ATY 111}

\section{VANOA IMSIGATS}

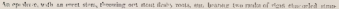

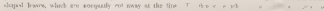

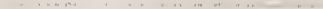

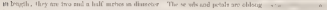

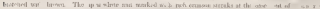

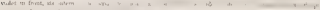

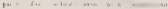

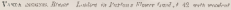

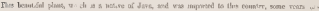

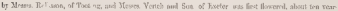

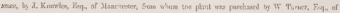

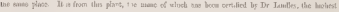

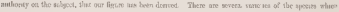

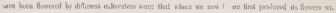

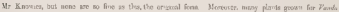

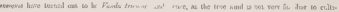

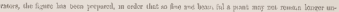

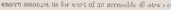

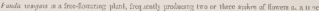

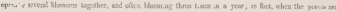

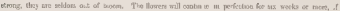

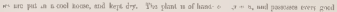

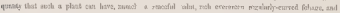

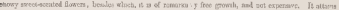

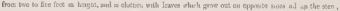

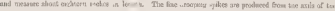

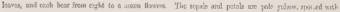

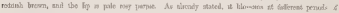
Ll, ker

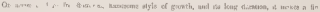

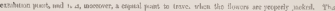

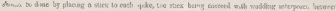

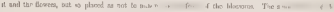

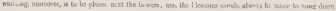

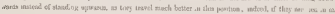

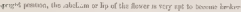

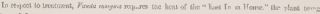

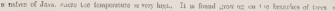

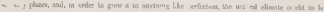




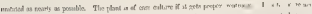

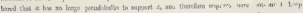

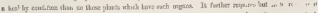

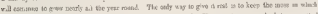

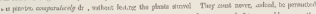

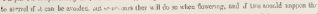

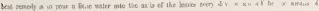

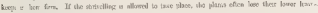
must arout ifstgine birn.

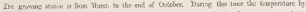

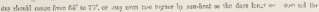

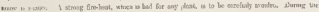

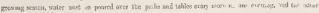

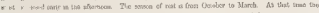

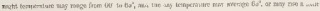

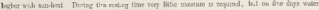

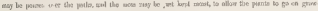

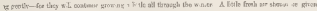

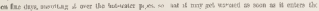

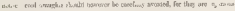

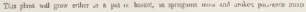

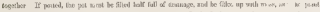

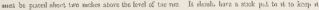

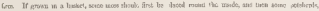

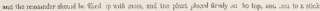

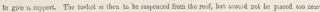

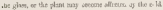

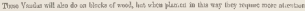

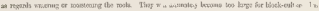

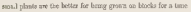





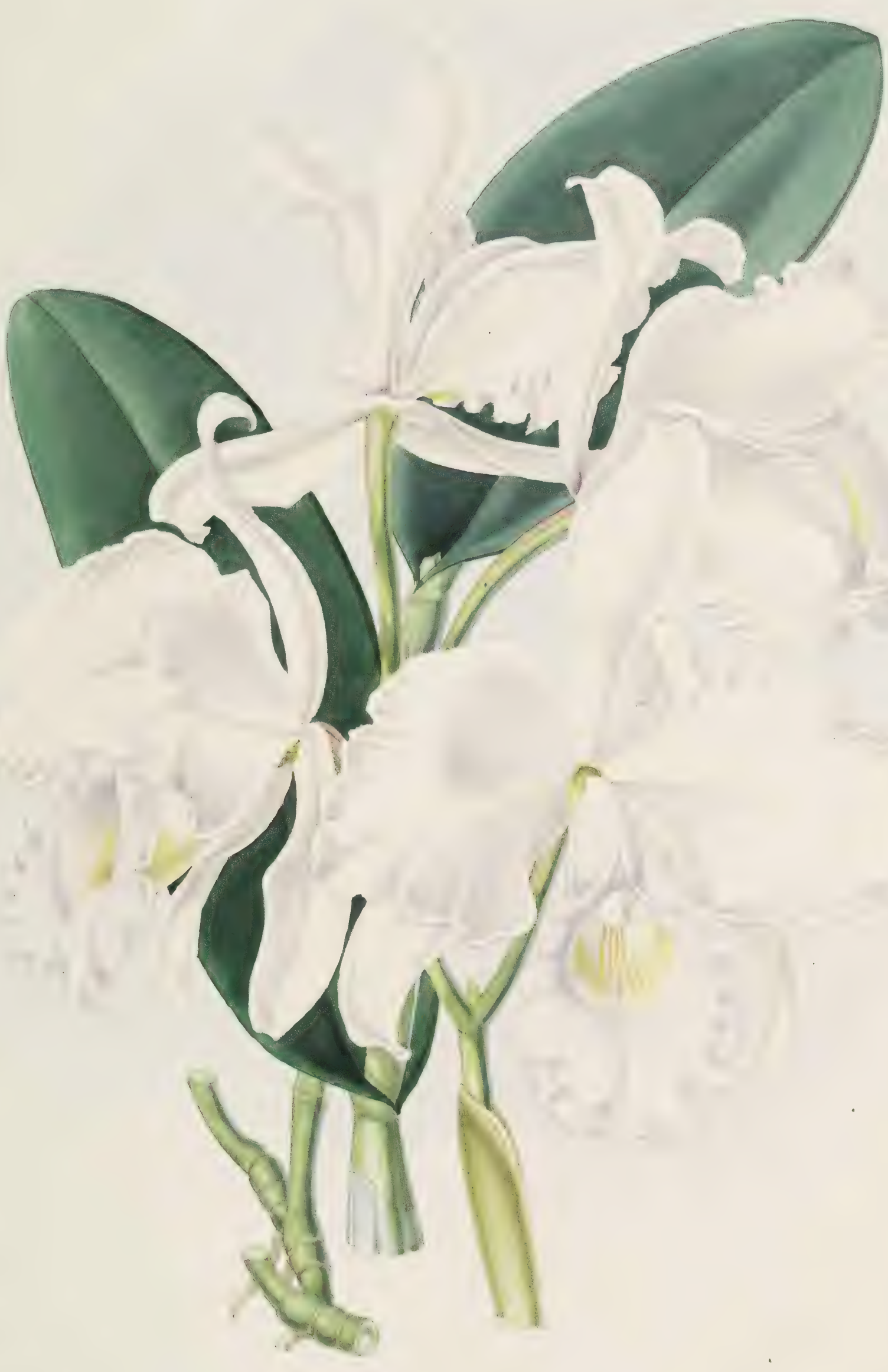




\section{In.tTo IS}

\section{C.THLEYA WARSC'RWICZII DELICAT'A}

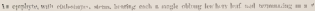

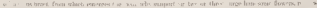

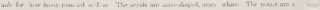

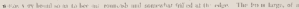

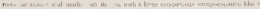

t m.

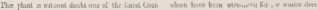

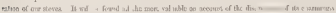

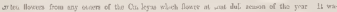

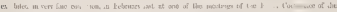

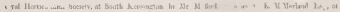

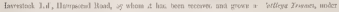

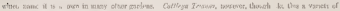

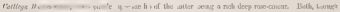

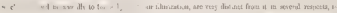

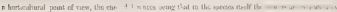

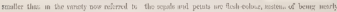

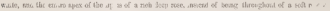

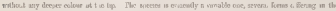

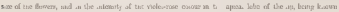

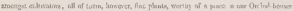

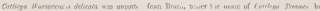

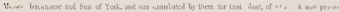

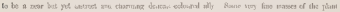

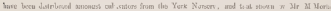

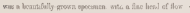

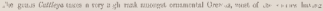

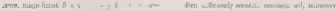

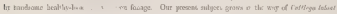

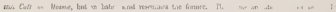

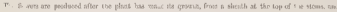

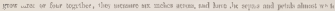

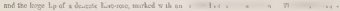

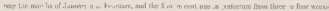

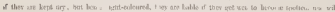
$+1$

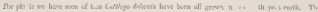

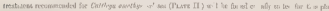

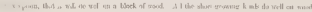




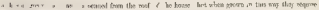

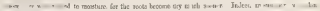

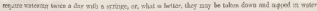

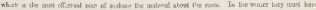

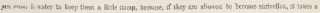

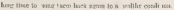

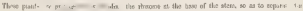

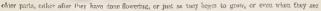

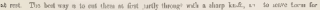

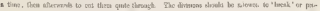

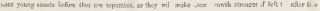

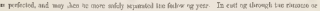

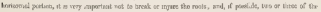

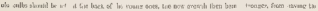

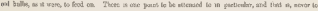

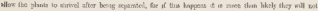

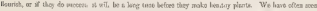

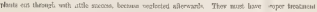

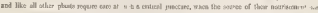

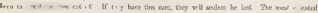

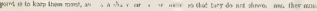

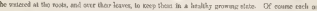

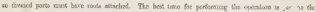

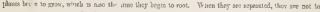

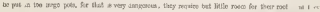

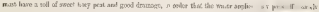

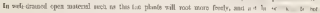

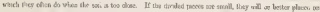

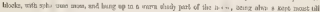

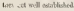

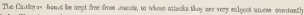

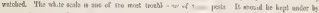

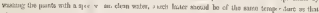

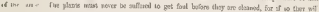

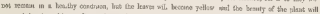

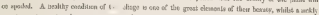

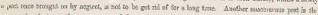

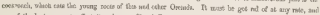

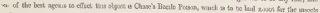
to gors. 411 



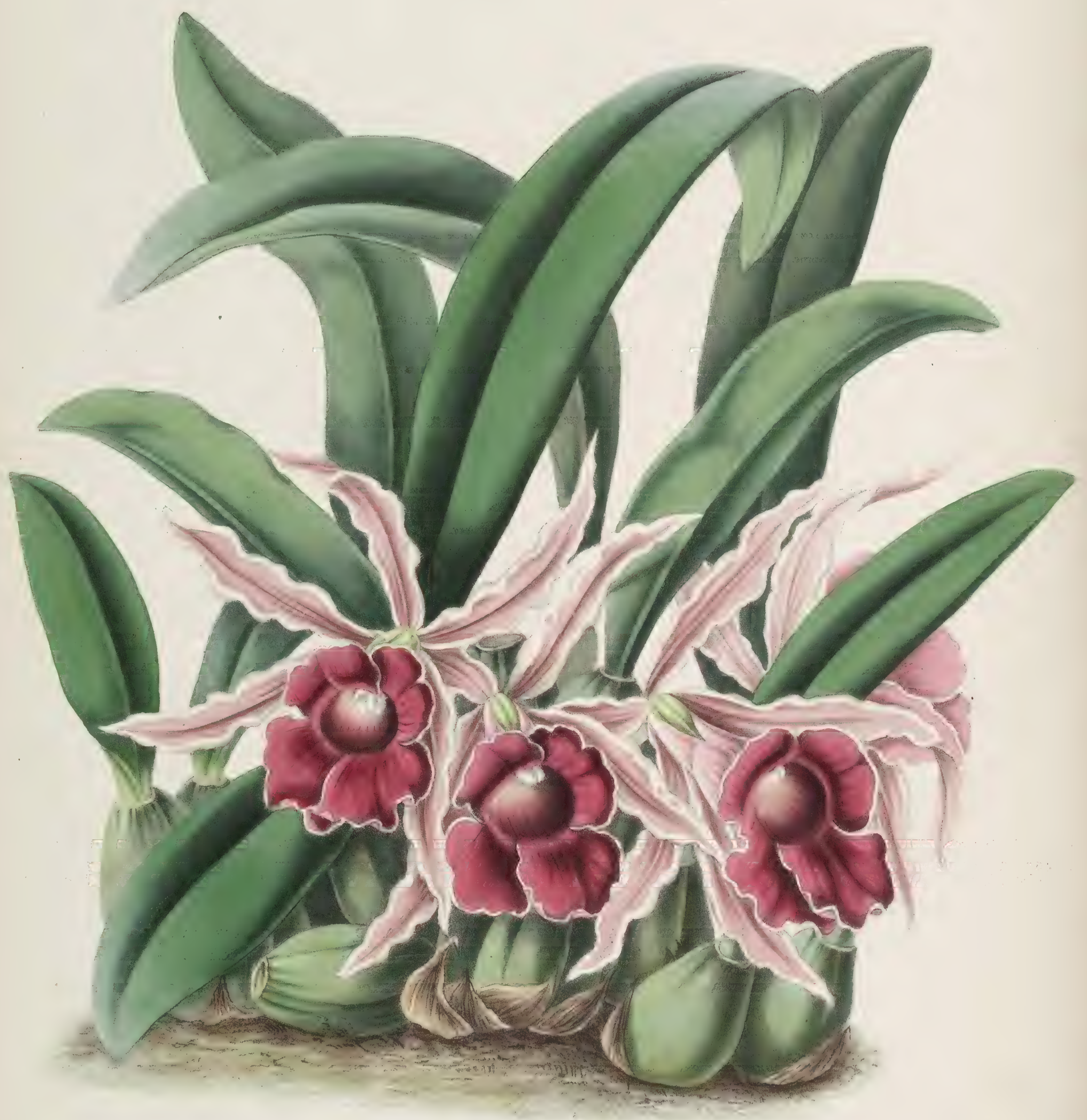




\section{'TRICHOPILIA CRISPA MARGIXNA}

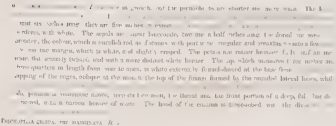

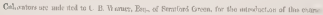

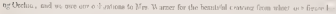

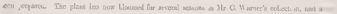

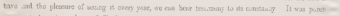

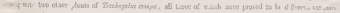

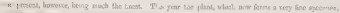

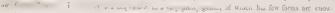

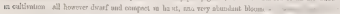

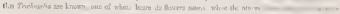

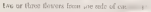

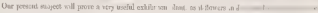

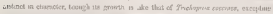

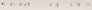

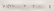

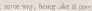

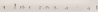

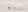

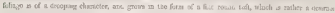

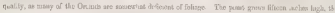

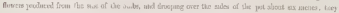

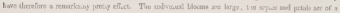

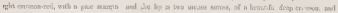

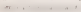

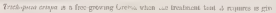

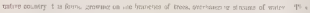

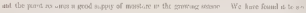

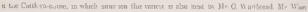

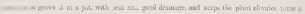

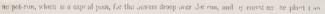

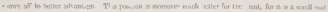

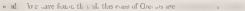




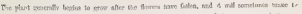

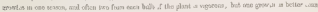

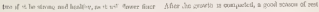

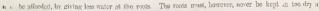

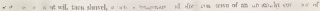

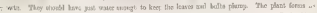

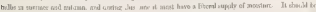

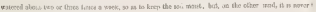

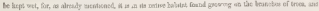

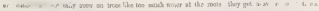

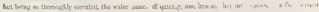

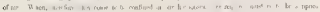

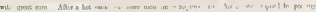

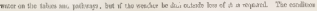

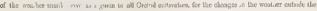

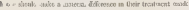

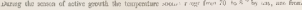

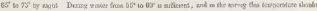

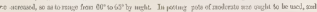

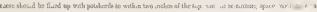

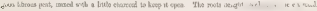

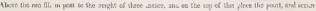

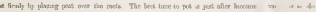

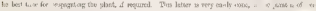

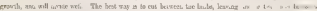

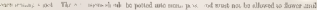

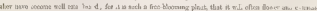

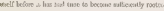

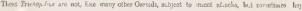

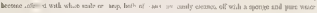

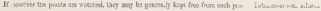

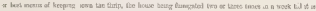

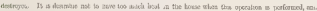

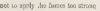





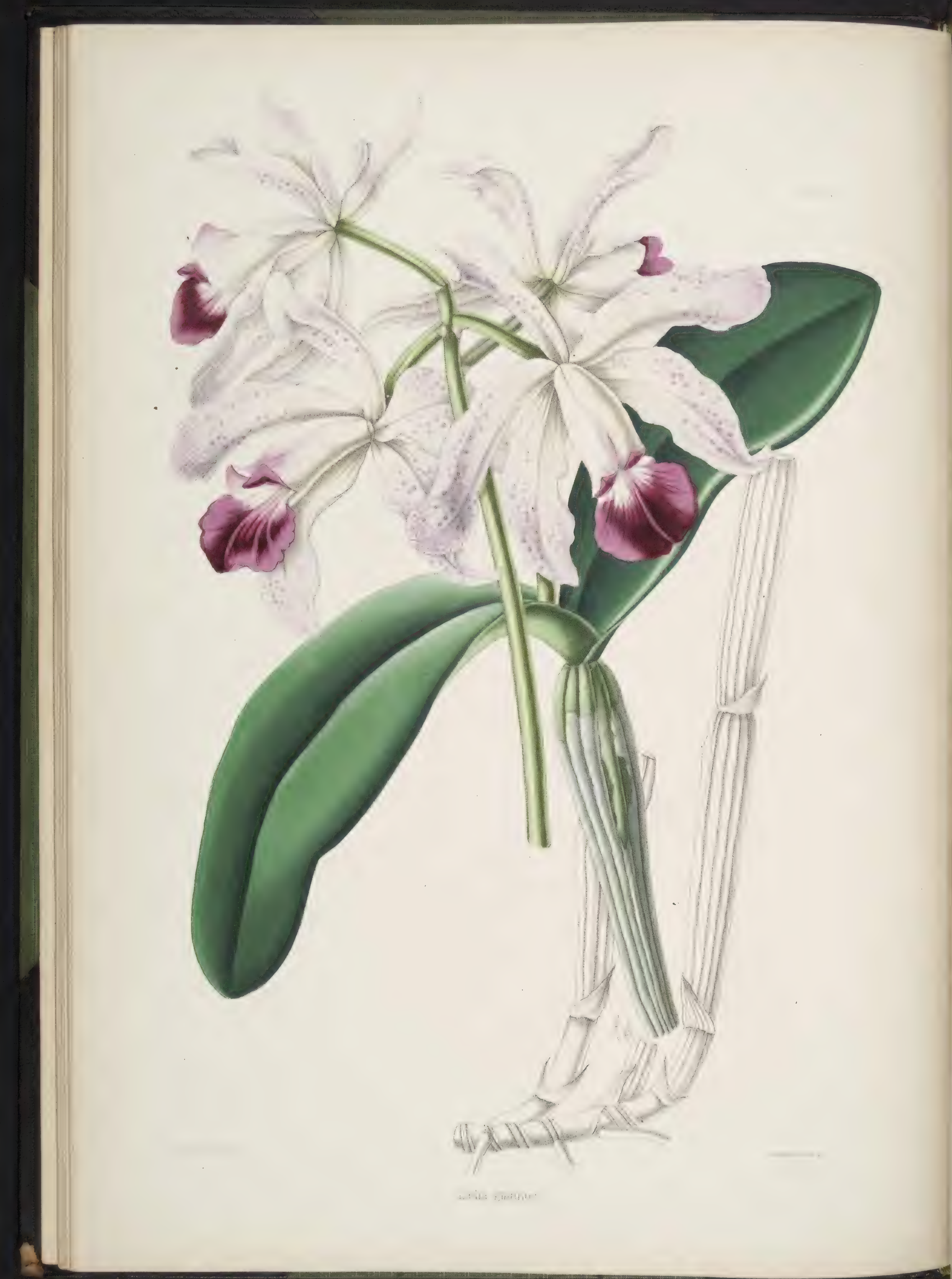


Dast 11

LULU GICANTEA
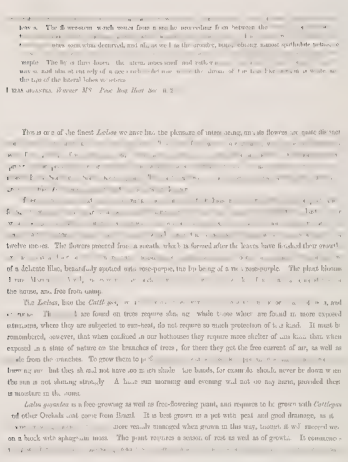



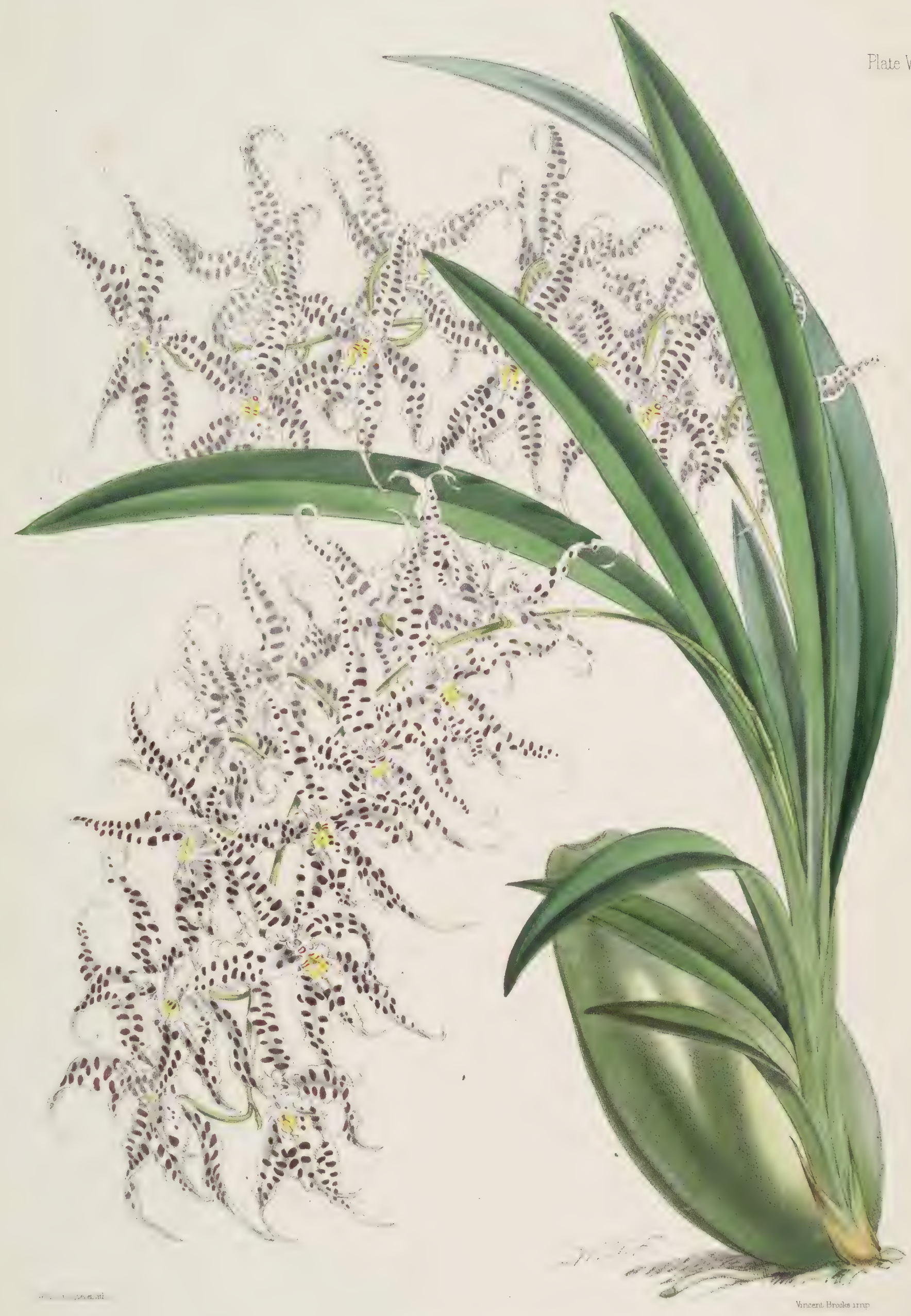

Odontoglossun r:ævium majus 


\section{$P_{t+v y}+11$}

\section{(1) NTGGIOSSEN BASVILM ALAL}

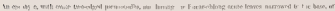

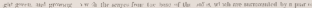

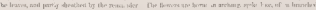

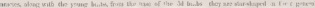

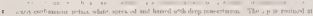

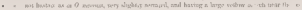

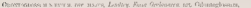

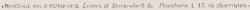

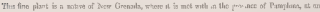

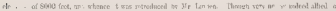

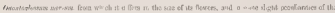

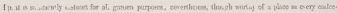

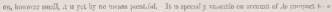

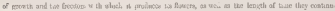
tin

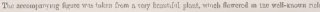

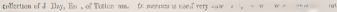

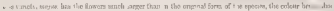

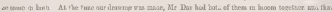

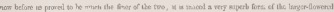

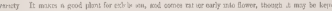

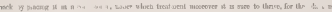

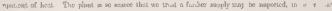

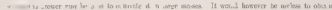

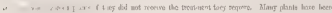

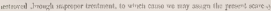

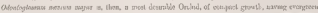

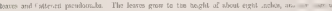

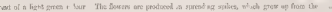

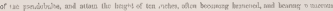

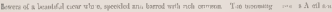

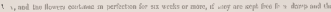

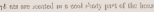

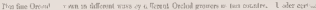

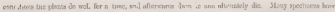

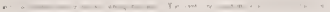

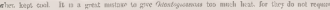

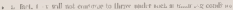




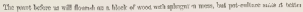

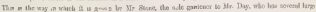

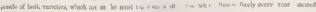

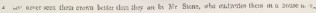

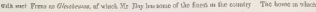

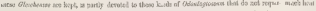

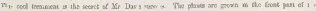

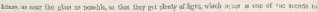

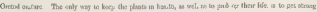

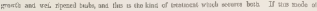

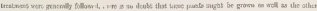

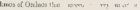

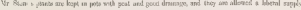

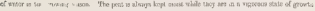

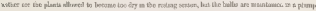

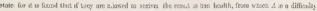

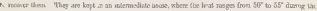

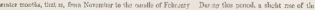

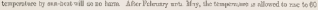

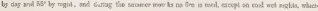

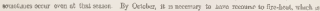

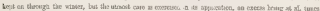
a siro.

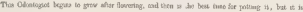

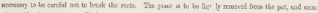

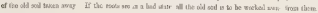

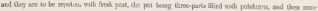

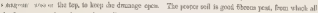

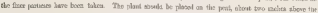

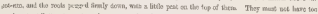

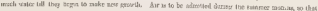

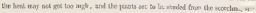

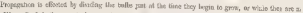

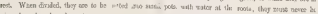

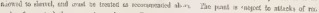

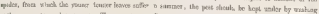

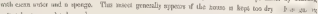

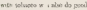





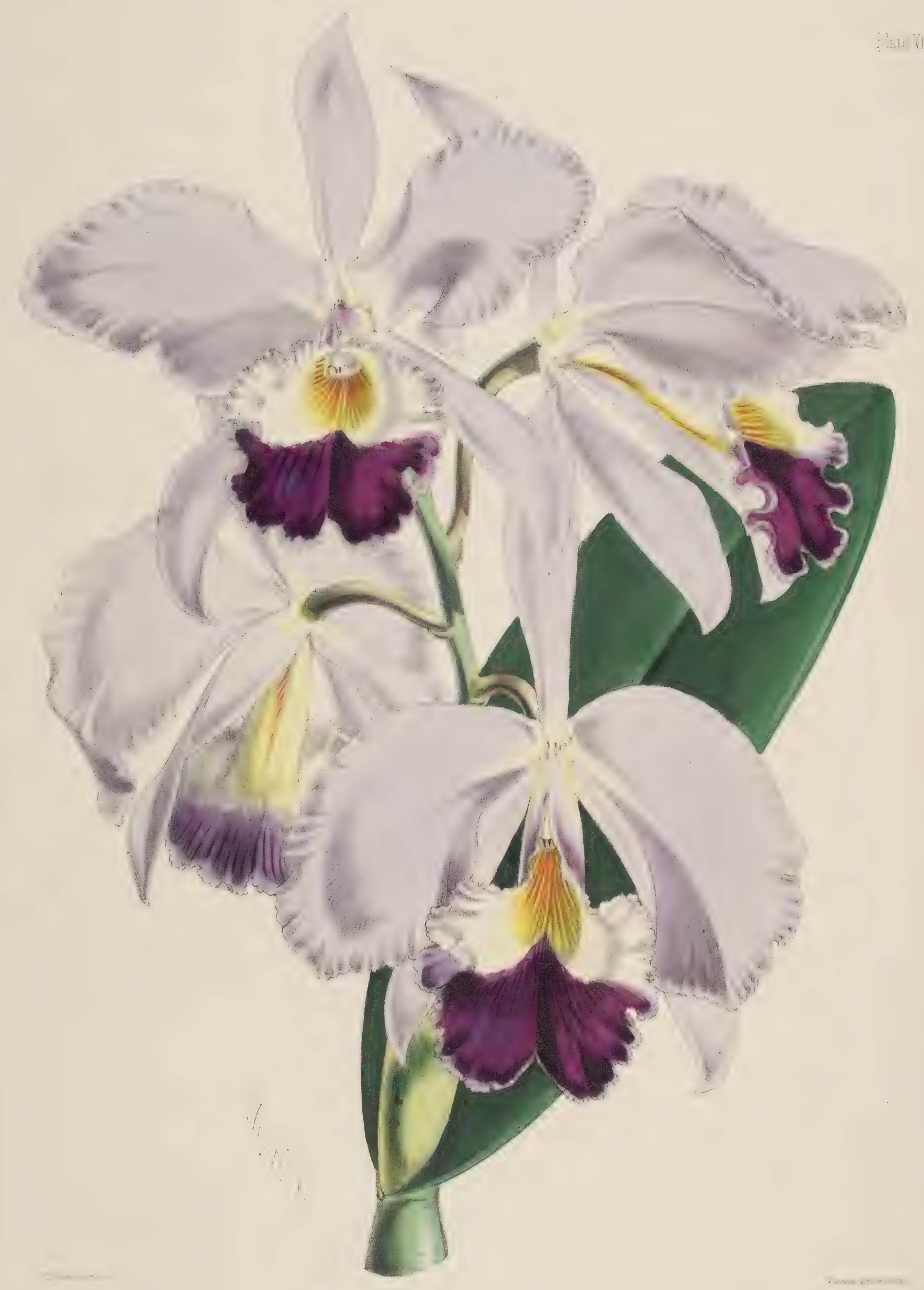

L 


\section{Puate VIt!}

\section{CATTLEYA WAIXEHI}

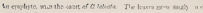

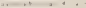

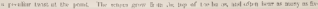

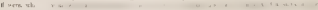

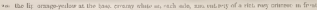
Mr-

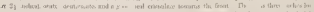

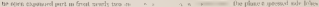

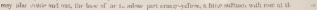

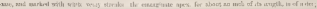

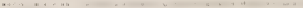

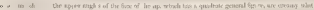

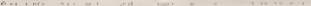

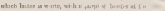

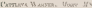

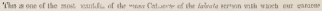

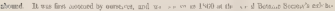

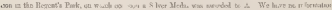

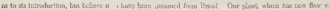

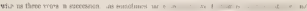

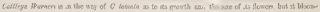

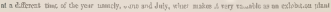

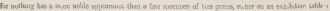

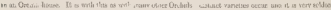

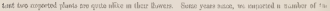

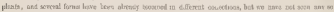

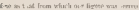

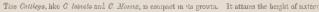

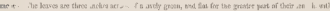

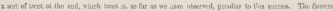

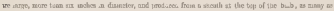

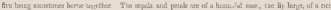

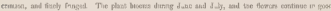

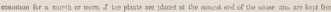

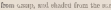

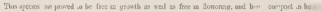

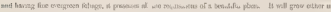

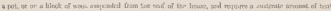

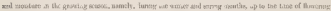

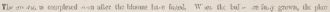

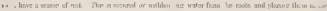




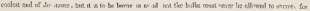

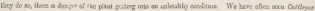

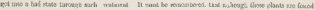

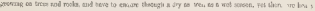

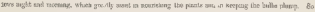

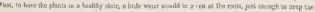

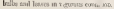

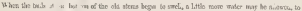

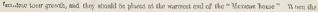

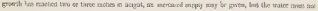

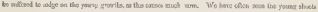

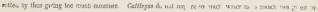

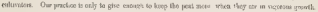

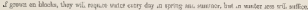

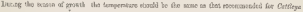

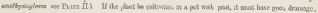

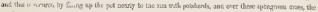

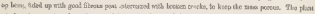

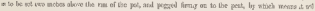

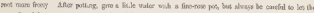

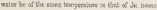

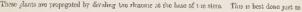

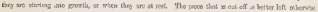

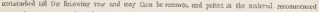

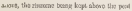

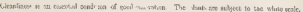

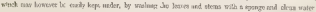

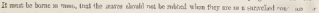

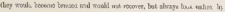




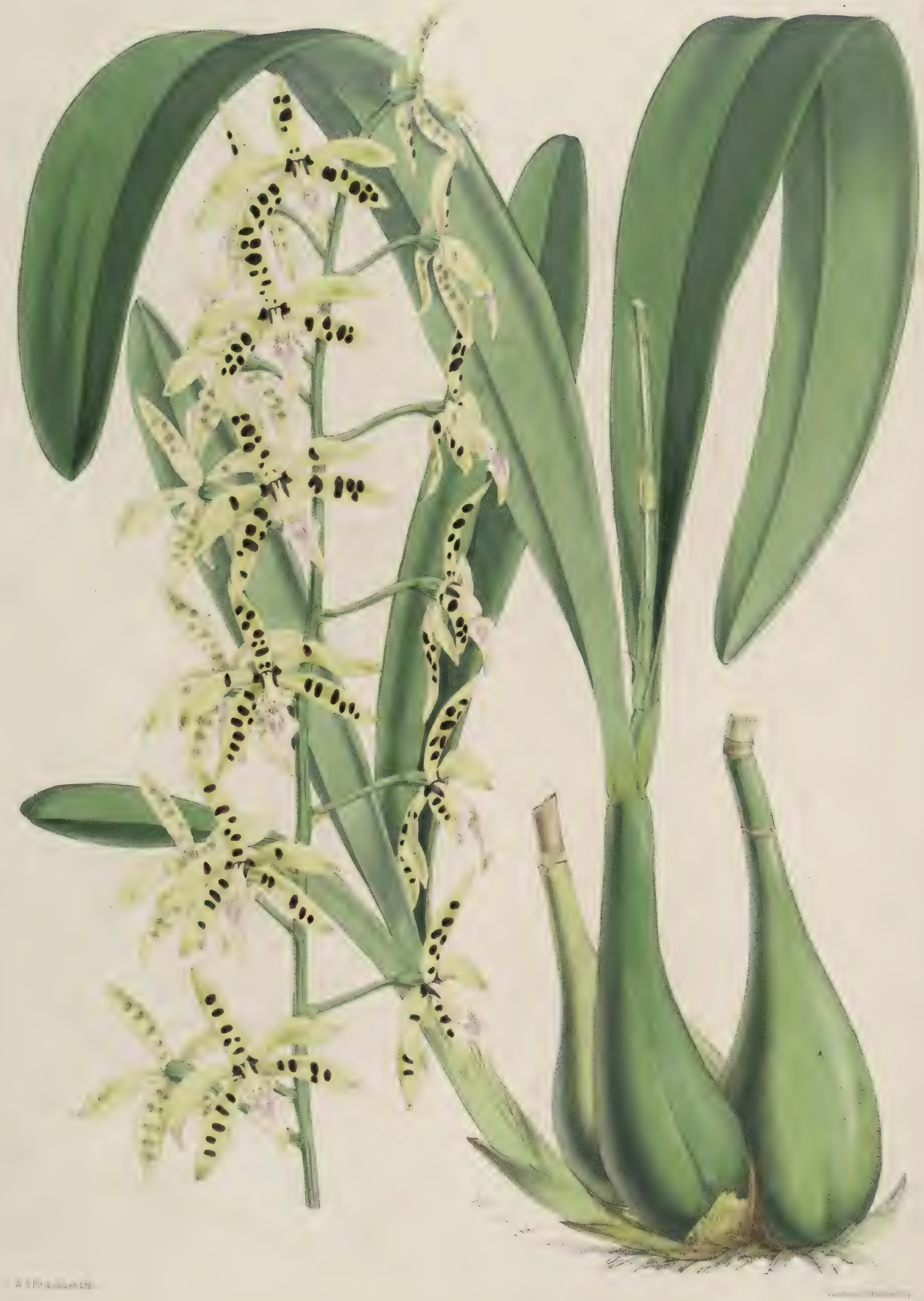




\section{1).nर IS}

\section{EPHENDECM TRLSAATOCARPTM}

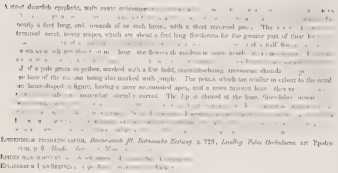

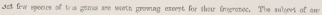

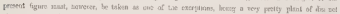

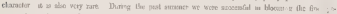

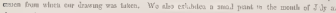

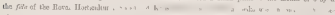

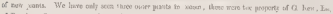

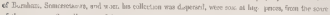

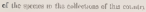

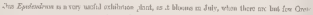

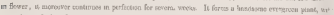

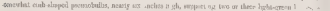

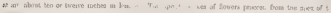

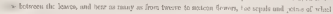

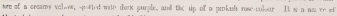

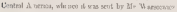

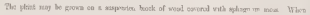

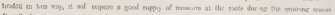

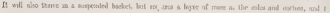

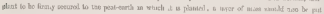

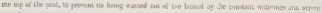

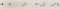

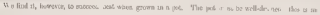




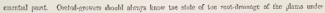

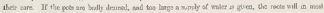

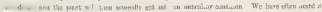

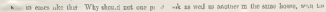

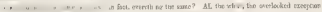

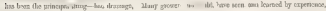

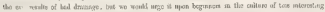

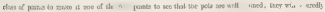

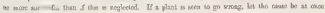

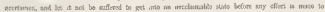
yor

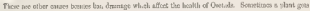

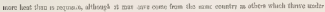

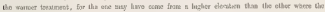

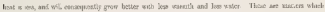

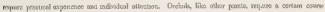

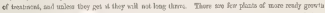

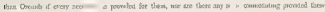

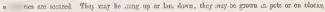

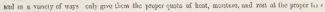

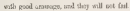

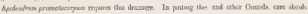

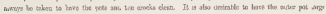

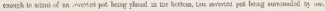

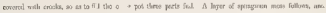

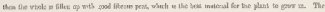

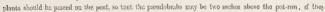

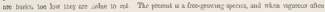

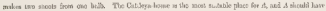

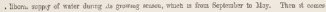

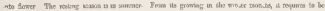

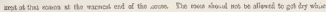
all $n$.

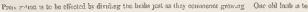

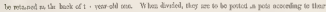

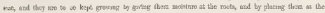

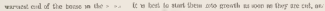

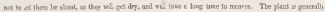

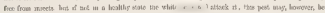

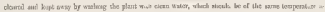
dis Inese 


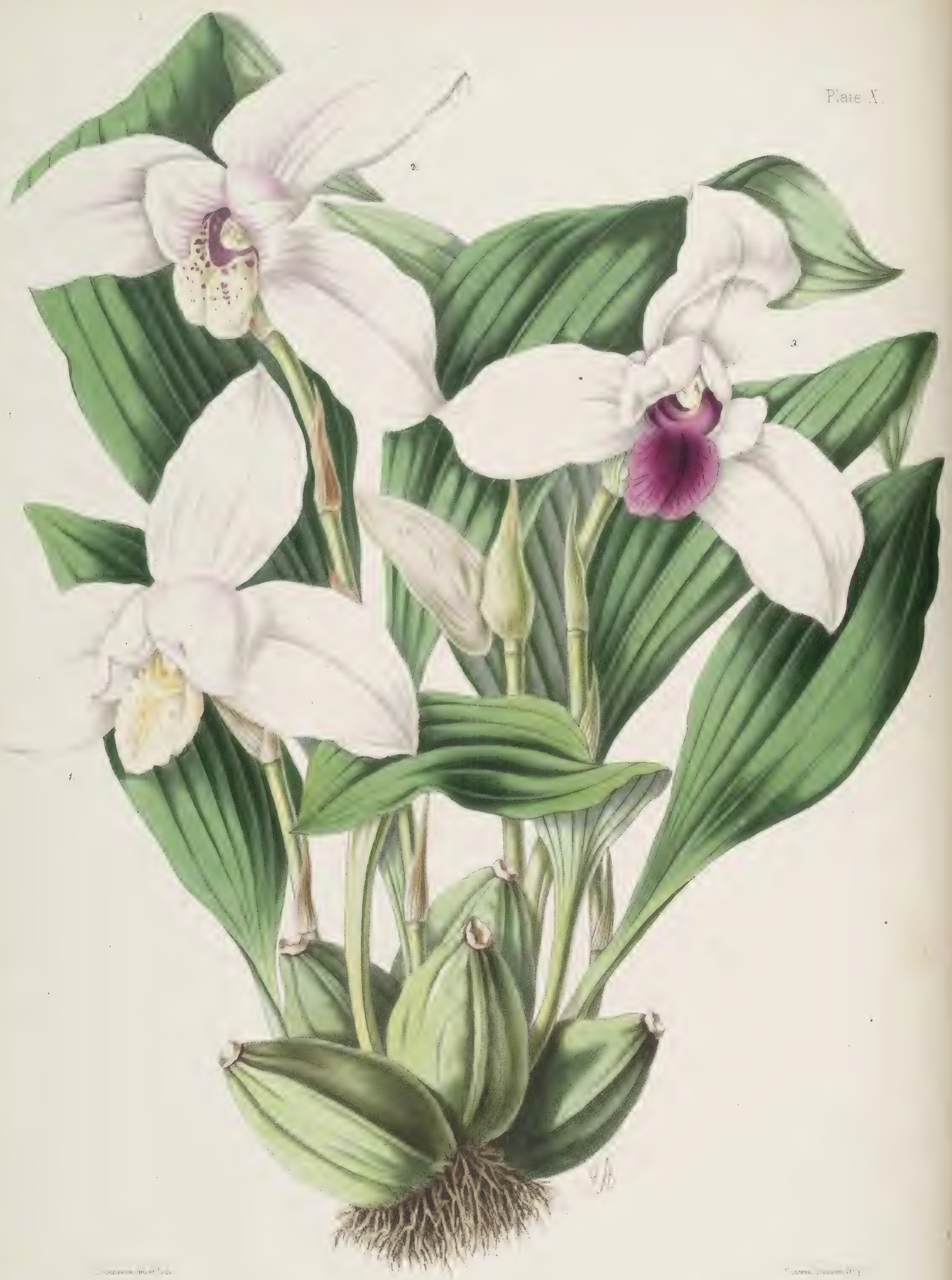




\section{$1, x T E=3$}

\section{WYASTE HKINNLH}

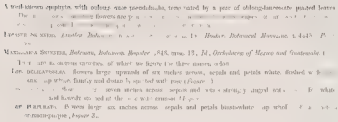

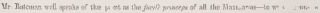

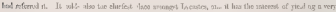

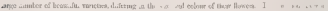

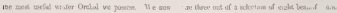

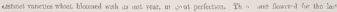

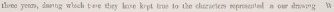

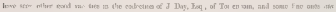

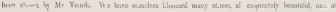

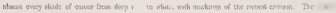

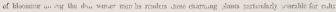

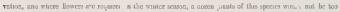

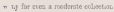

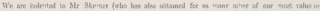

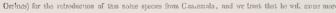

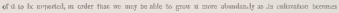

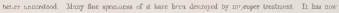

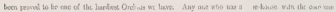

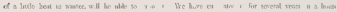

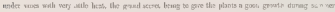

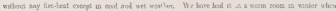

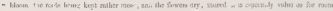

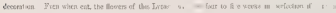

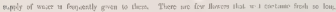

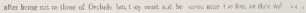

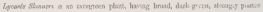

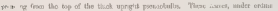

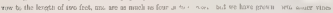




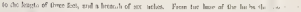

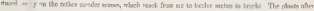

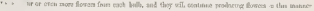

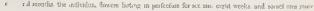

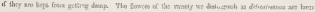

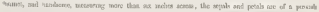

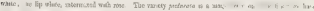

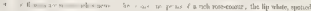

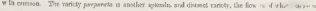

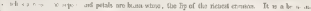

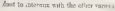

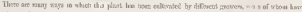

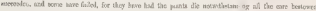

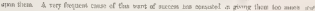

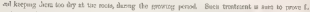

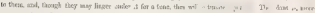

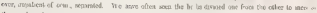

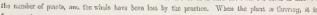

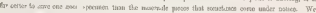

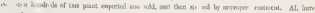

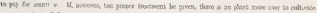

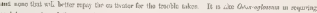

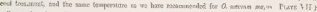

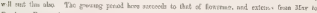

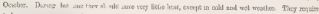

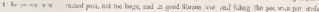

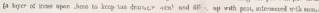

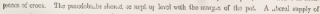

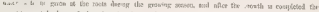

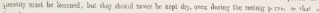

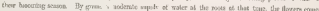

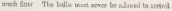

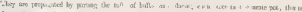

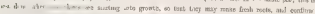

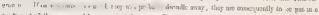

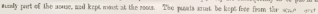

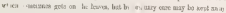




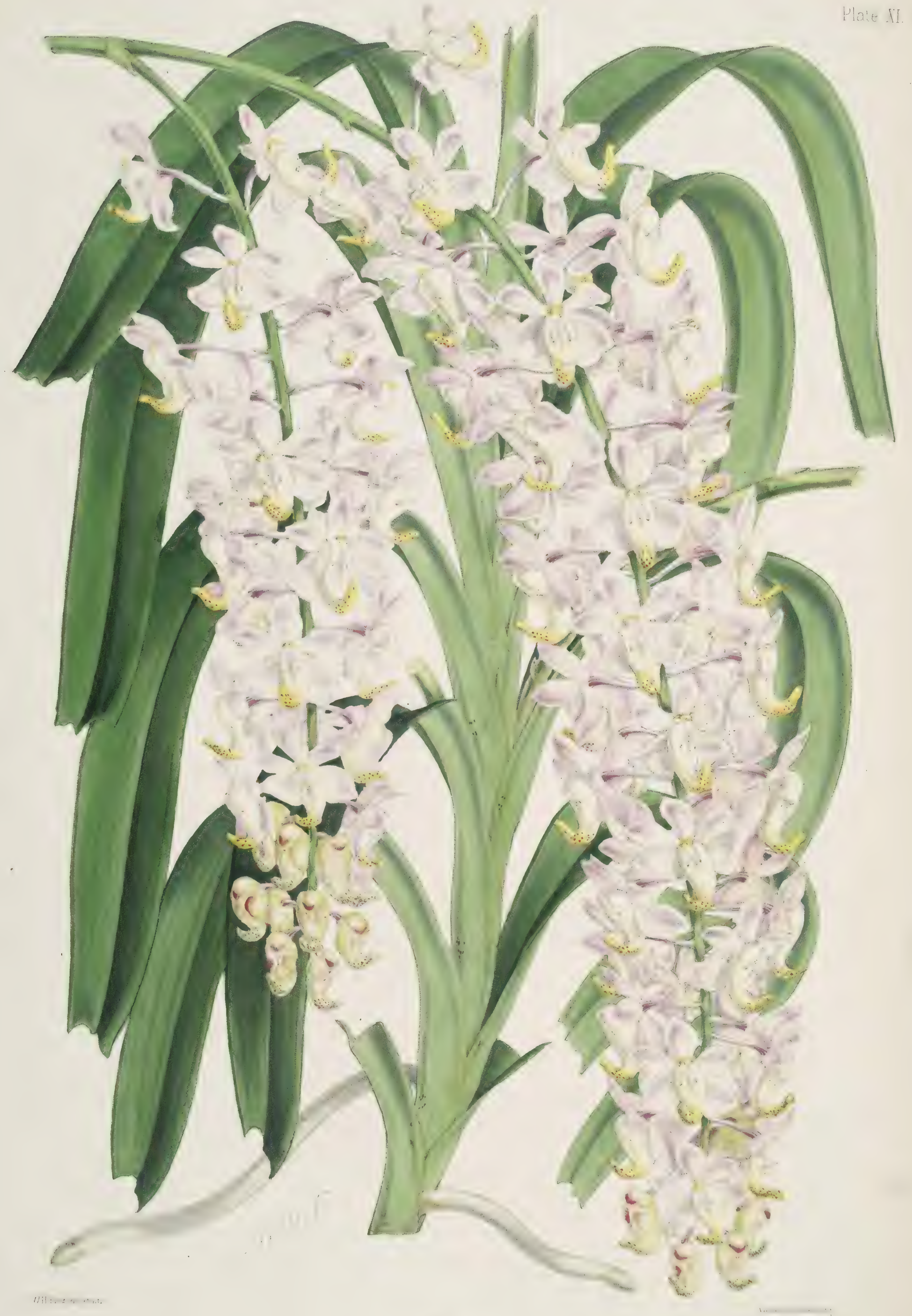


Peari N

\section{STRIDES NOHHIV:}

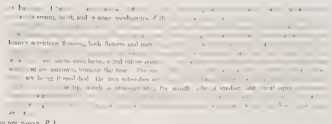

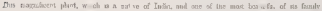

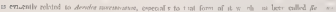

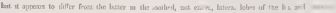

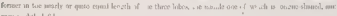
Torr hutulh atili

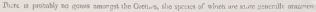

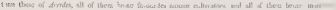

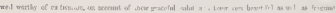

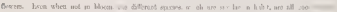

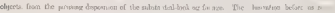

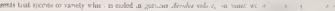

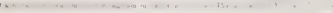

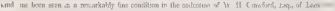

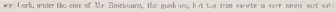

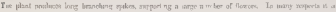

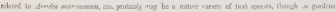

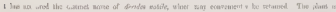

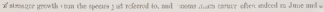

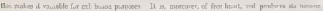

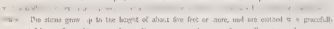

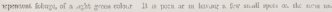

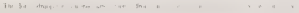

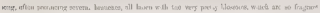

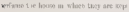

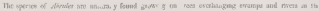




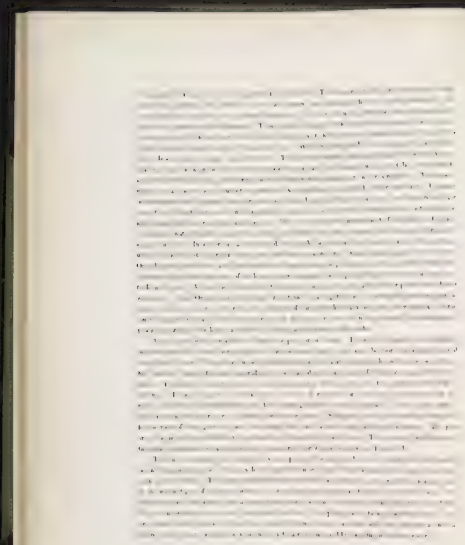




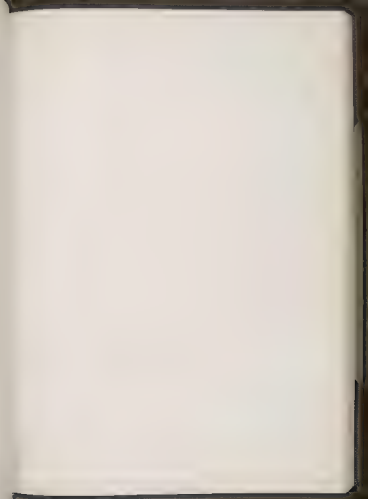




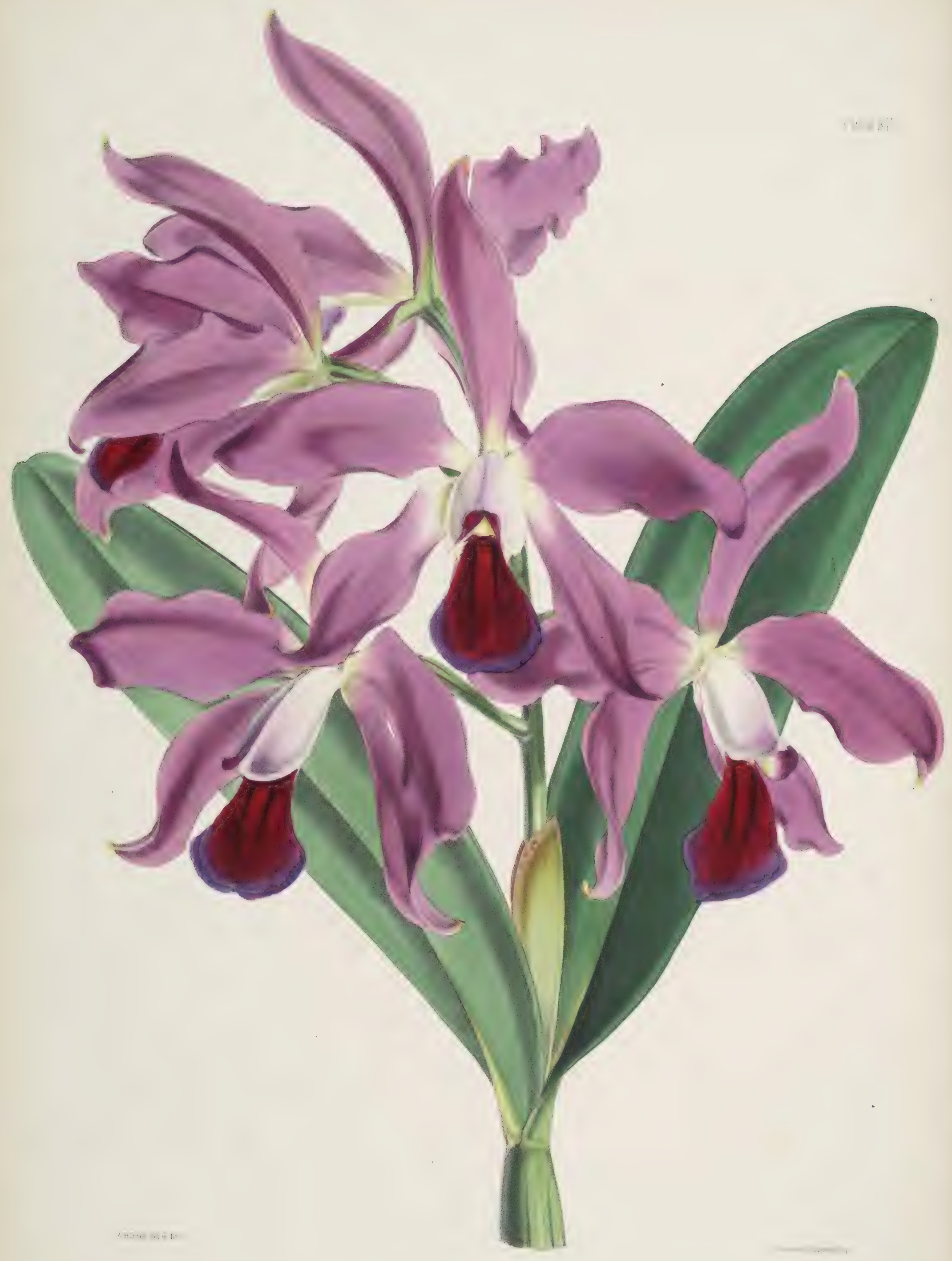


P).גY XI1

\section{LALIA TURMIIRI}

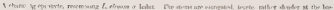

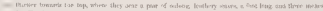

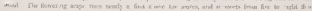

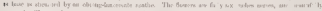

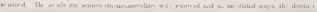

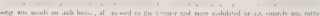

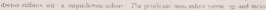

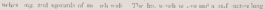

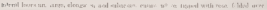

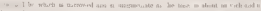

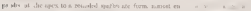

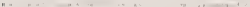

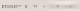

Itretsigen $x$ II

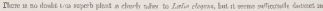

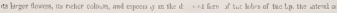

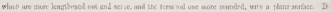

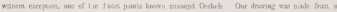

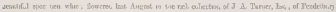

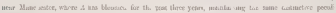

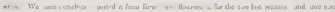

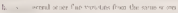

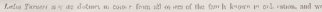
2.

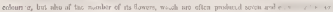

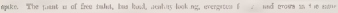

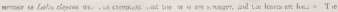

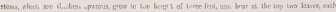

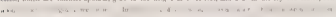

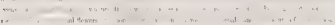

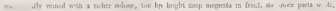

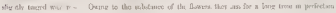

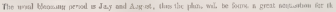

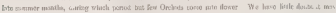

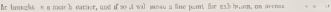

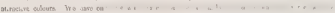

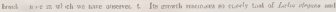

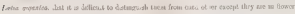

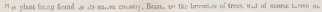




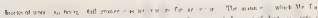

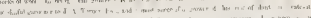

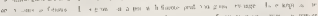

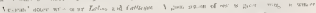

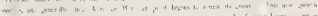

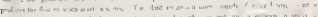

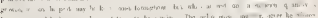

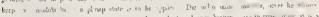

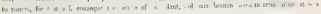

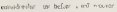

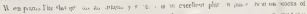

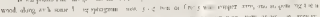

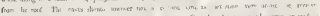
Thil on:ale res

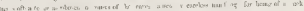

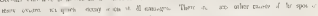

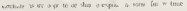

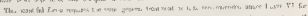

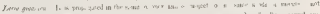

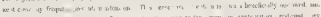

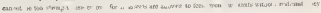

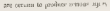




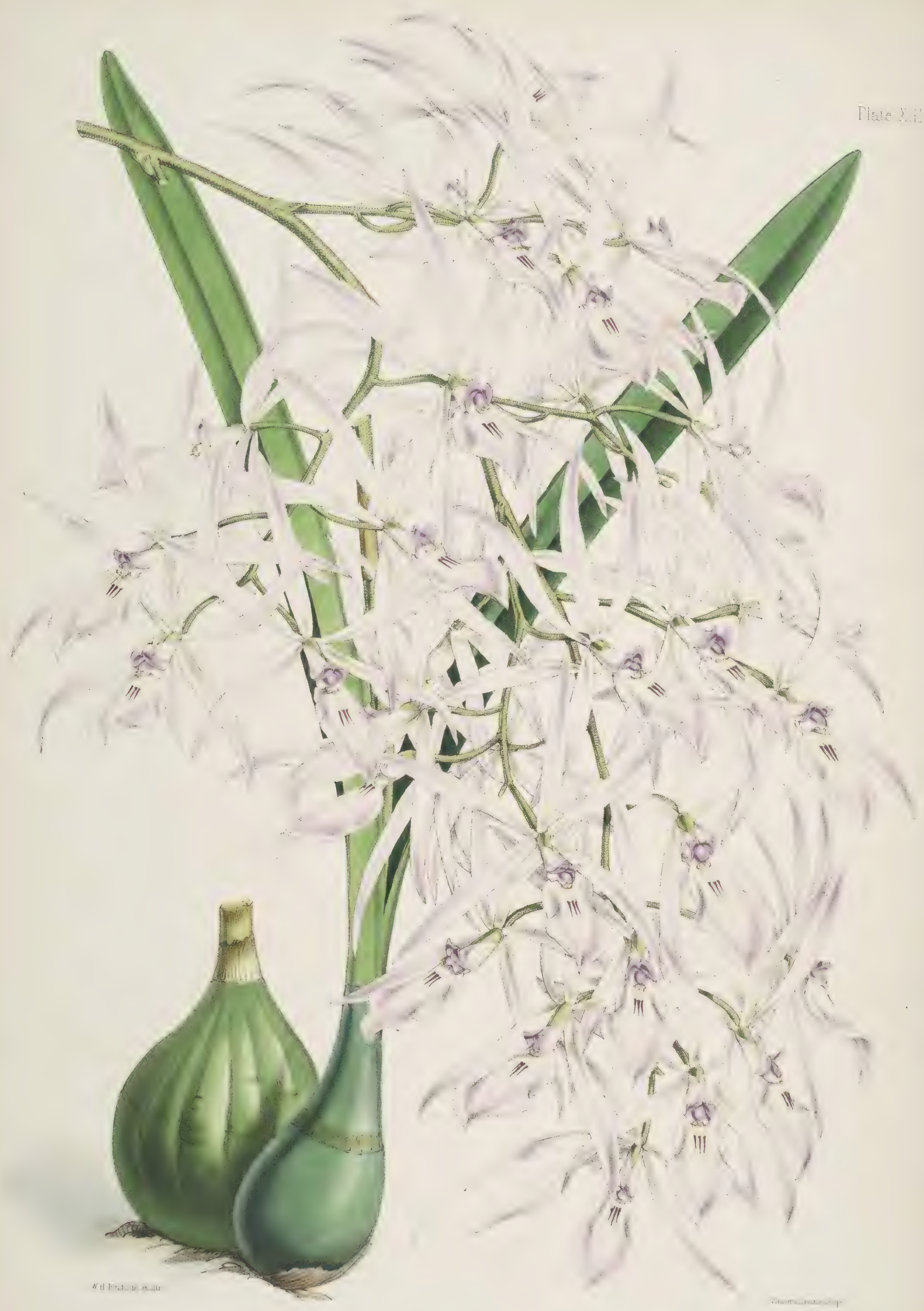


PLAT, XII

\section{LPHECNDRTM NEMORALR MUI:}

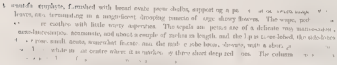

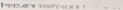

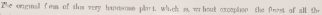

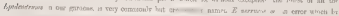

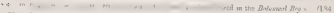

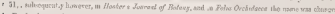

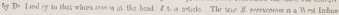

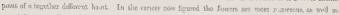

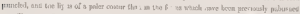

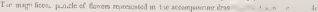

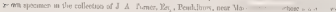

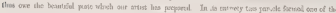

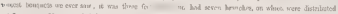

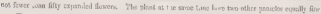

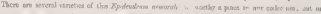

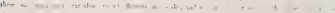

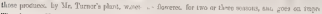

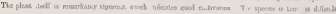

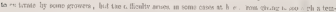

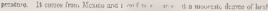

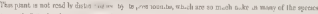

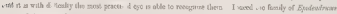

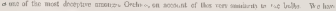

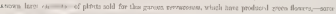

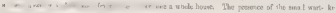

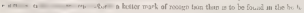

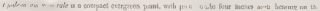

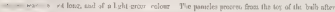

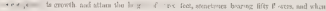

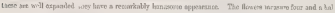

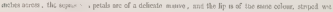

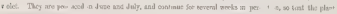

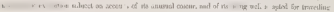






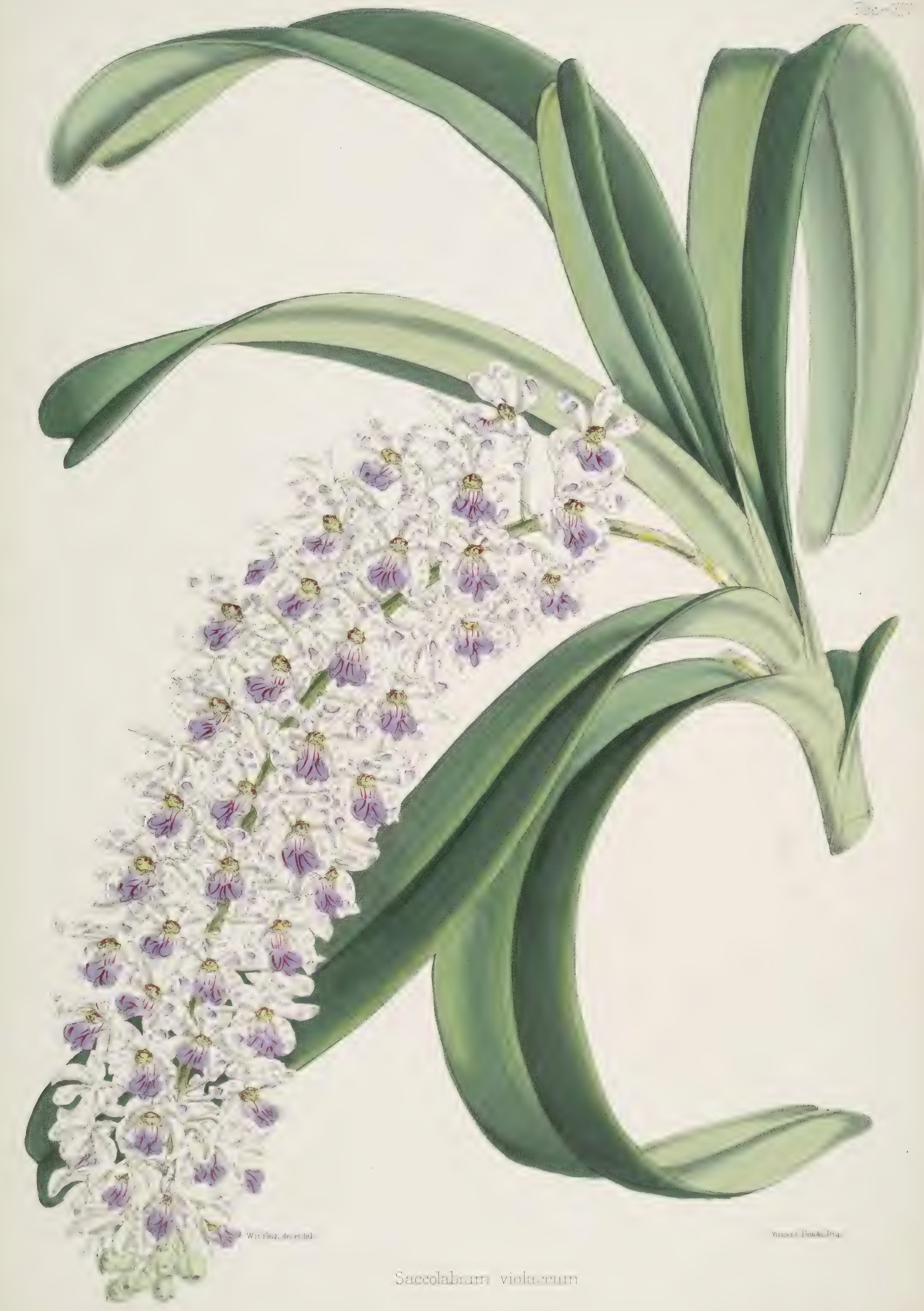

a 


\section{PRSTE 3.15}

\section{SIC'COLATIEM VIOLAC'ZCY}

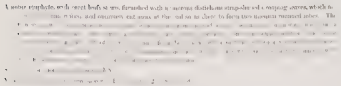

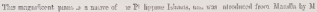

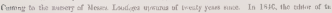

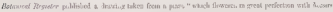

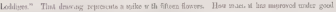

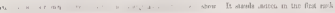
in + +. Q Orelaib

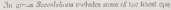

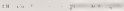

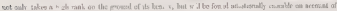

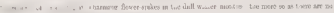

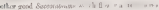

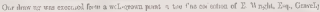

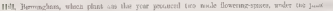

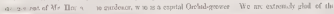

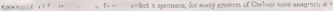

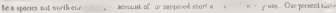

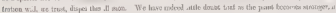

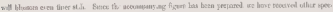

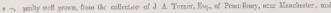

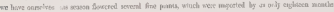

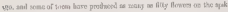

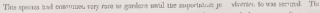

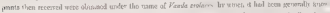

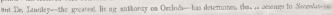

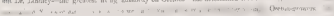

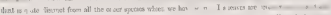

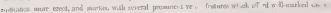

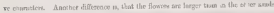

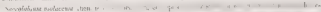

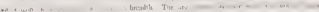




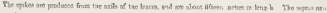

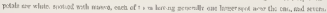

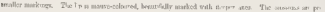

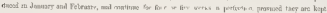

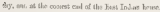

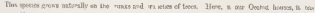

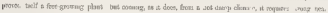

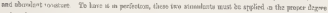

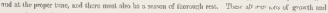

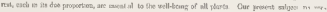

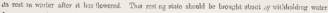

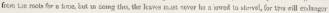

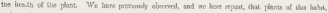

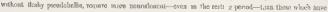

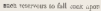

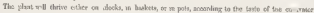

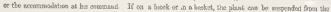

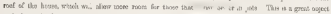

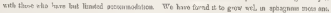

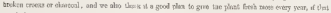

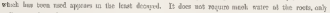

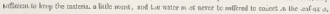

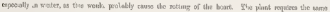

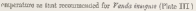

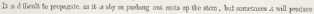

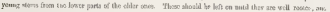

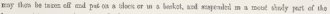

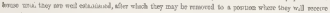

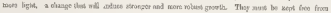

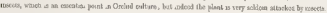





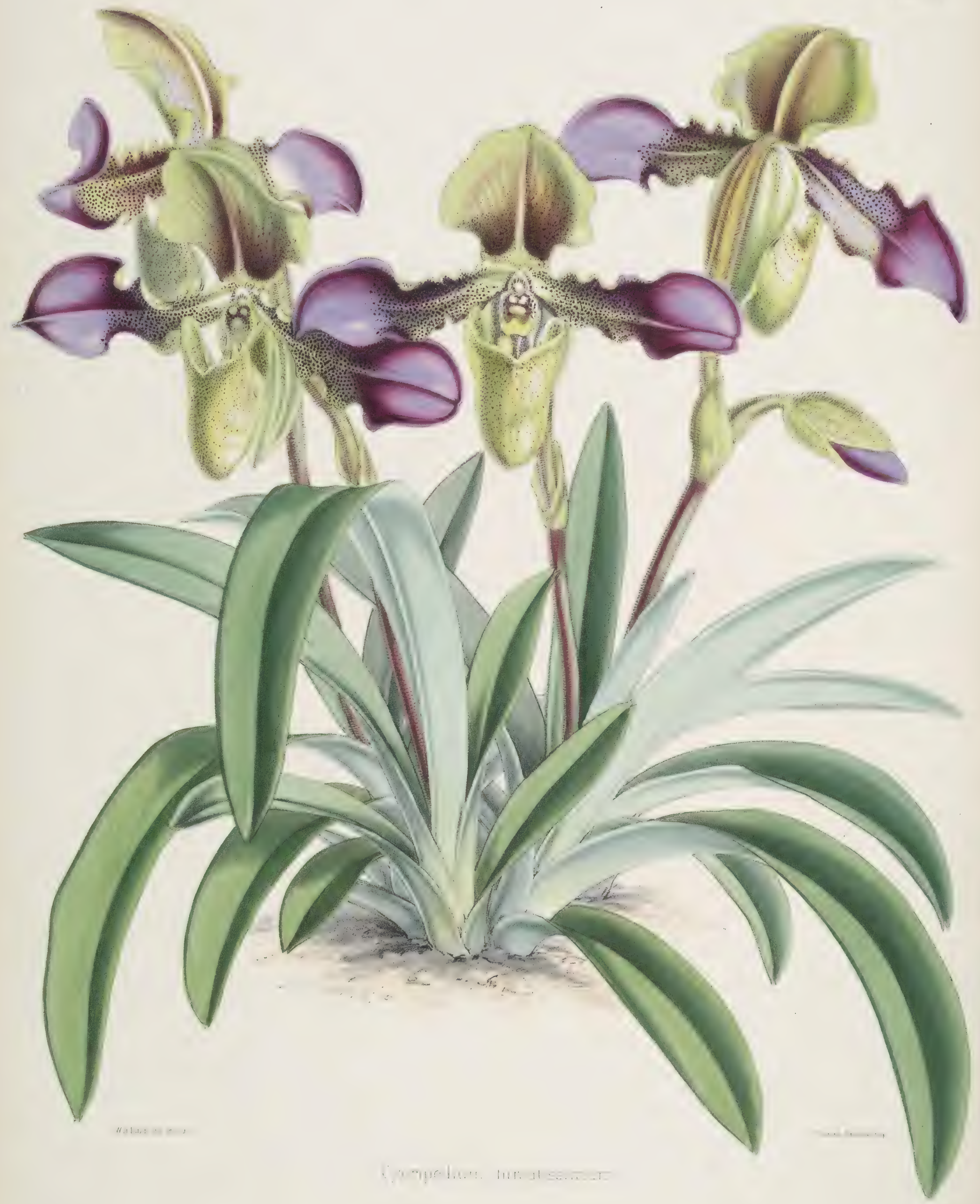




\section{P1 atr XI}

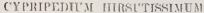
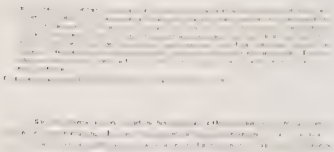

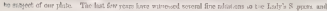

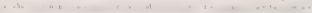

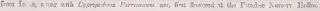

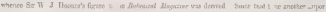

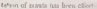

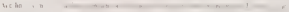

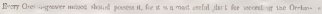

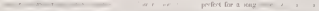

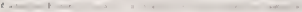

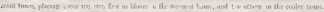
nifl fir

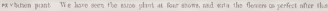

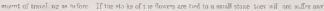

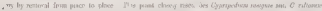

$*$
$*$

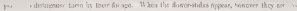

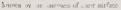

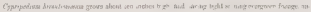

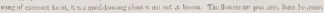

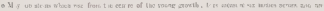

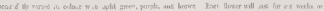

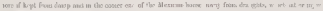

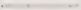

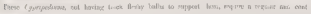

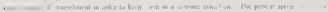

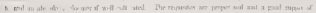




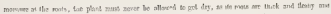

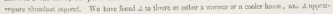

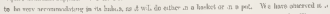

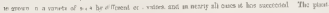

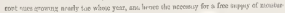

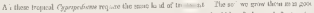

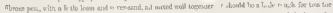

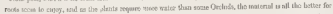

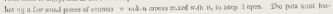

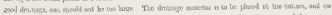

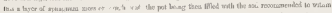

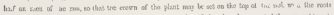

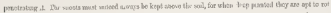

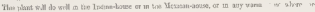

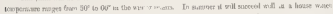

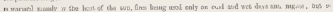

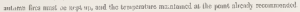

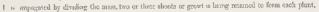

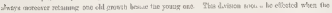

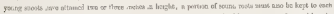

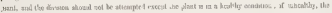

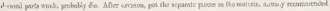

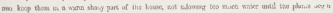

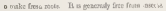


int 111

CATTIEYA DAWXONH

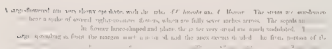

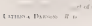

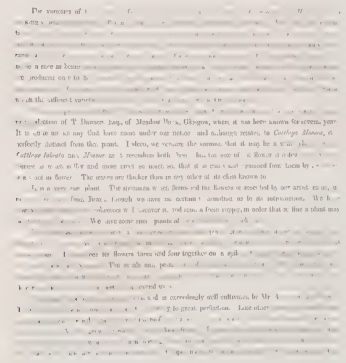




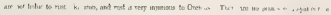

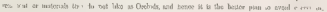

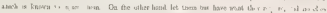

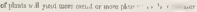

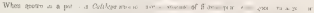

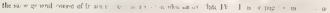

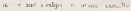





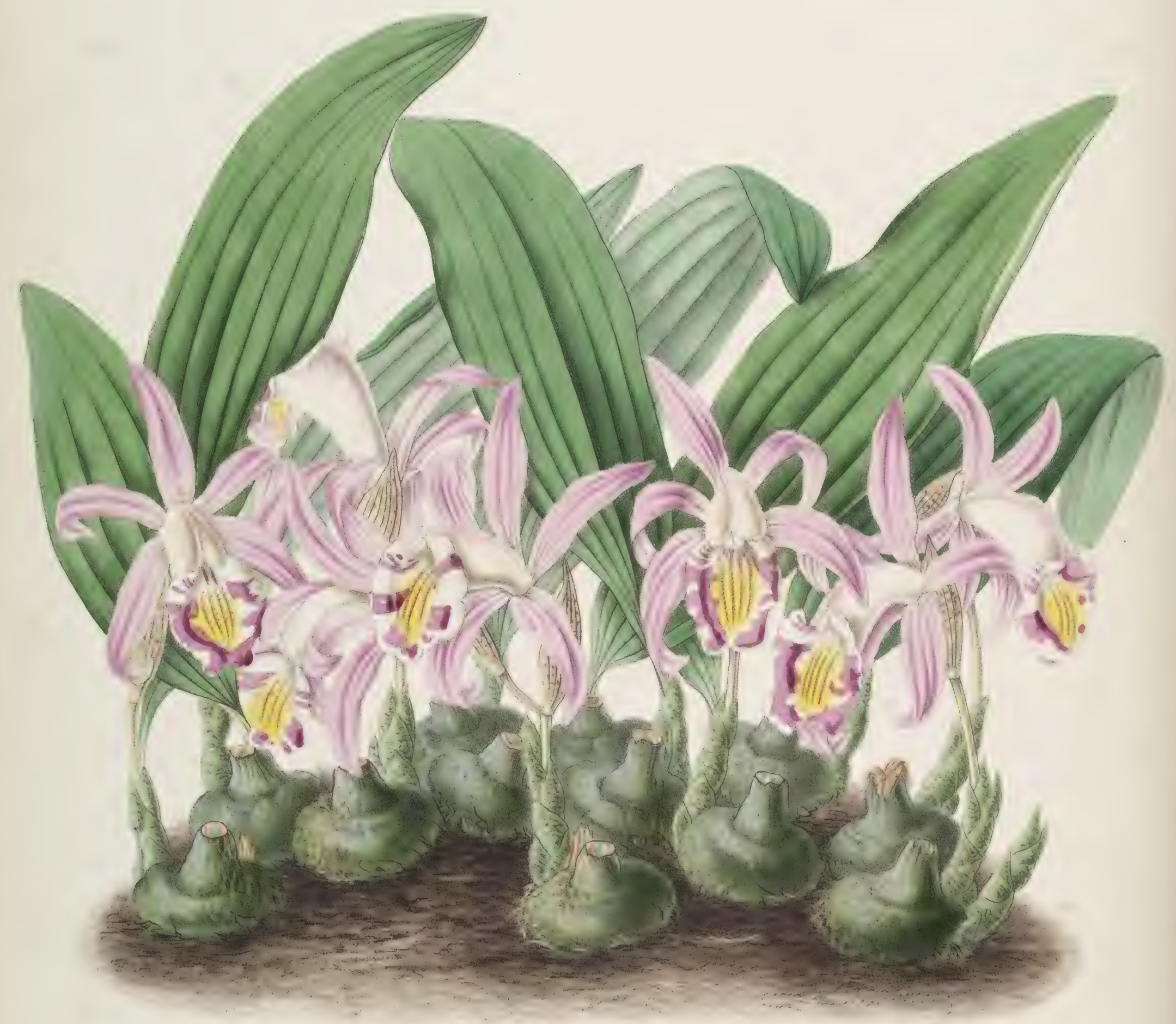

$\alpha$ 
ravg Xvit

I'LERE LAGENARIA

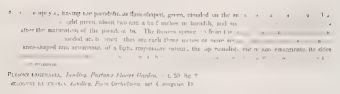

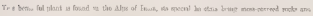

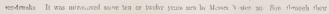

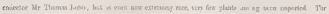

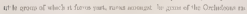

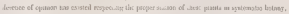

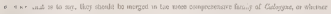

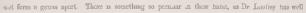

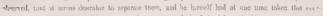

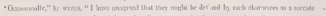

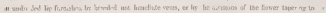

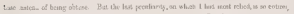

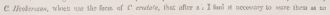

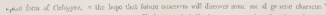

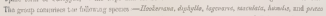

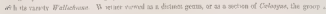

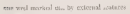

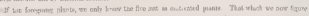

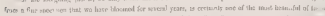

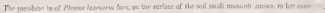

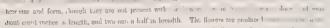

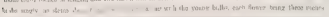

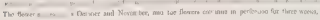
teret Irx Gan asalp

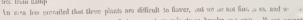

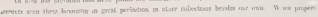




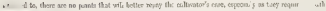

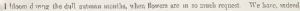

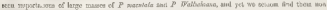

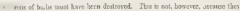

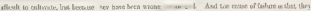

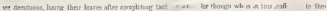

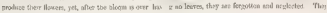

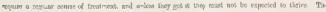

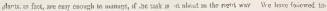

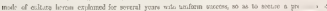

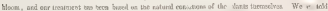

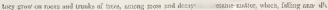

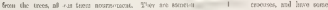

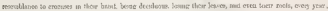

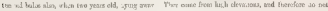

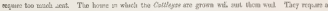

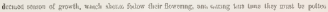

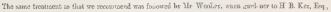

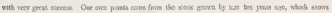

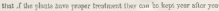

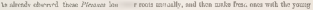

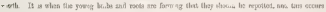

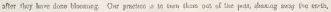

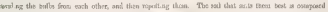

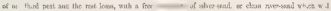

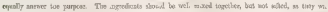

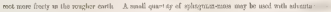

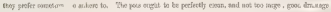

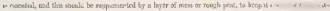

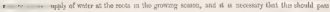

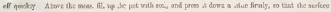

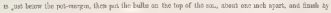

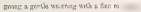

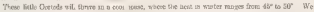

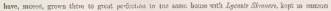

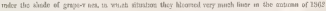

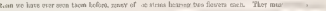

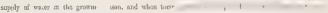

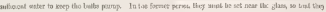

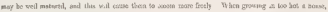

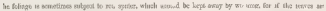

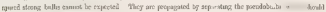
to them stan ting l. . 


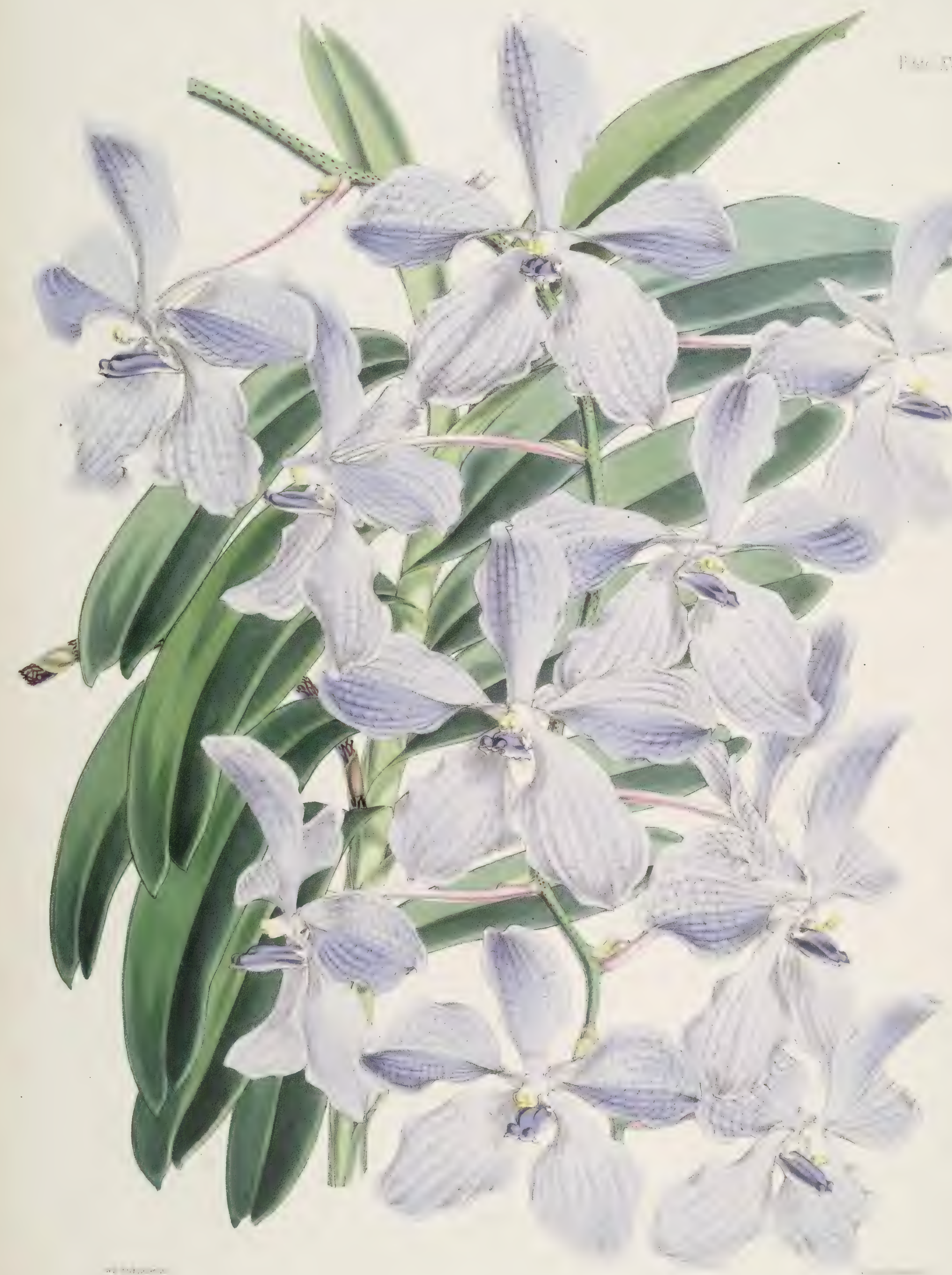


Privi XuTा!

VAYDI CURLYEA

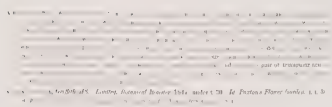

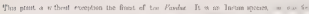

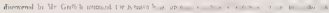

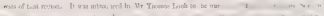

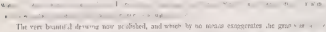

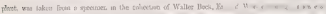

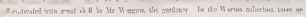

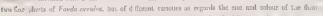

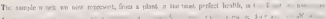

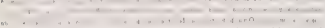

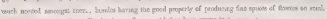

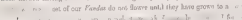




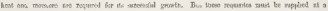

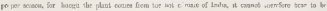

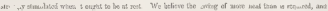

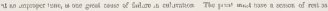

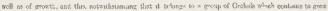

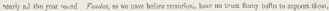

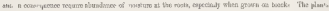

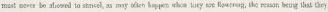

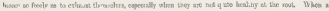

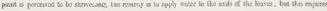

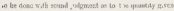

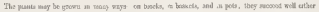

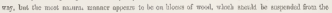

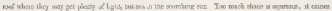

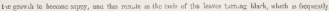

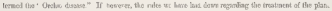

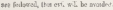

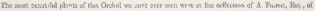

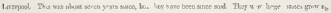

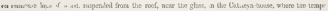

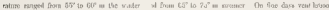

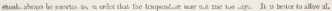

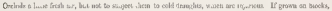

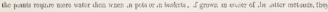

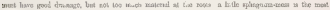

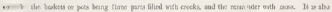

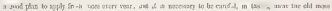

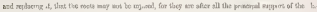

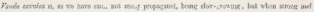

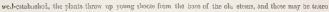

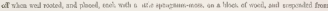

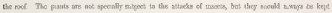

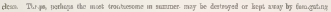
mith braree 


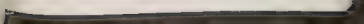




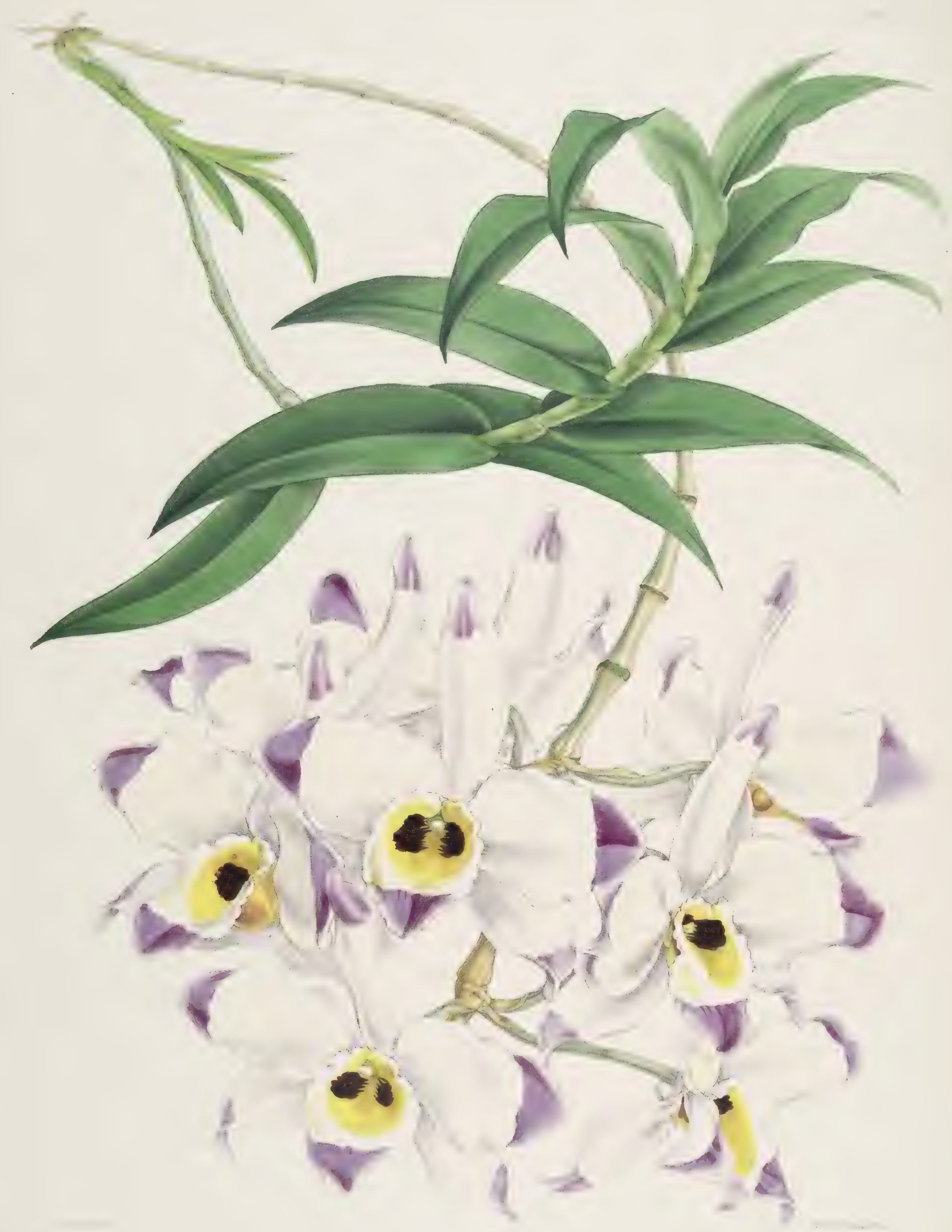


WE 815

DЕХDКนแ 


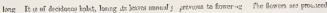

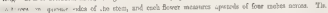

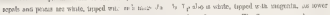

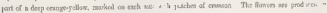

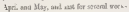

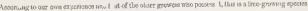

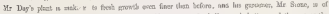

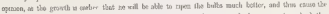

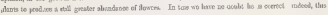

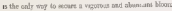

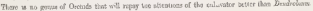

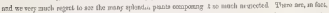

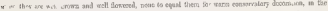

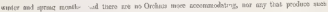

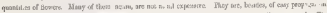

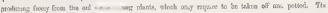

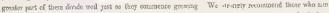

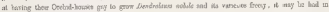

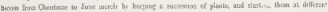

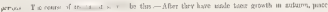

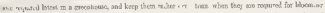

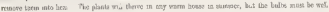

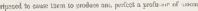

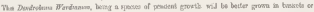

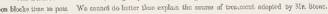

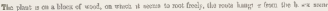

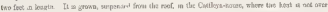

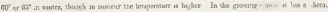

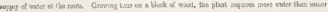

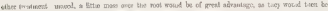

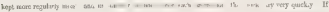

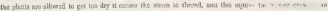

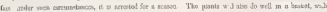

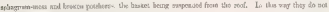

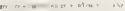

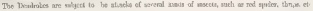

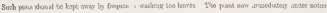

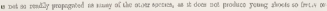

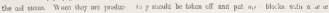
orits o a 


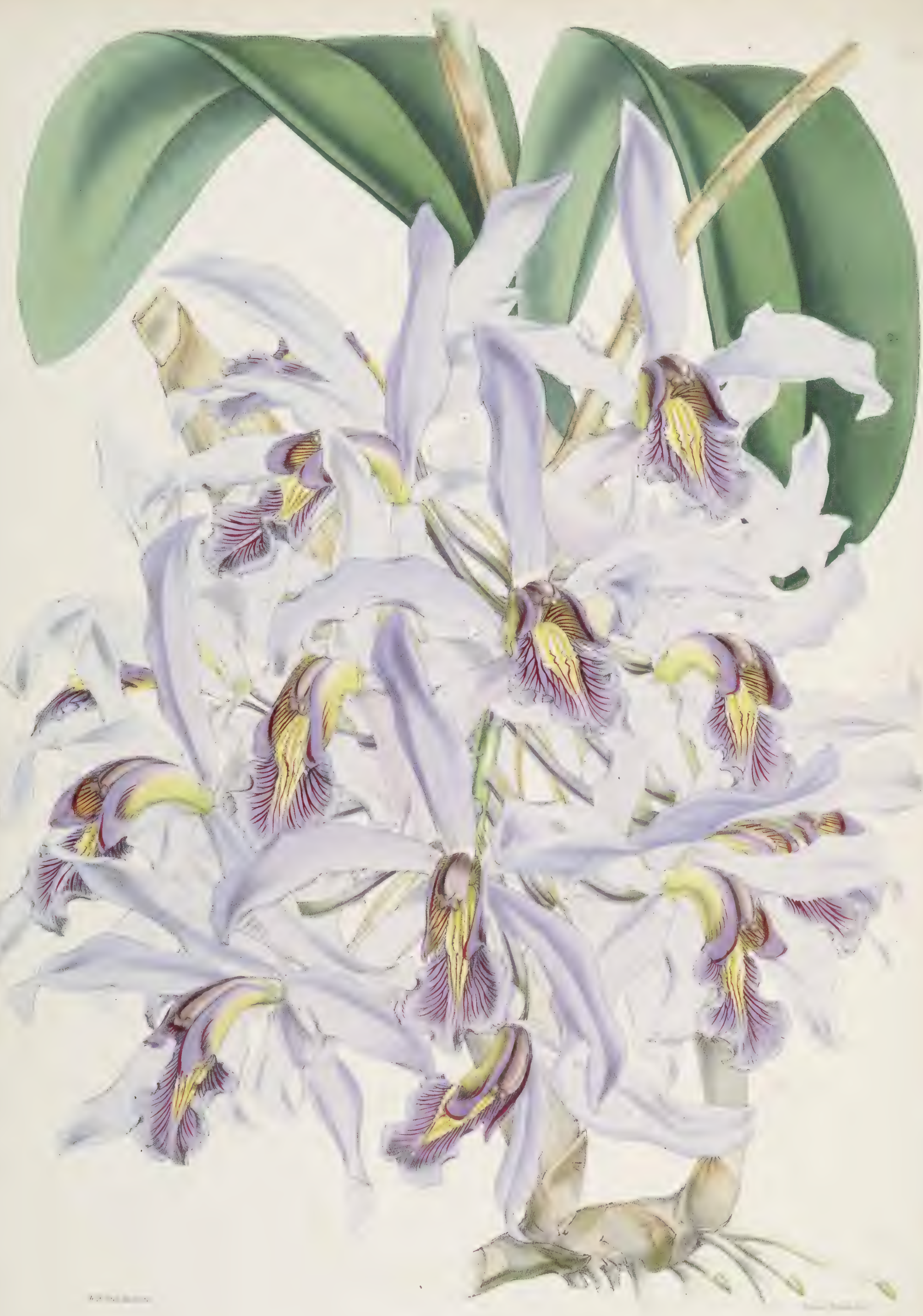


I't.A. XX

L.LLLA SUPFIHIES.

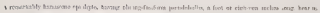

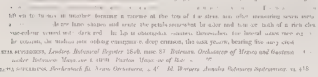

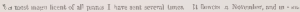

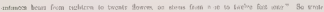

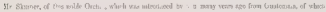

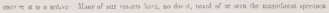

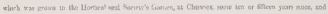

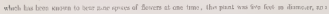

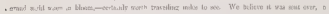

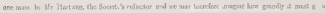

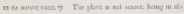

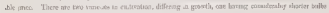

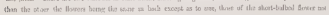

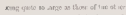

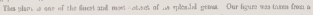

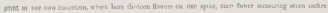

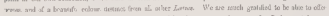

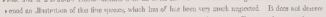

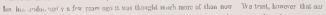

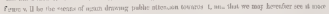

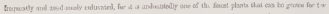

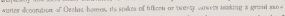

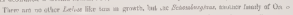

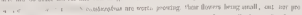

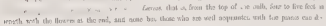

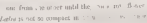

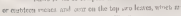

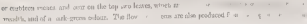




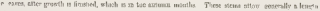

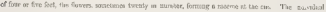

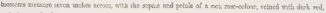

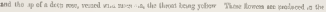

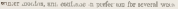

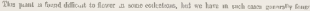

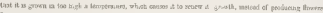

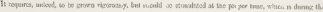

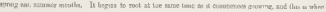

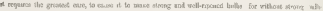

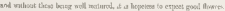

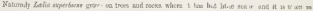

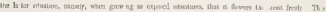

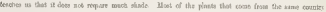

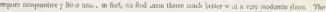

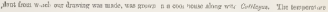

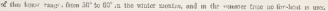

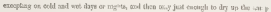

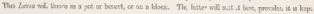

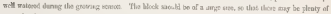

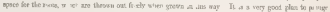

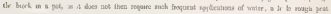

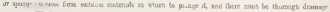

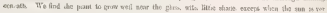

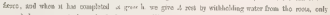

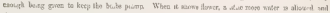

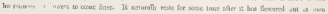

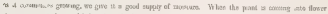

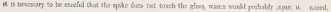

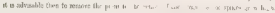

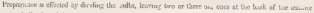

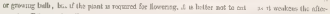

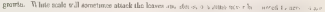




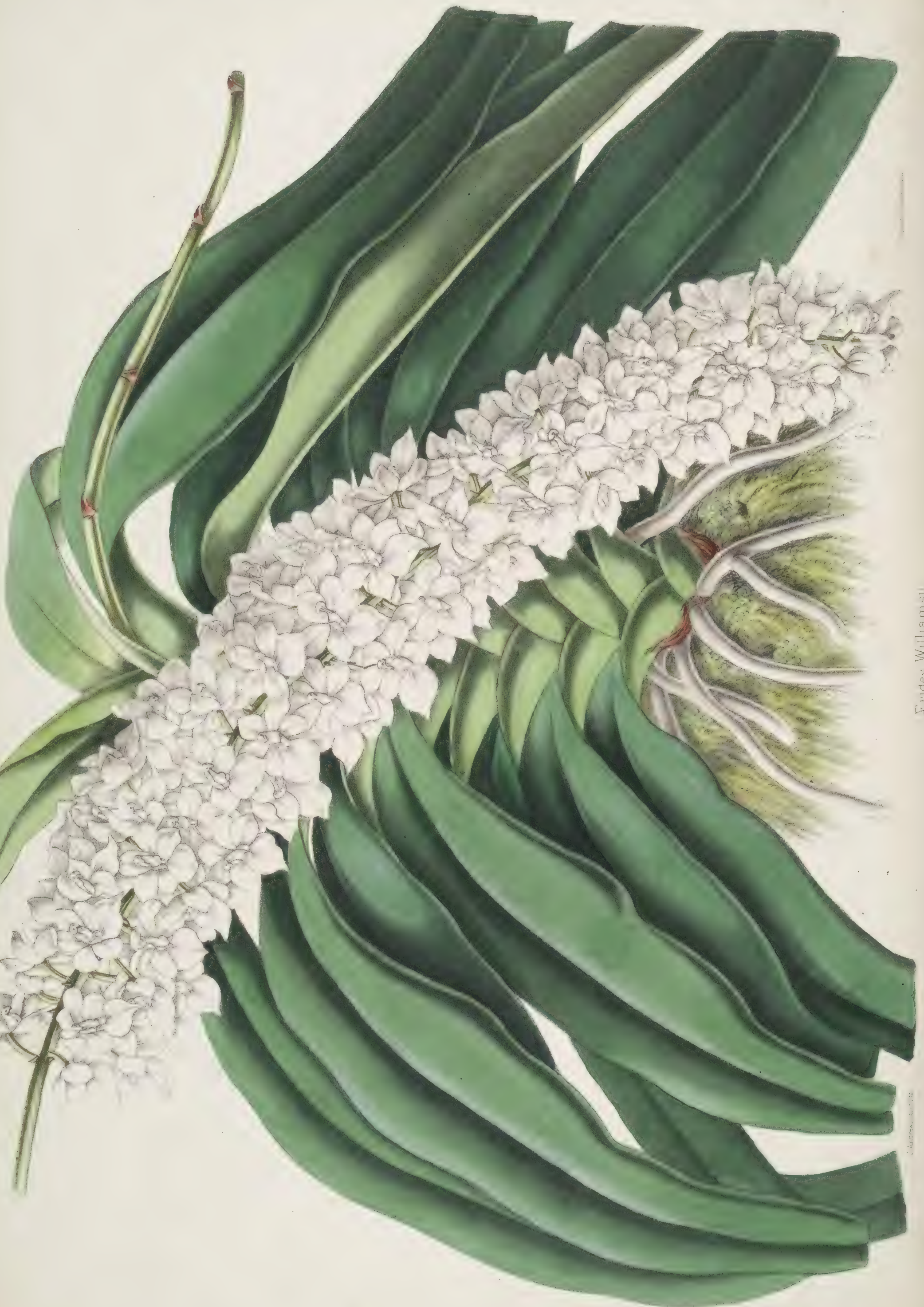


PI.TE XXI

IELJDLA WILIAMAII

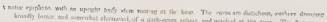

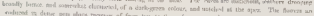

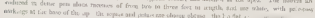
ir $-4 x$

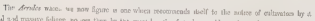

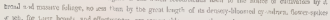

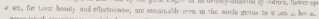

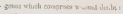

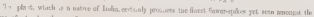

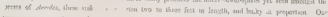

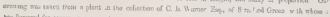

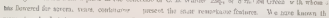

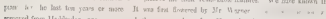

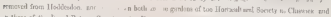

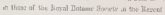

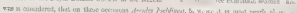

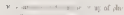

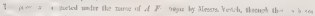

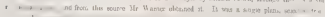

1

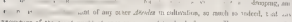

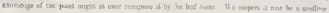

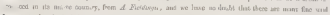

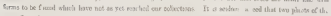

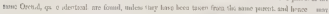

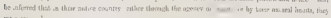
vere neti sai nere.

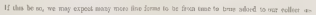

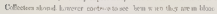

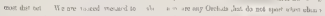

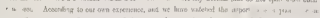

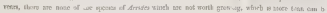

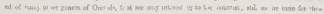

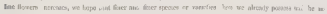

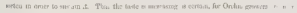

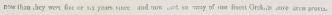




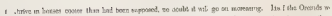

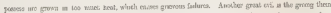

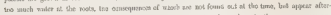

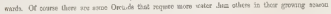

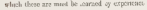

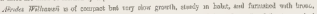

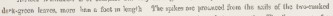

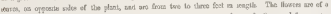

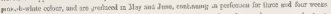

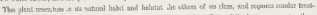

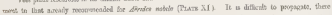

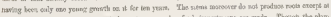

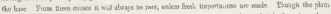

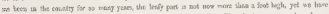

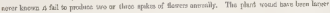

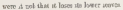




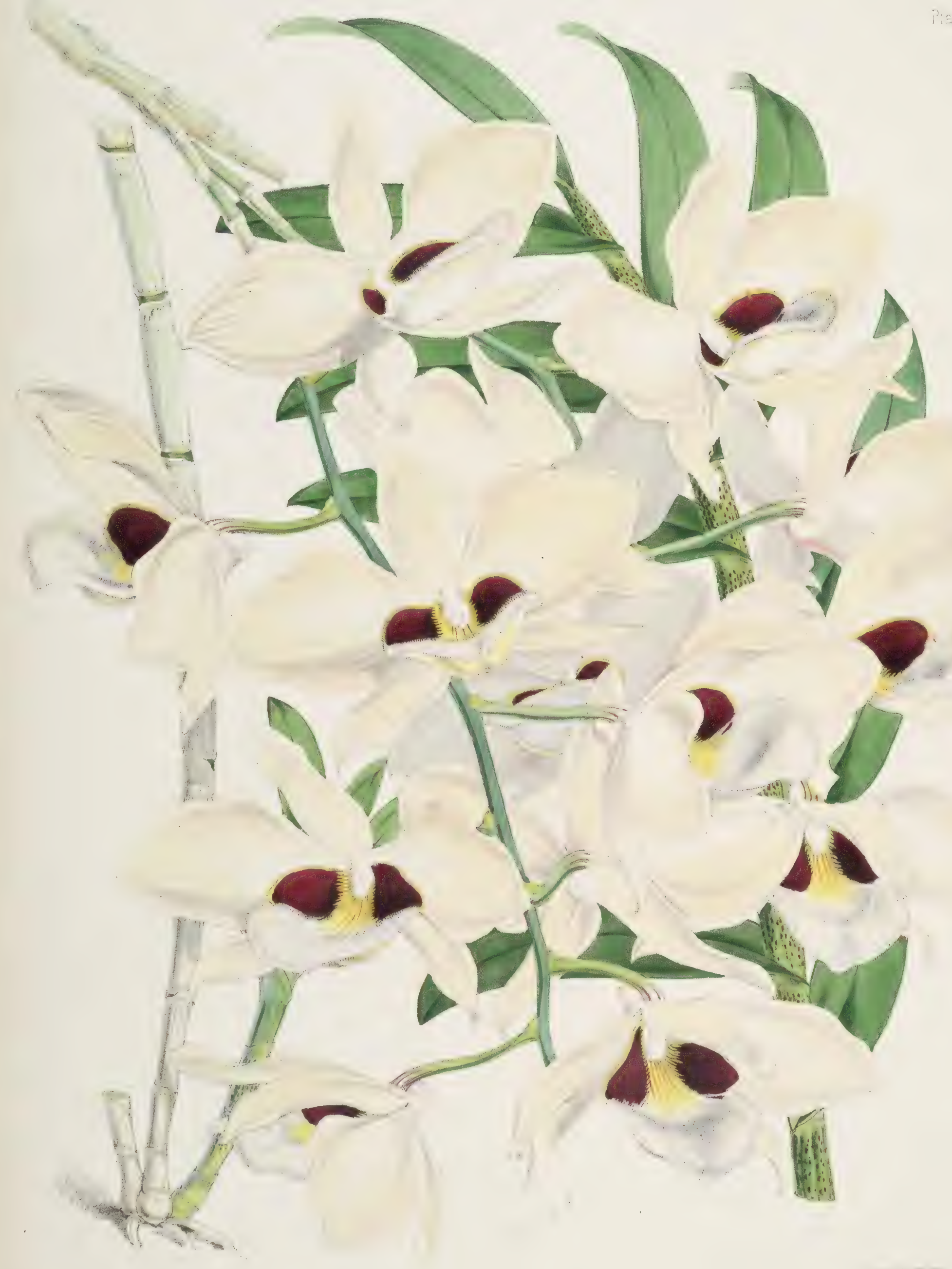


Prane XXIT

[) MLIZOBHLN TALTROTSIE IXIN]
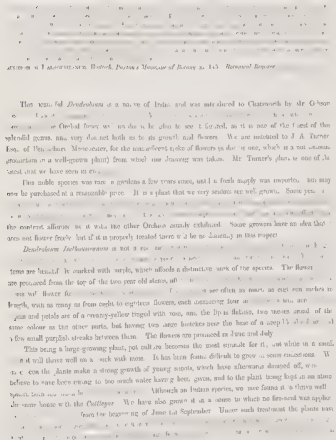


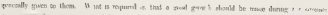

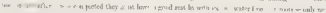

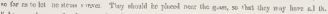

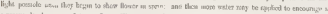

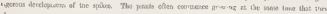
keris

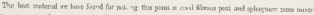

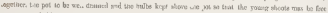

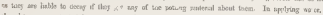

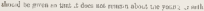

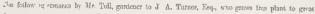

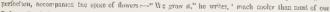

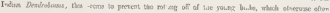

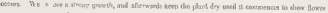

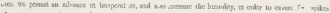

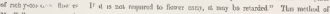

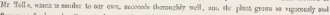

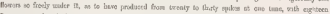

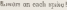

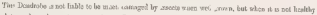

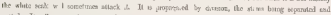

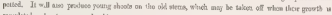

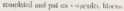





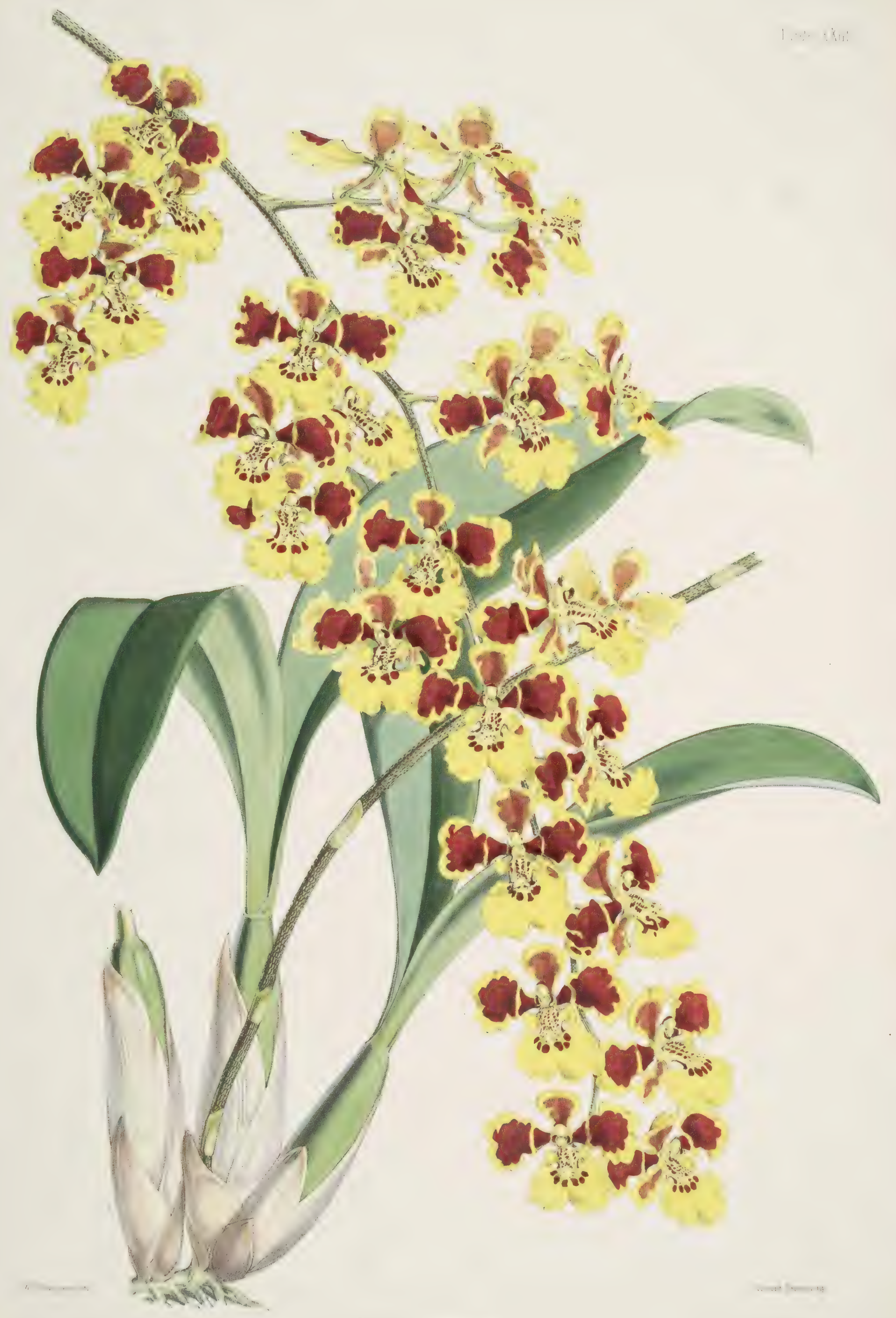




\section{I'rist: $>$ MII}

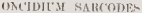

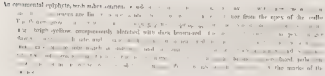

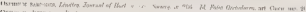

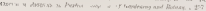

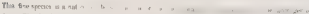

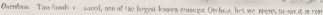

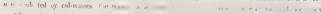

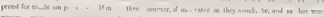

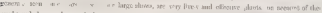

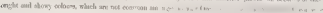

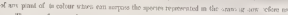

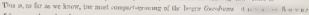

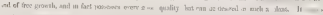

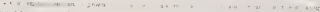

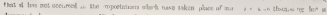

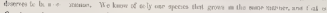

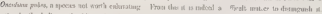

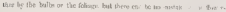

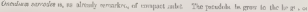

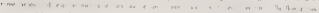

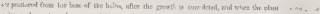

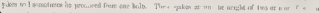

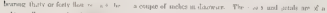

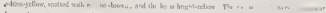

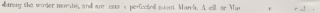

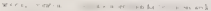

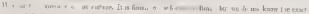

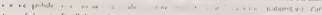

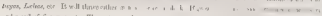

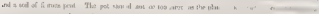

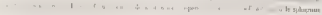




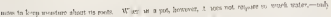

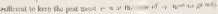

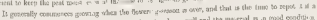

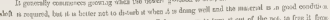

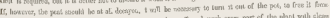

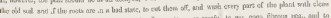

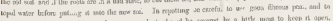

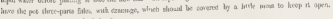

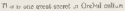

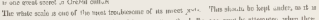

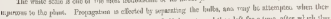

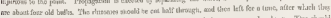

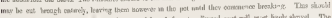

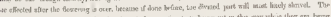

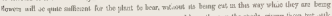

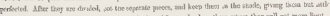

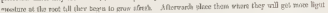





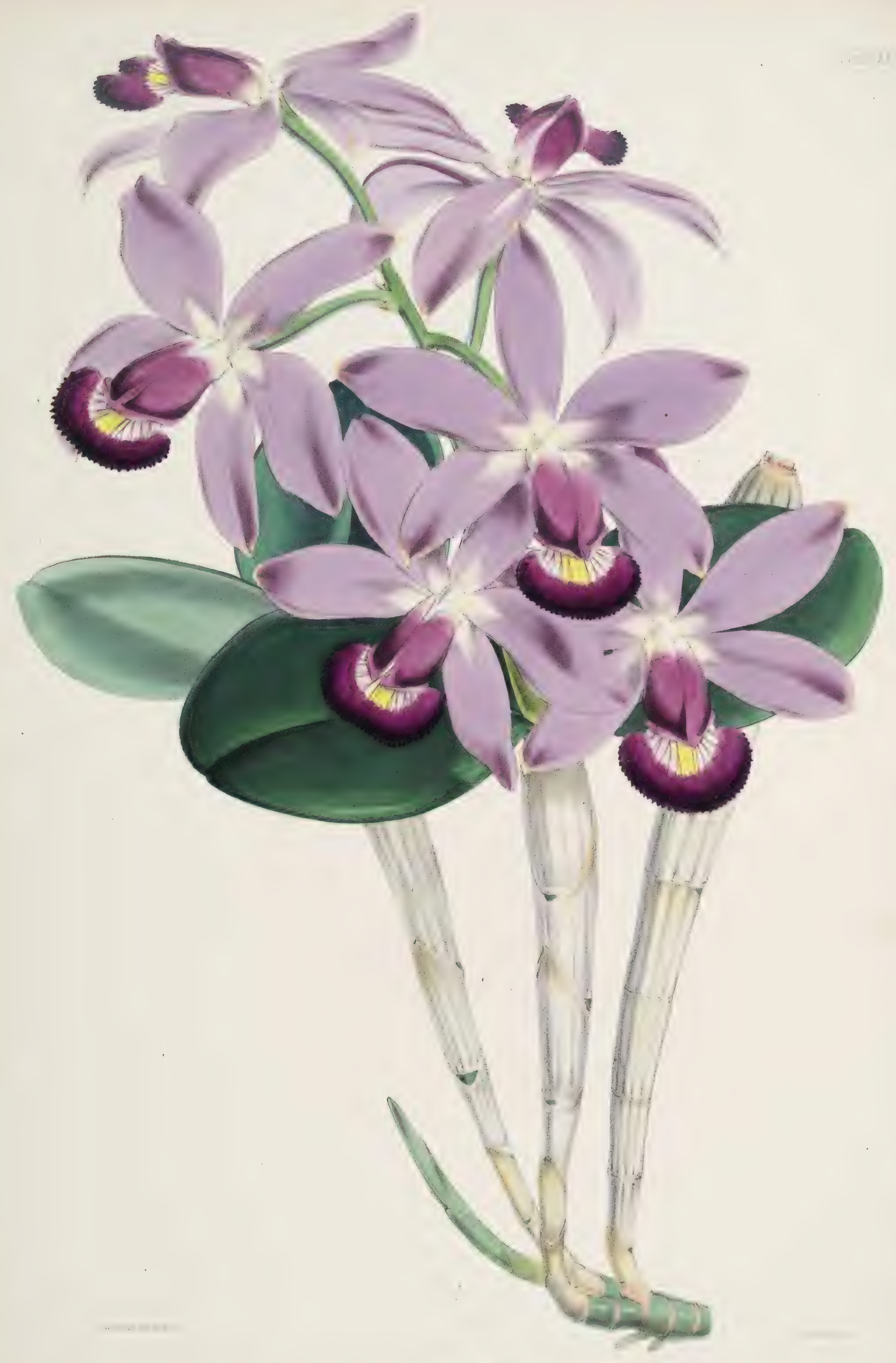




\section{CATILEYA STPFRISA}

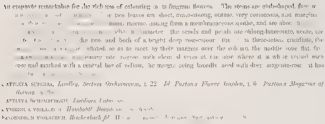

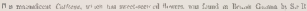

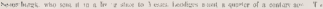

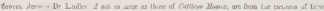

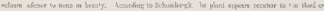

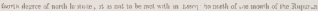

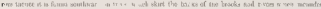

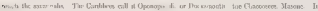

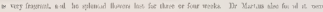

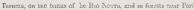

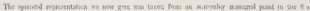

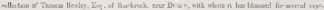

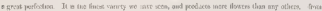

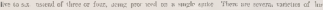

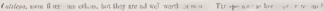

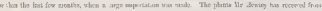

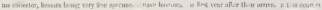

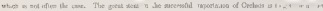

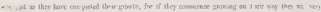
it baks panis

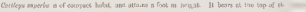

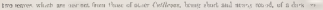

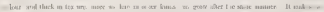

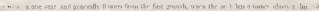

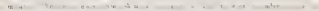

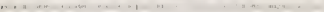




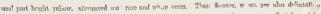

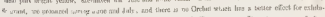

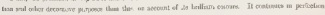
Hine oc forr onels, if wot des

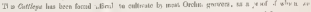

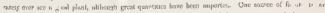

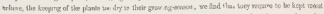

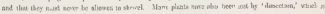

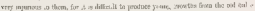

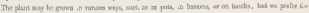

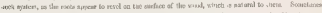

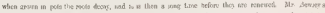

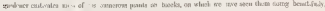

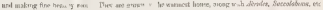

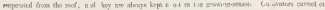

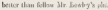

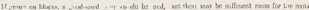

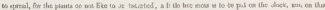

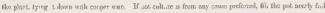

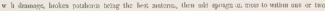

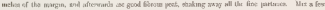

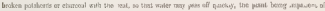

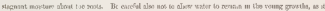

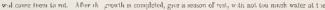

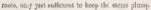

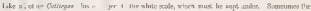

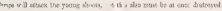




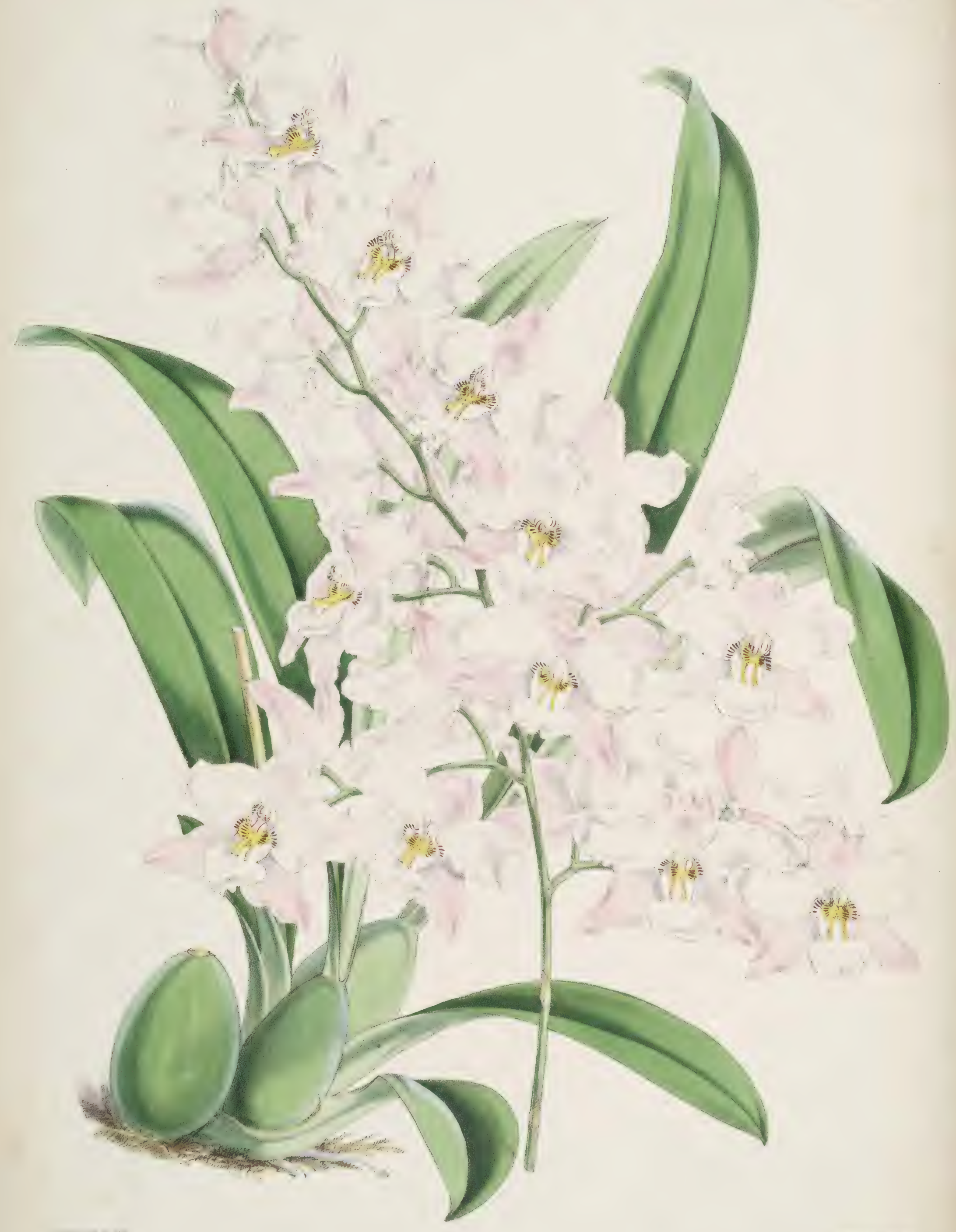


$\operatorname{ran} \times 11$

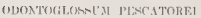

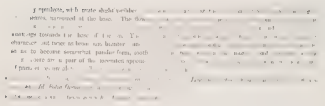

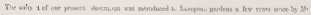

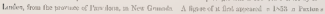

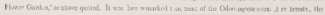

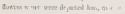

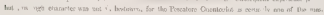

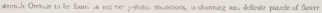

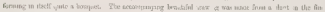

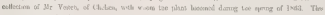

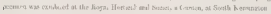

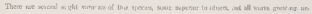

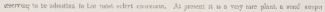

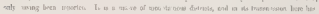

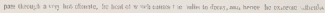

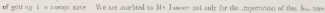

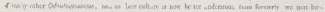

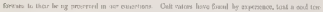

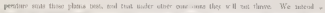

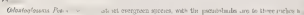

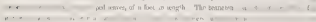

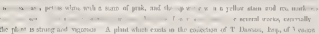

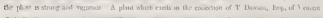

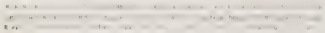




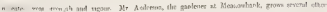

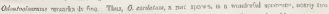

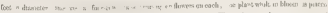

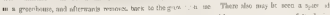

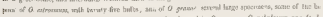

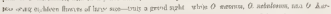

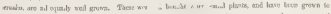

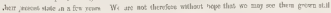

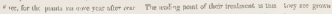

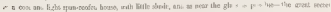

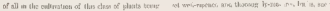

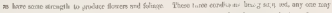

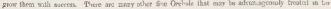

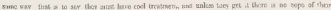

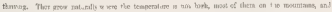

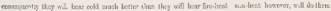

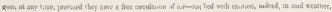

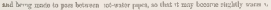

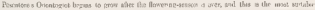

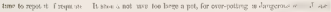

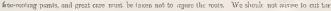

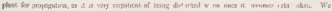

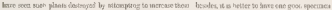

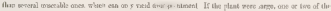

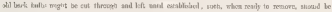

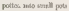

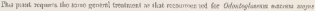

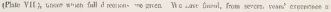

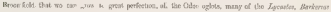

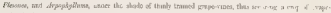

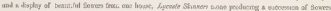

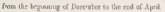




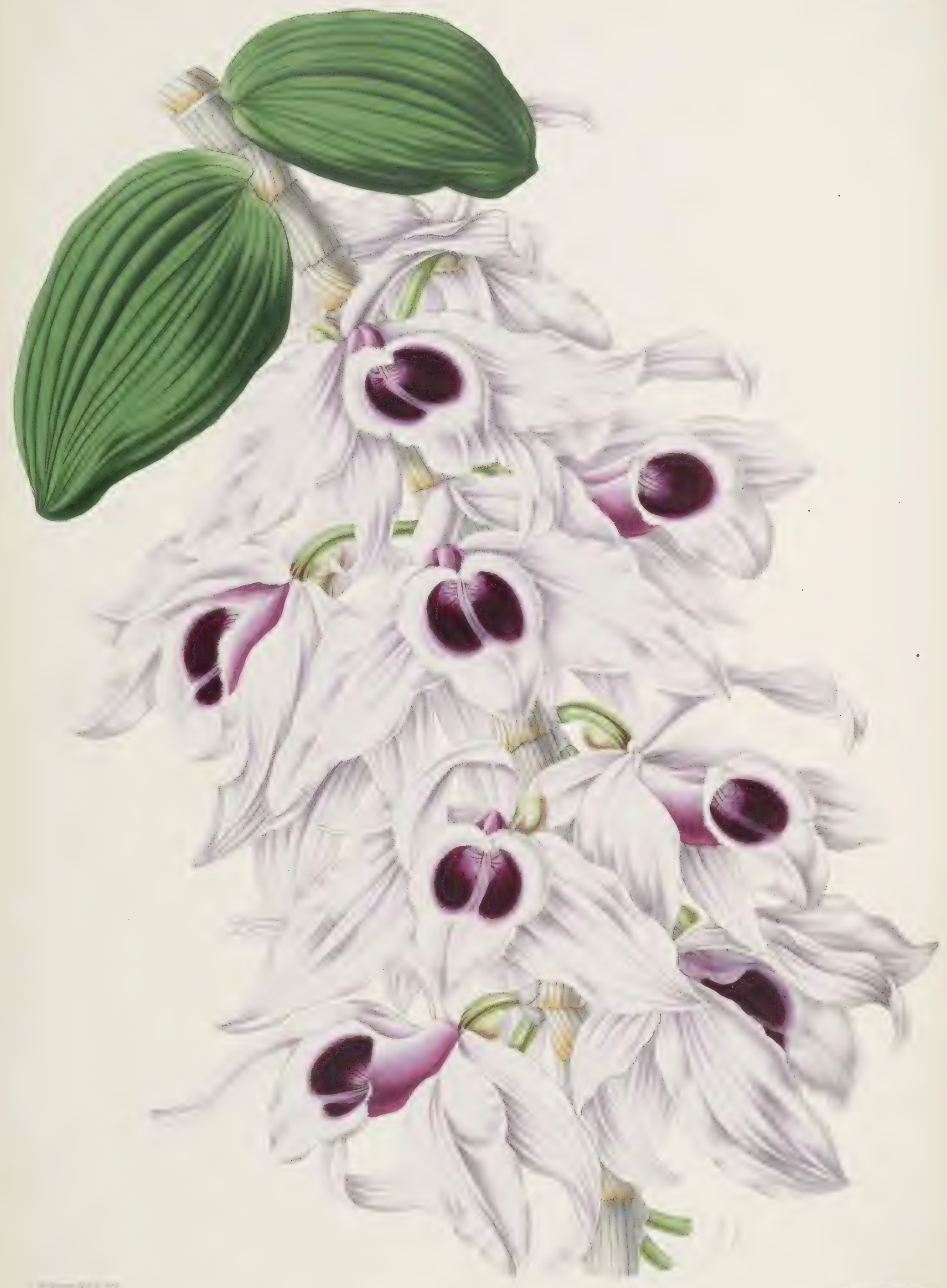

1 
Penth SAM

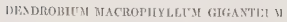

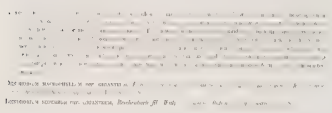

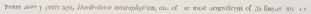

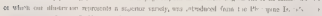

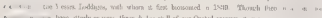

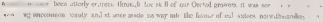

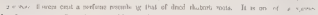

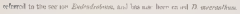

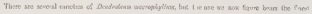

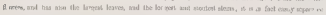

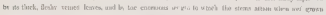

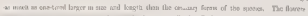

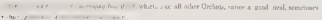

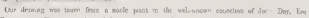

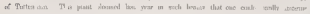

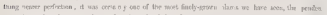

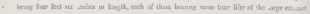

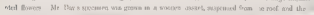

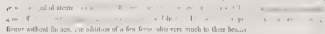

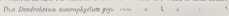

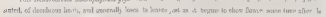

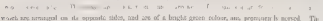

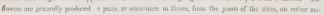

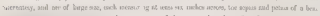

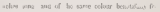




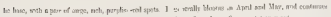

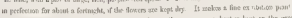

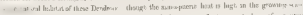

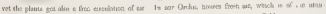

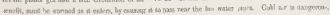

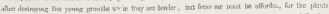

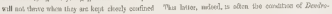

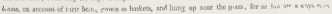

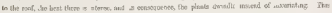

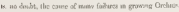

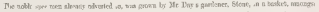

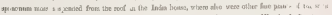

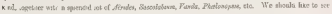

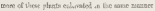

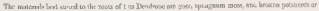

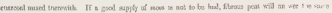

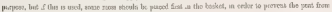

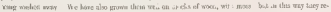

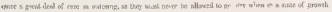

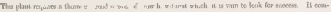

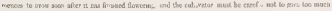

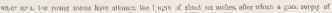

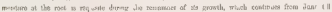

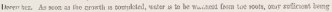

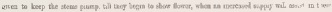

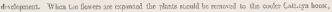

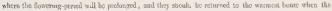

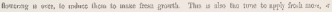

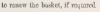

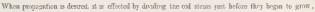

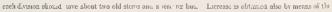

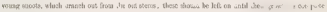

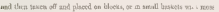

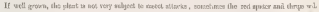

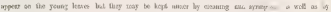

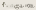




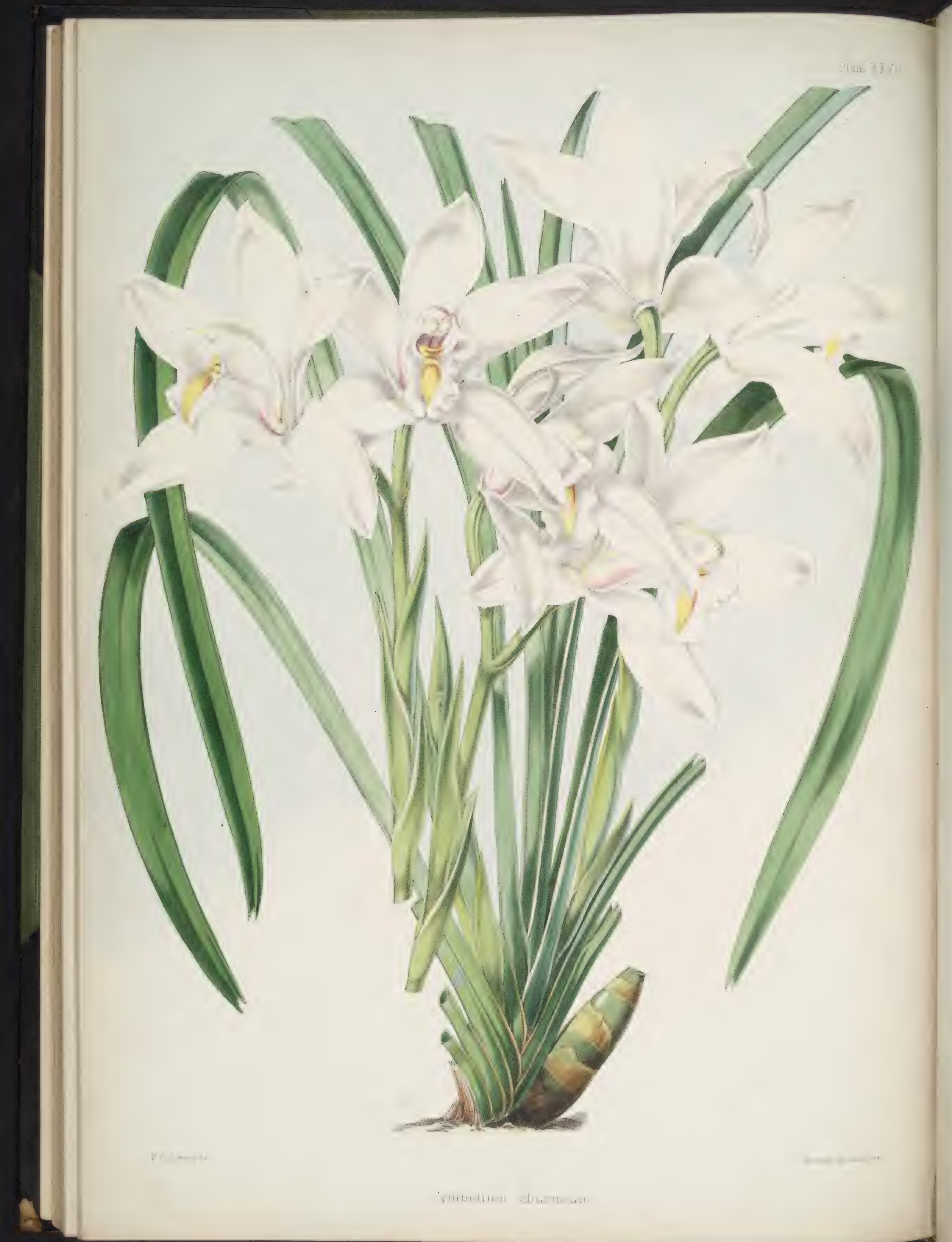


Ir: $19 x \times 1311$

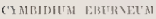

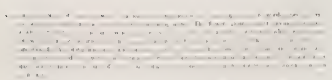

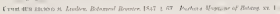

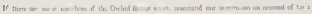

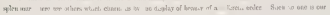

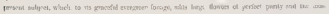

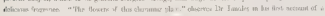

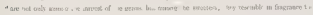

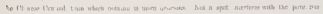

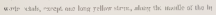

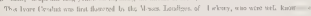

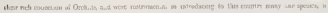

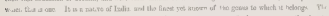

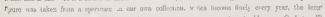

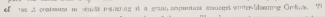

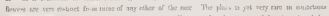

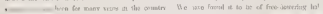

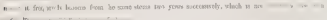

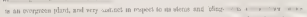

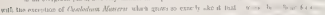

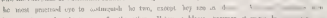

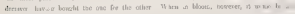

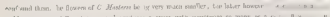

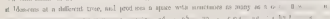

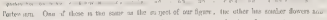

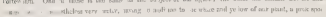

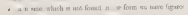

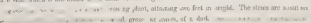

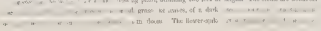




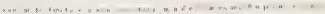

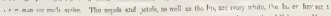

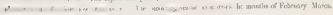

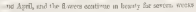

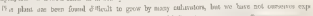

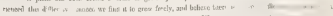

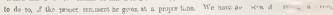

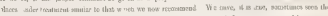

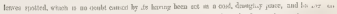

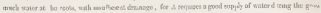

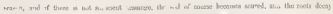

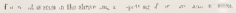

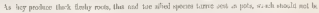

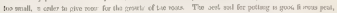

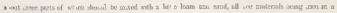

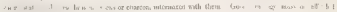

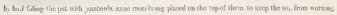

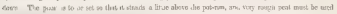

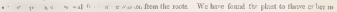

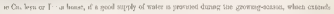

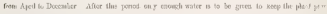

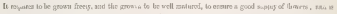

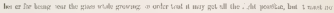

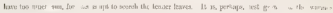

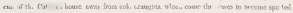

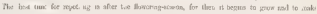

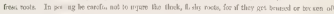

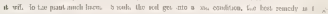

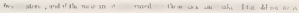

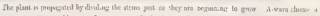

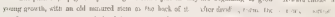

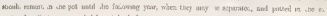

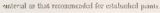

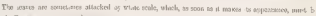

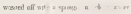




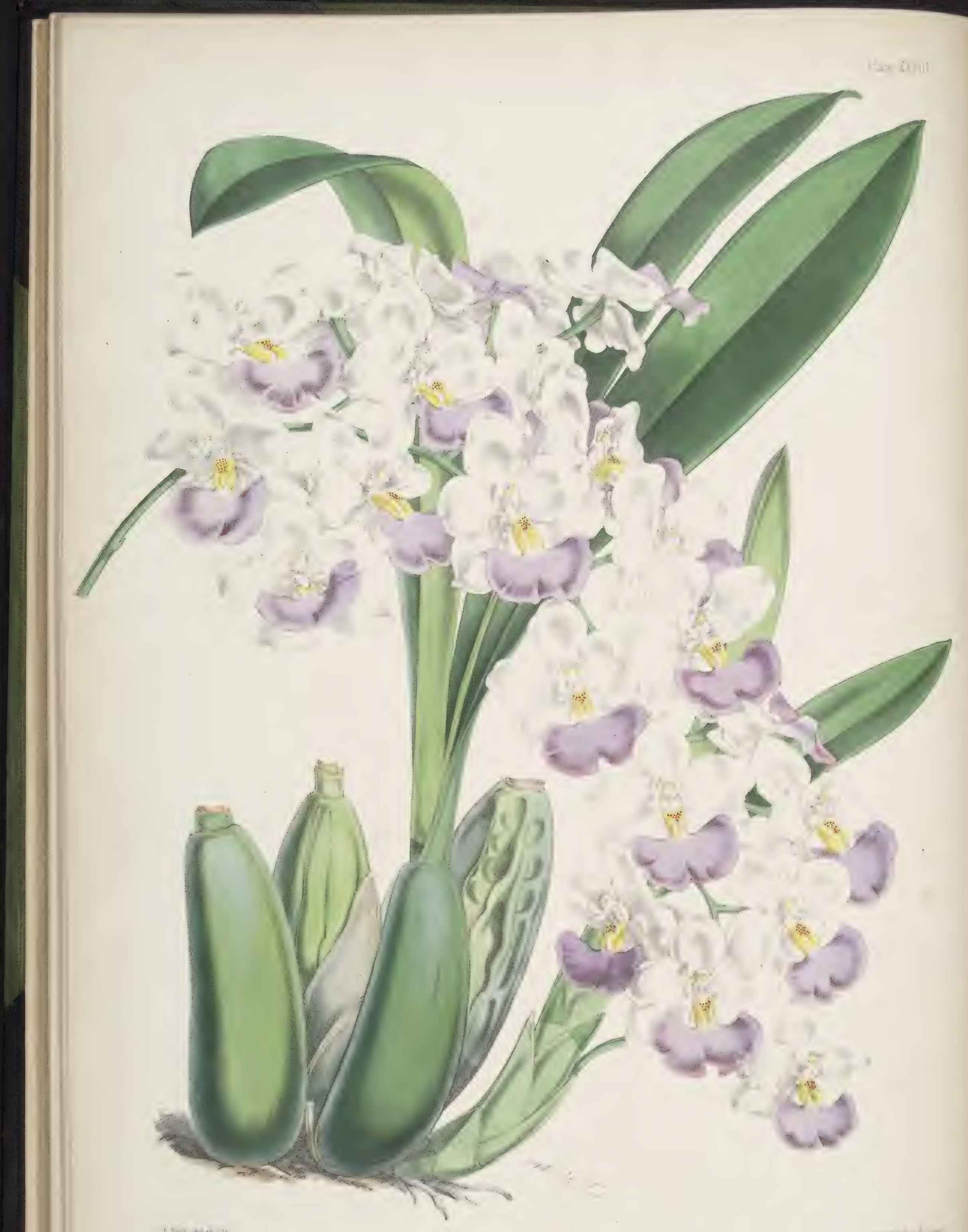




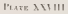

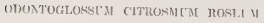

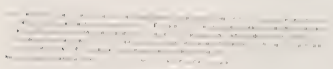

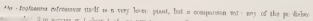

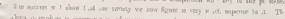

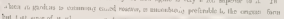

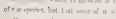

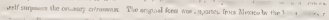
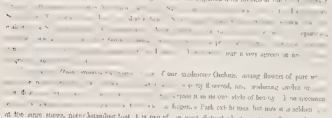

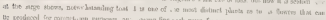

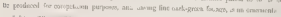

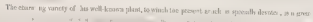

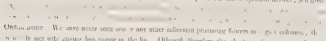

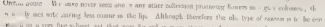

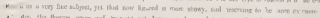

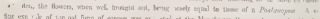

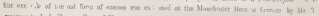

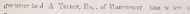

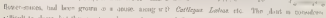

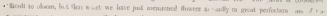

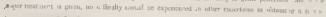




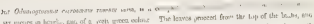

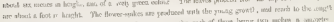

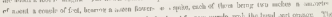

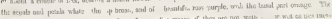

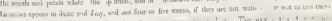

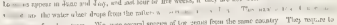

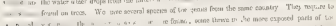

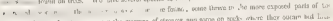

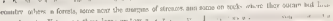

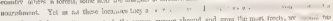

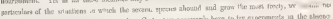

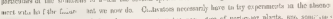

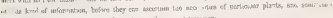

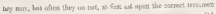

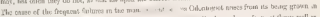

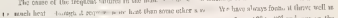

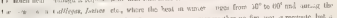

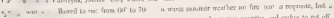

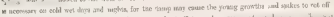

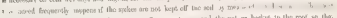

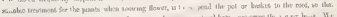

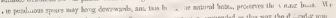

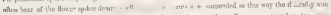

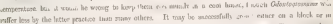

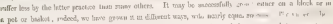

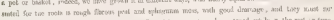

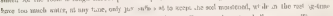

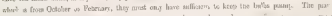

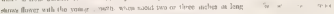

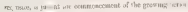

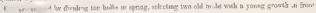

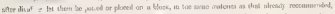

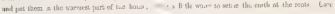

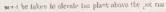

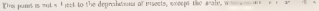

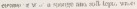




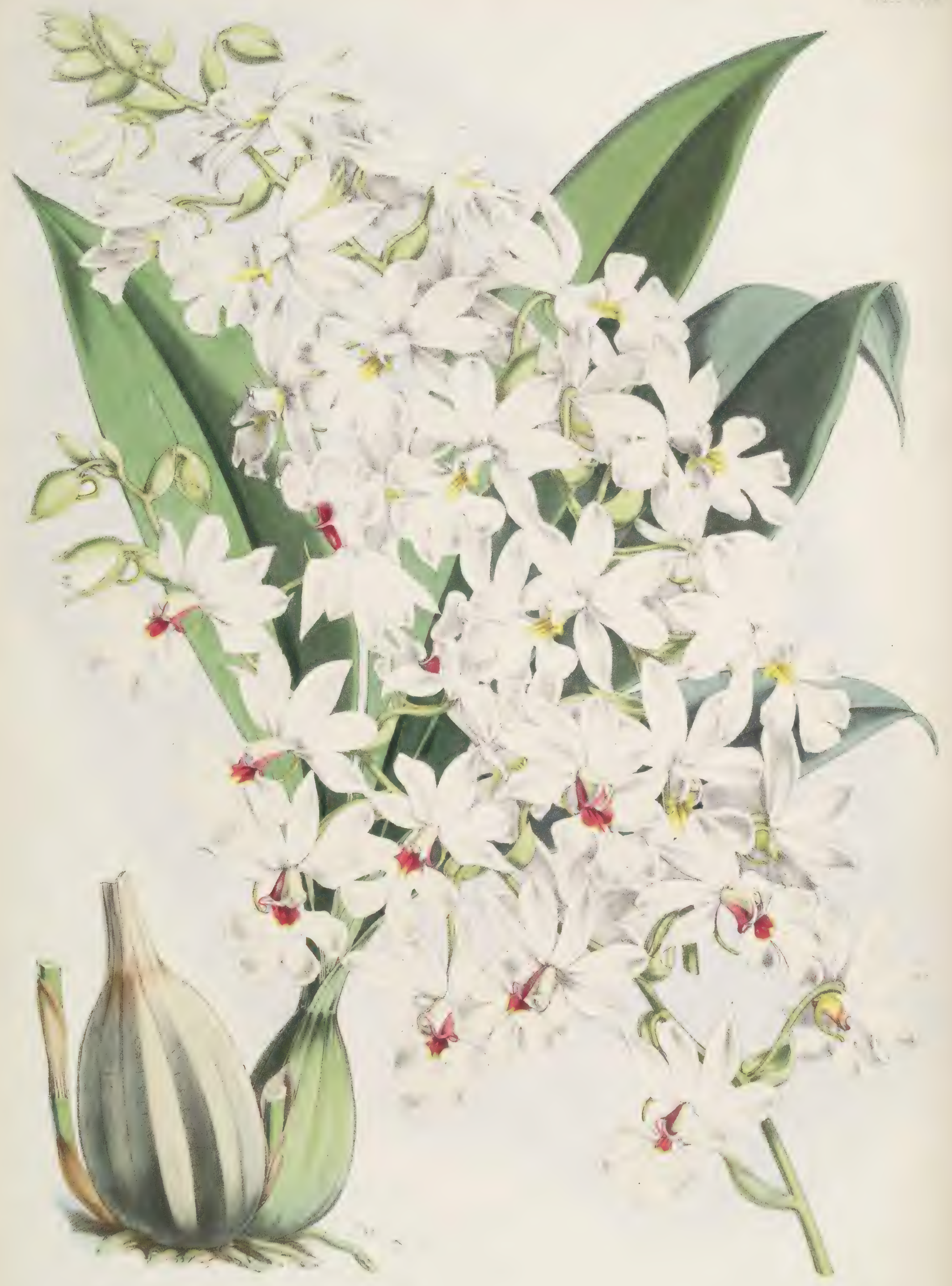


H'WTE XVI?

CALANTHE VLSTTA

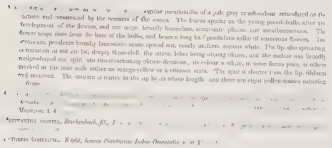

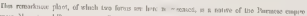

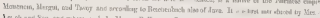

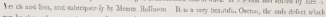

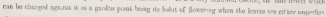

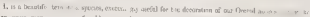

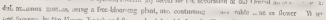

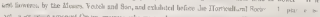

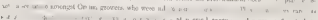

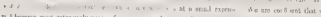

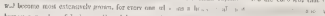

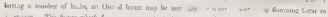

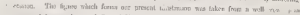

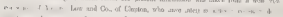

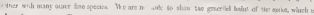

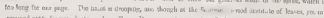

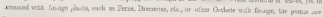

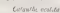

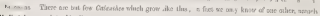

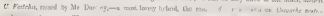

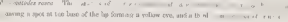




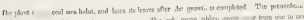

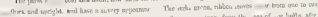

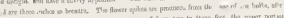

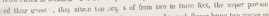

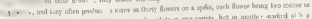

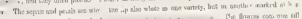

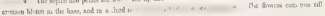

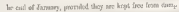

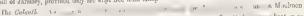

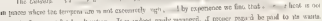

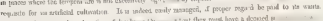

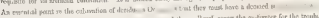

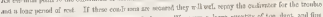

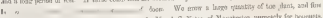

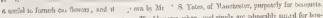

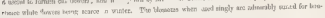

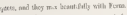

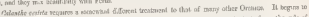

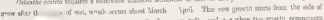

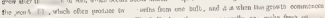

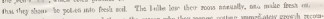

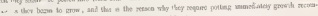

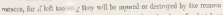

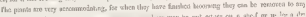

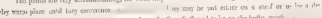

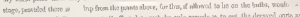

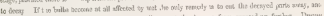

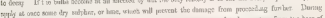

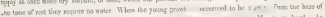

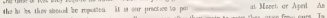

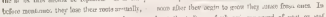

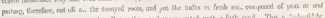

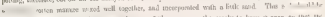

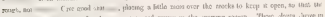

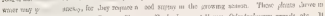

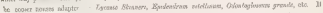

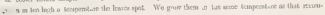

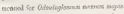

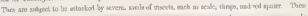

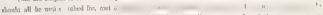

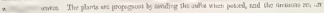

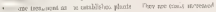




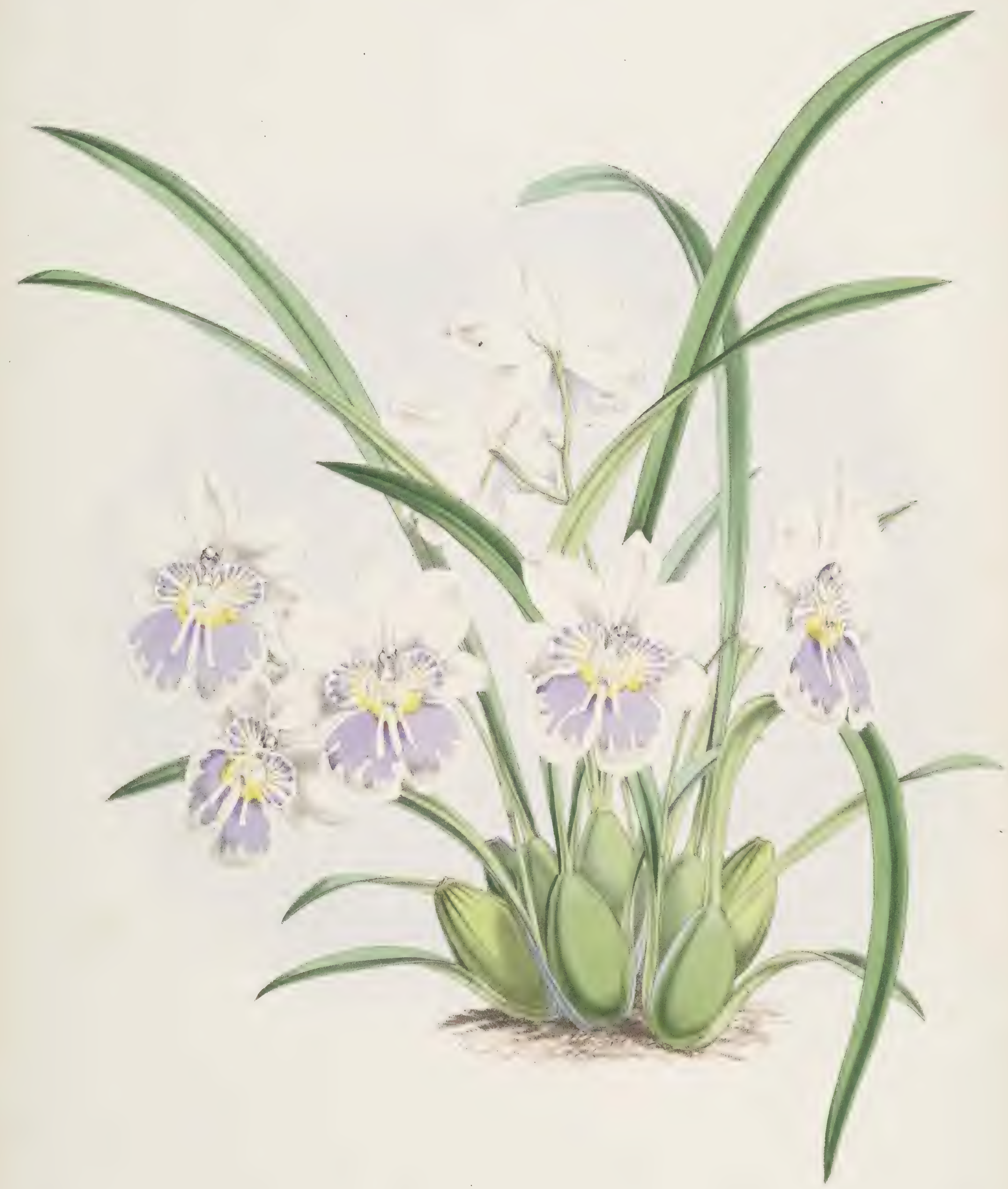




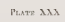

ODONTOCTOOSETTM PIIATLENOPSIS

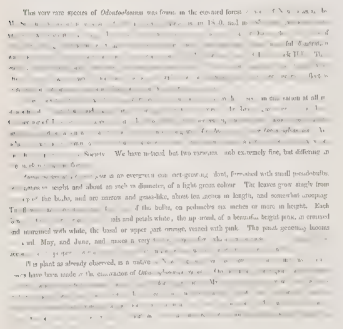




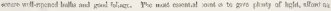

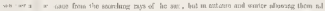

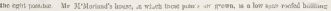

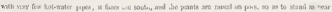

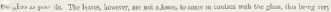

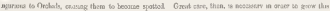

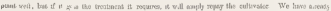

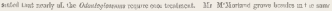

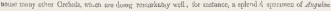

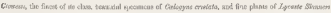
reat easion

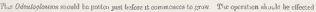

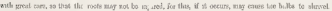

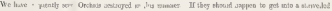

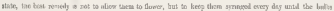

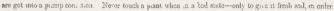

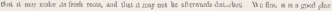

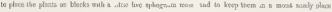

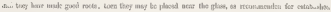
mutre

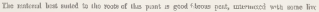

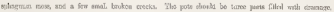

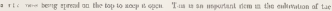

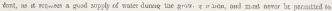

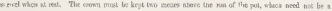

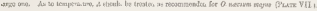

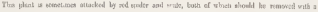

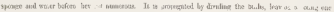

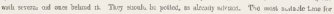

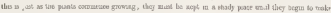

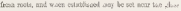




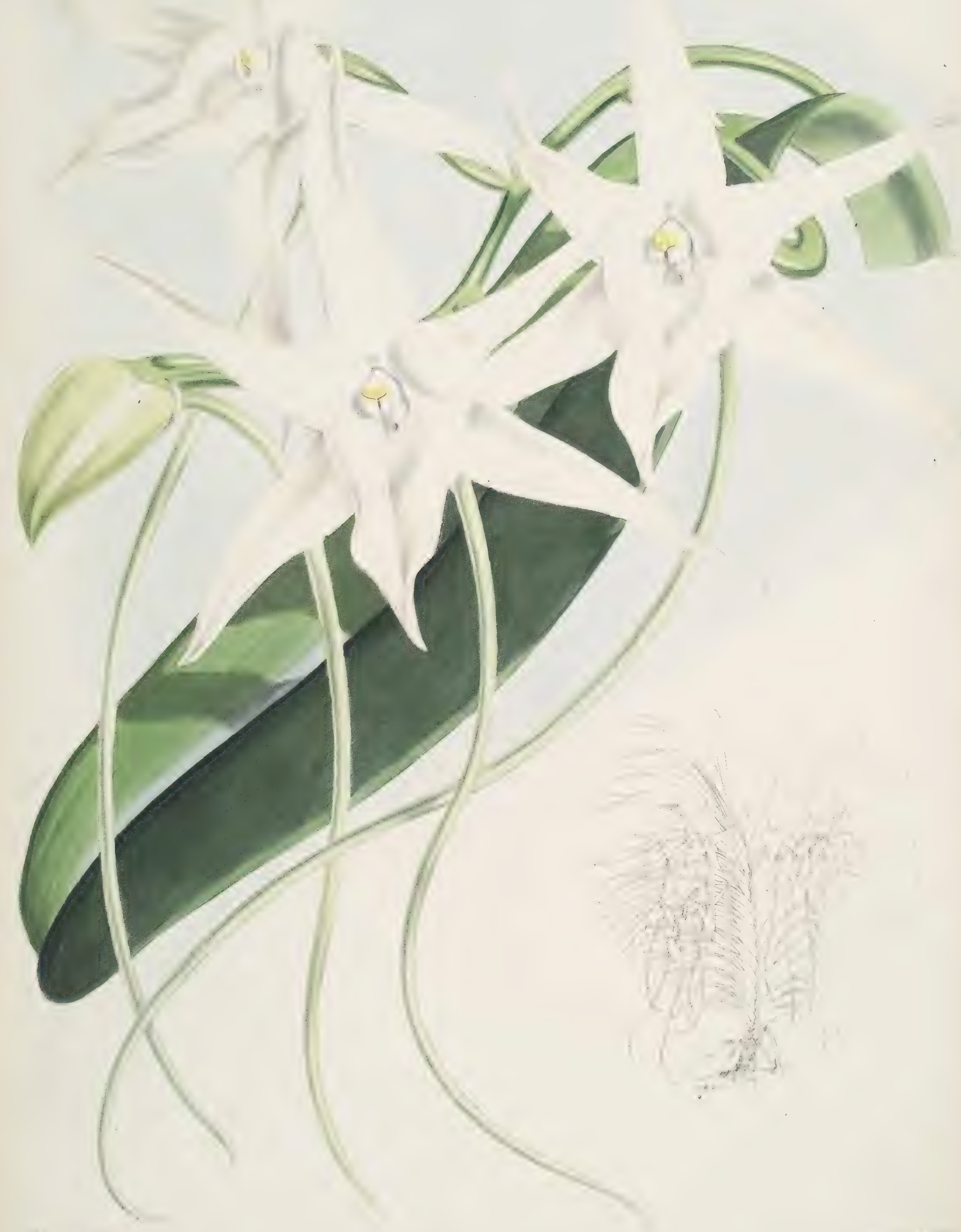


IIAT: $\mathrm{XXY1}$

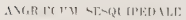

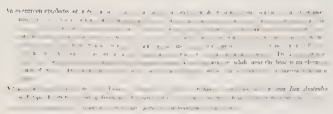

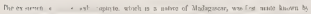

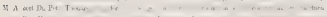

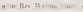

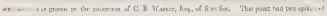

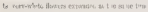

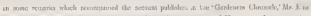

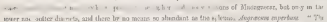

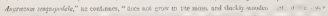
in 7 in

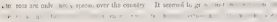

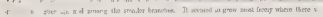

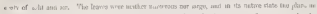

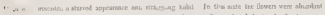

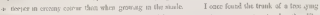

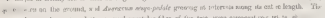

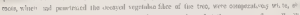

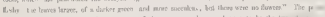

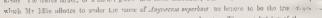

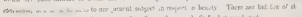

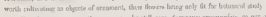

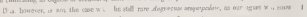

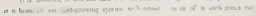

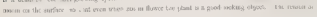




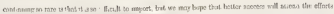

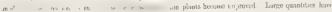

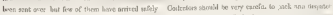

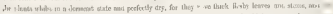

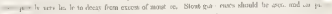

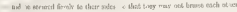

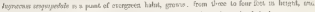

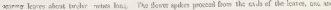

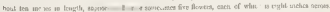

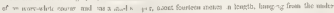

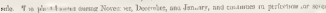

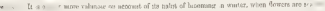

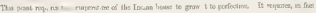

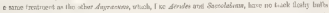

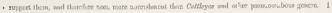

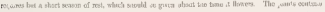

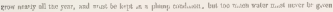

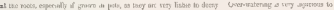

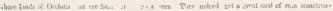

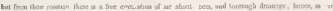

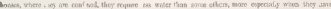

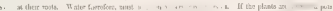

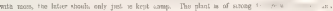

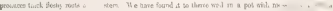

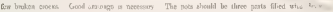

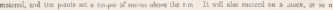

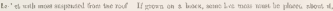

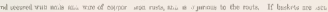

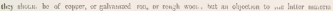

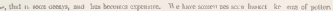

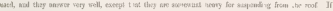

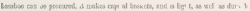

se $x$ *

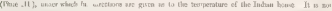

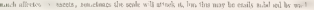

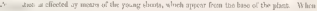

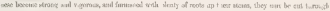

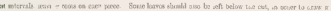

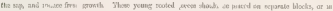

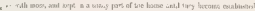




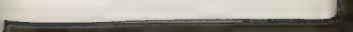




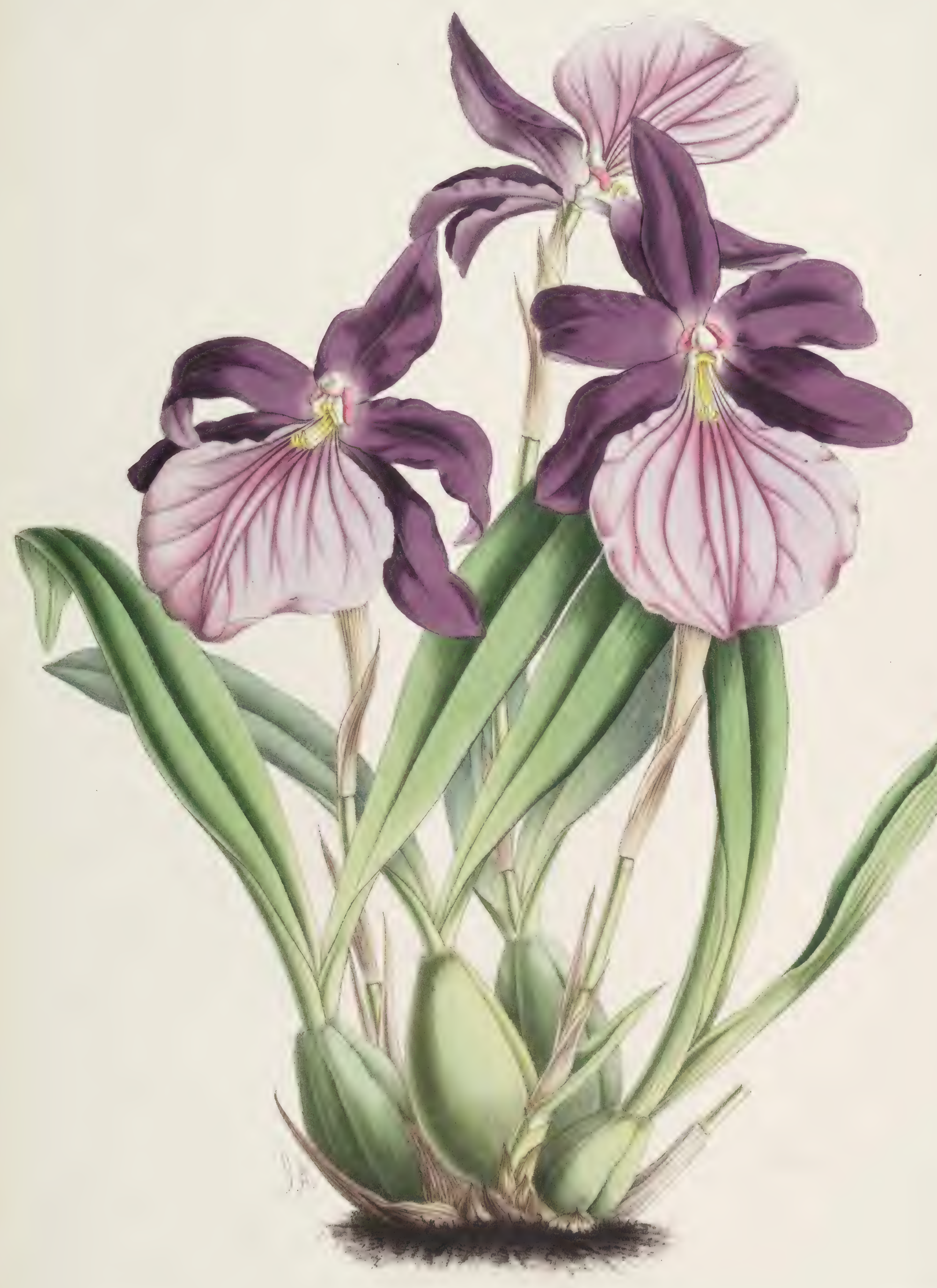


Panig $8 \times \times 1$ !

IILTONIA ALORELIANA

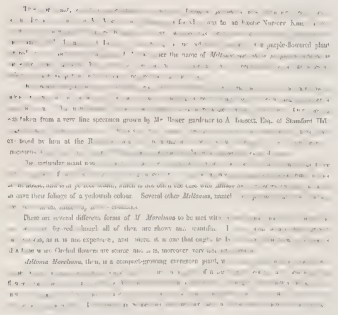




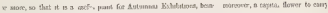

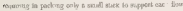

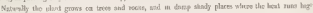

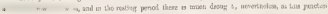

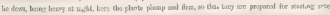

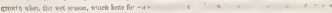
asi, bionerne

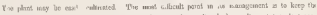

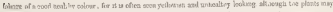

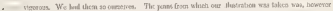

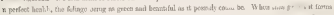

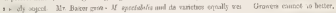

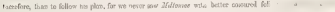

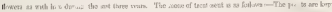

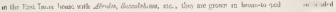

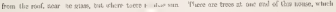

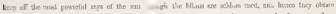

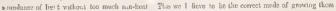

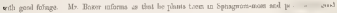

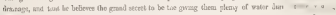

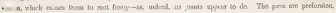

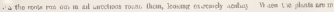

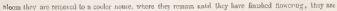

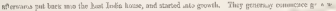

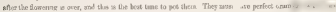

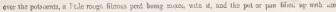

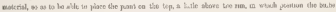

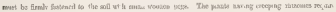

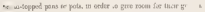

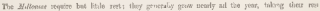

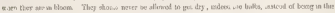

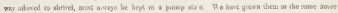

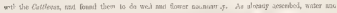

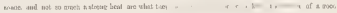

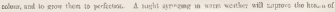
be jiat

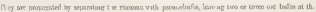

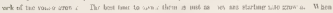

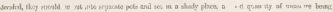

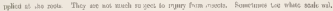

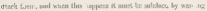





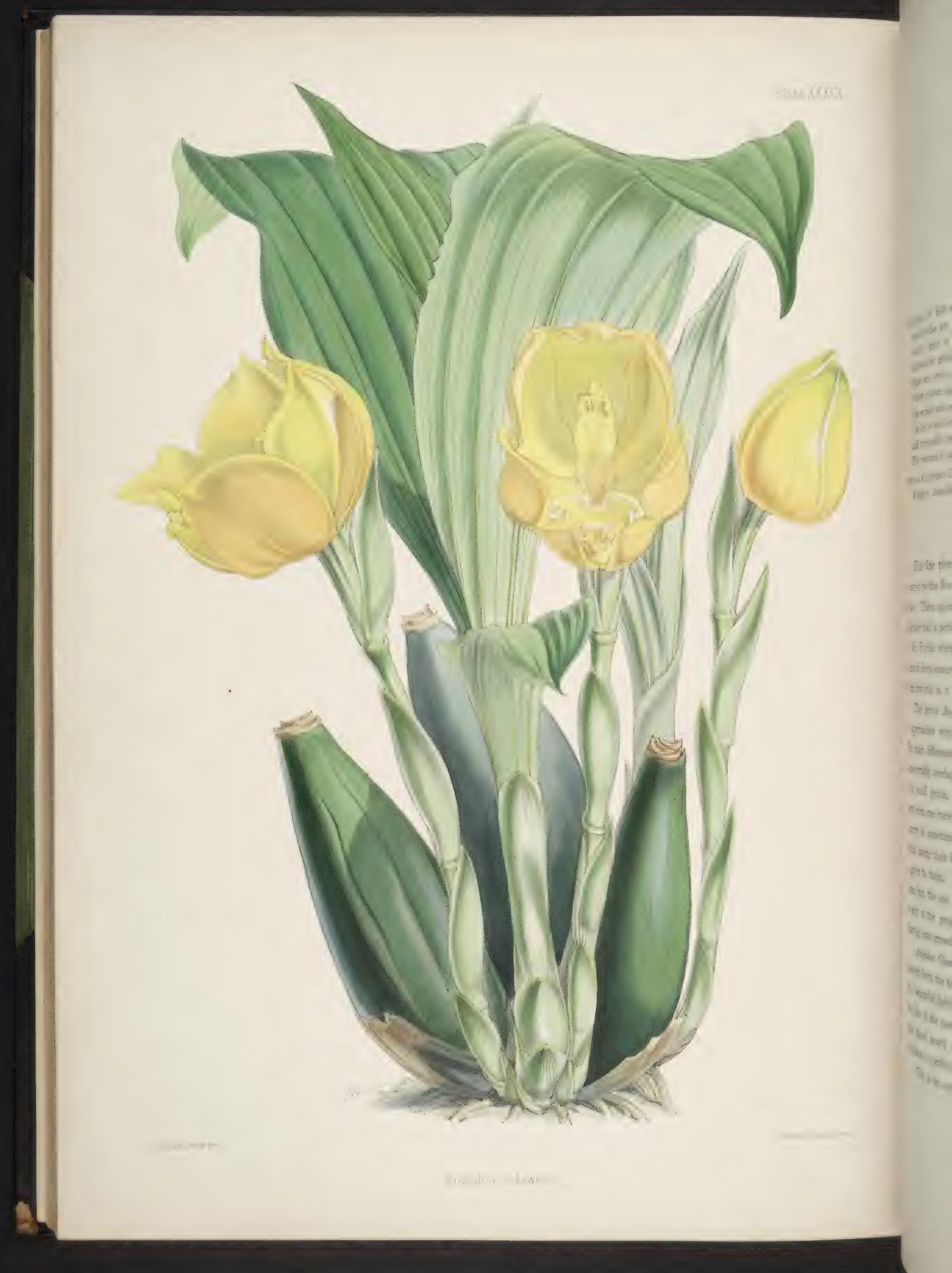


in 1 ine $\times x$ ill

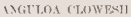

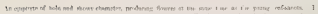

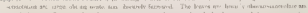

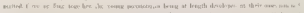

,

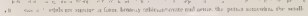

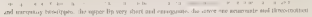

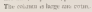

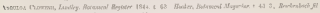

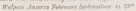

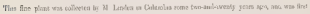

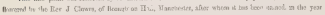

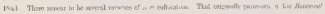

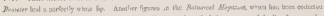

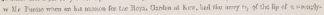

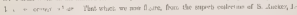

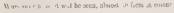

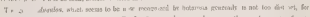

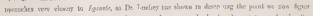

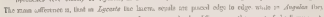

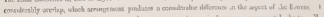

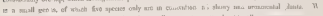

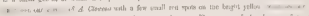

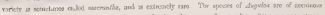

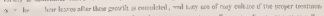

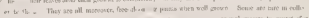

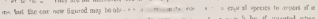

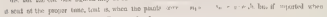

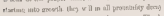

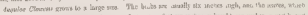

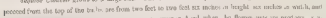

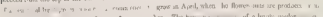

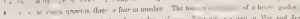

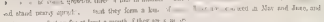

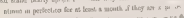

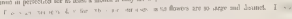




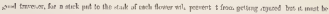

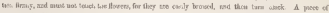

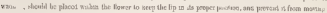

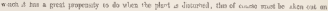

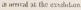

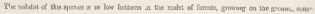

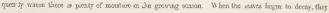

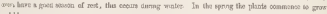
atul tibuer

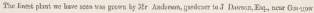

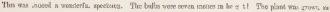

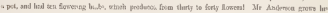

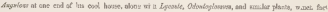

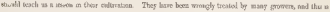

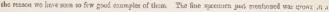

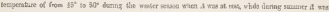

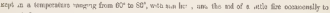

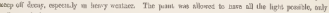

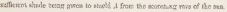

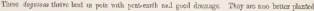

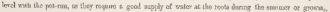

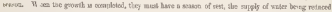

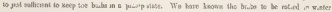

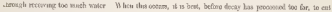

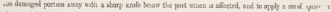

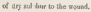

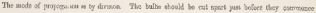

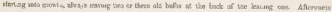

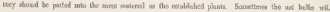

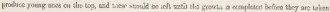

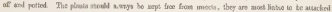
ig toe thinpa 



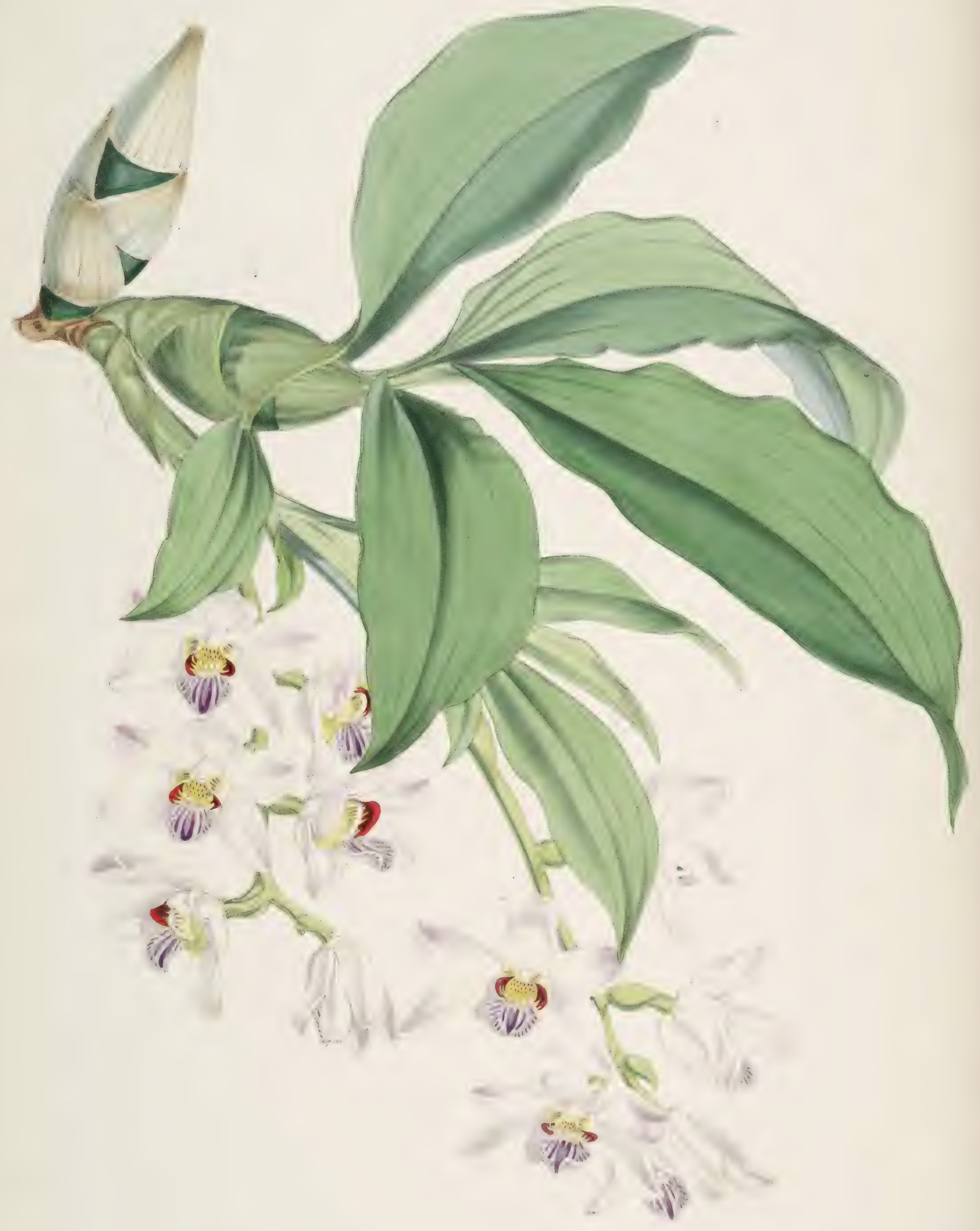


PLATR $\lambda \times x$ I

CIIPGIS JAMHIXYHII

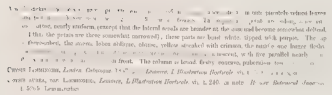

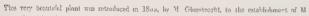

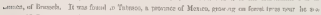

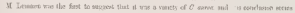

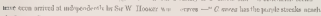

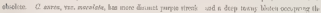

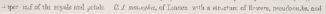

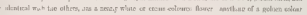

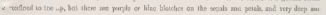

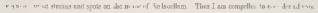

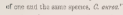

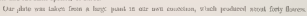

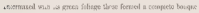

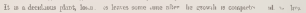

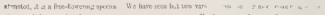

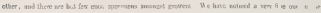

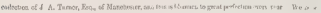

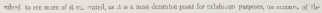

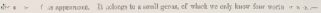

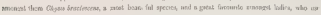

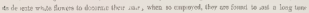

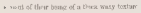

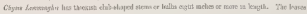

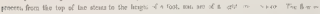

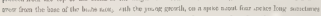

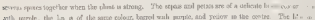

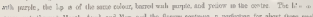

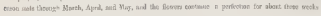




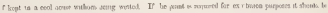

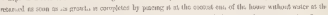

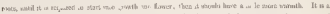

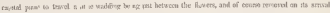

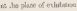

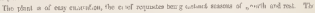

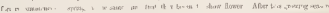

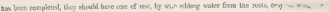

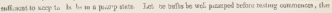

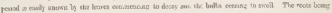

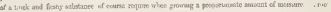

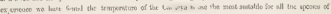

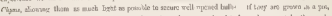

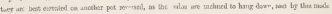

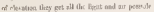

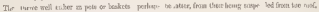

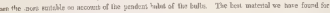

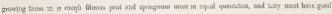

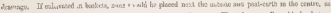

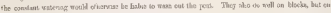

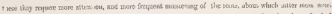

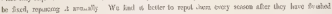

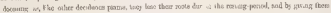

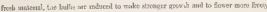

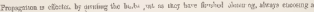

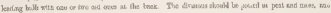

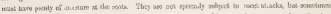

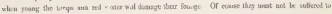
min the sectatecor 



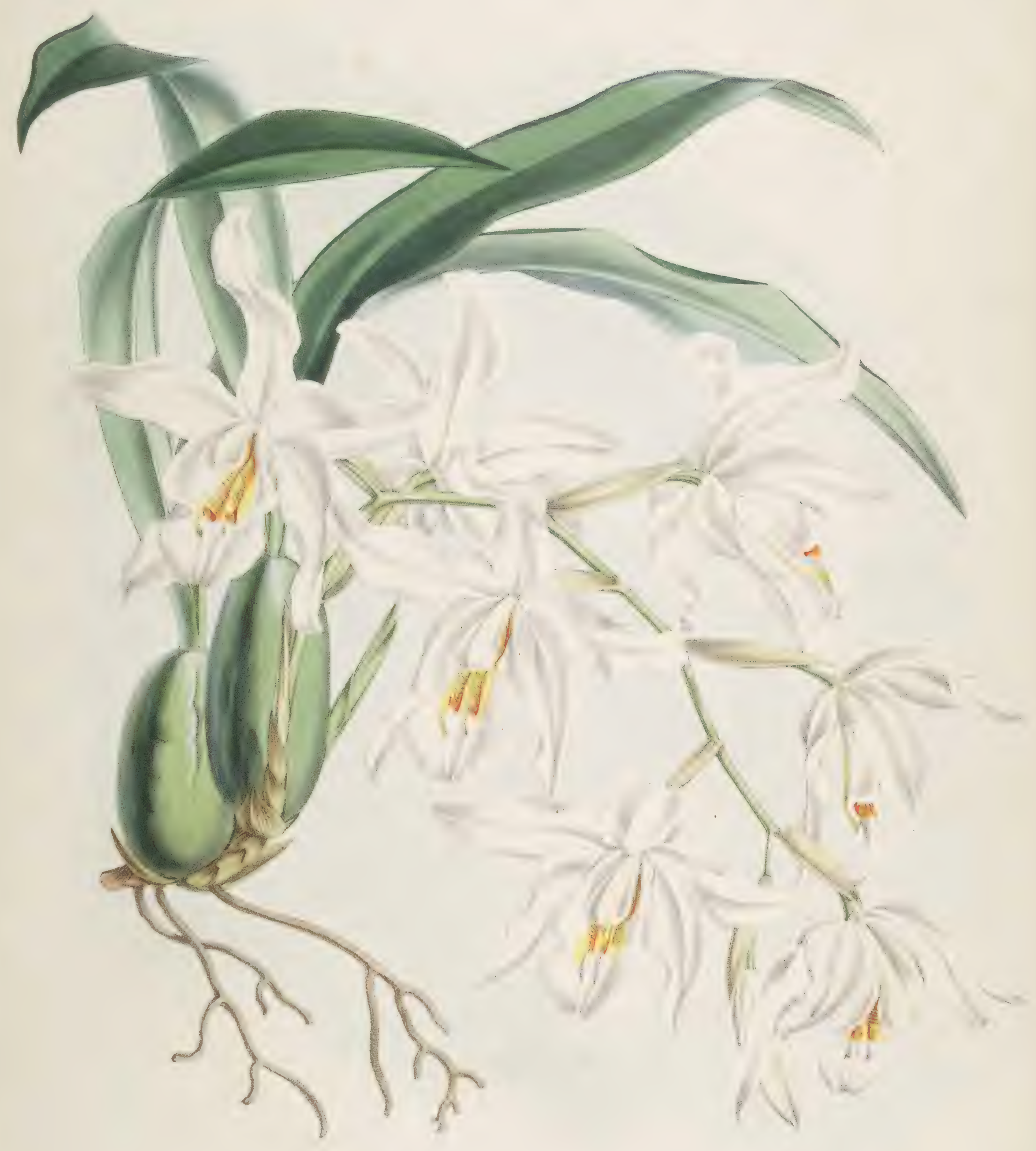


Pa $\mathrm{XXN}$

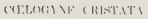

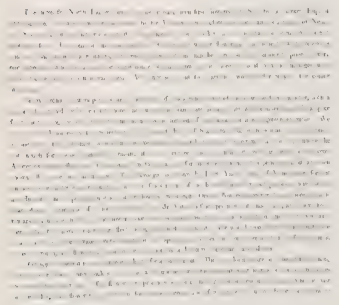




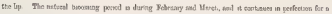

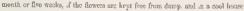

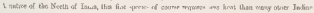

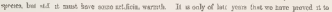

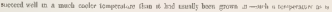

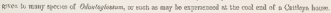

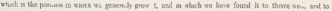

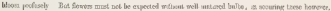

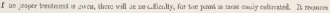

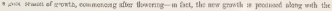

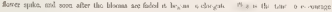

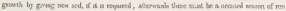

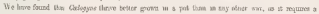

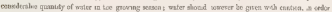

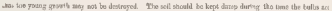

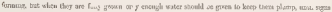

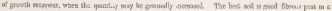

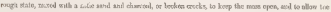

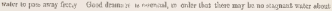

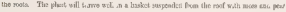

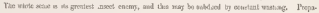

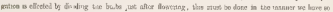

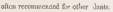





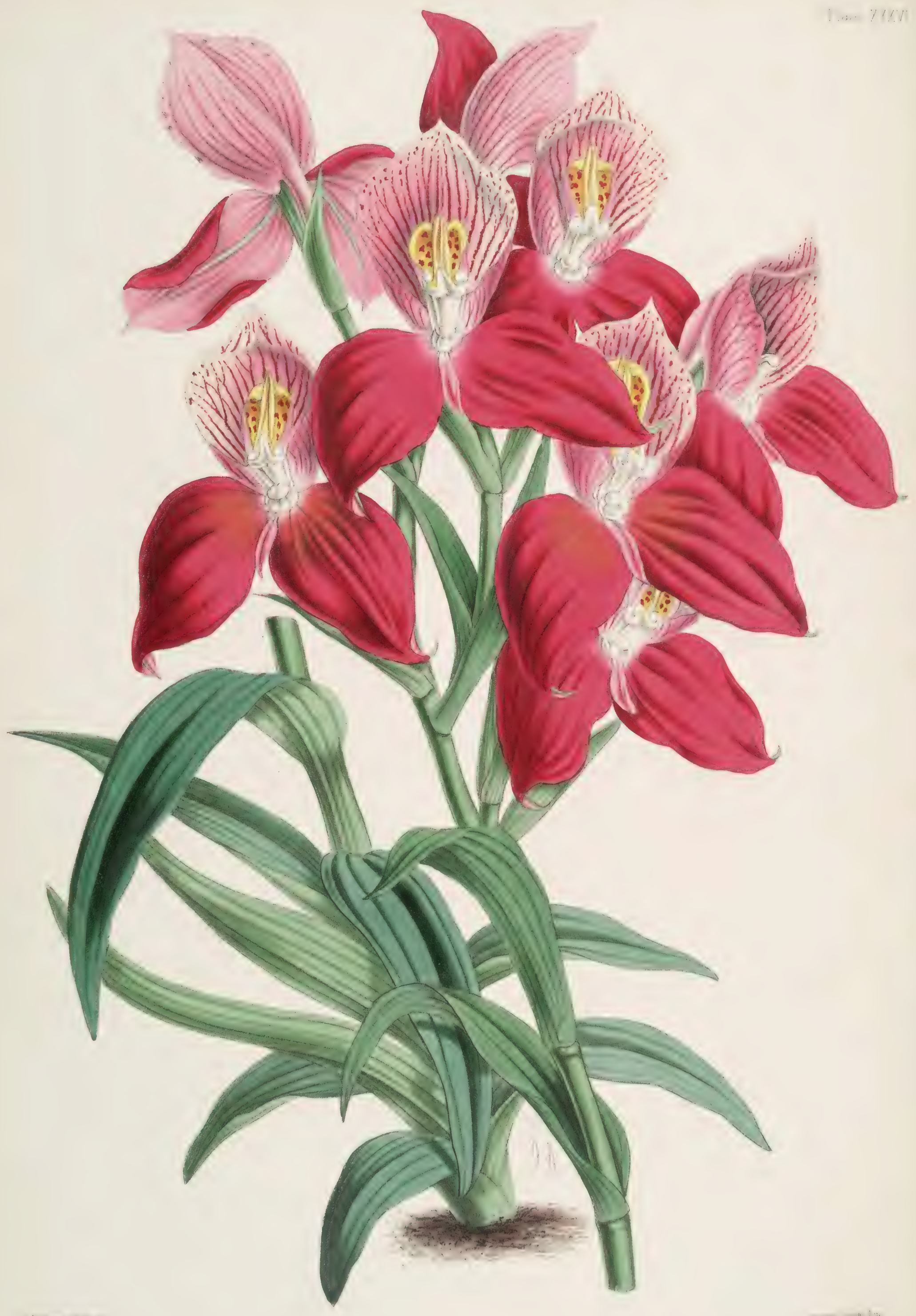


Pesre XXXVI

URA GRANDIFLORA KEPERBA

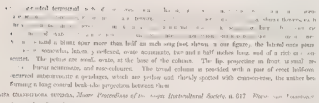

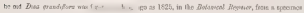

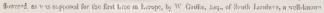

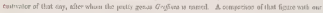

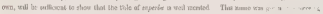

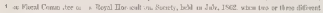

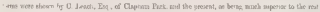

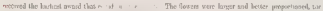

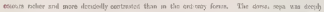

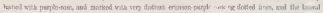

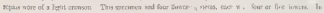

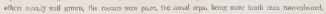

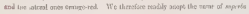

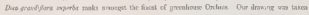

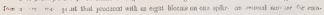

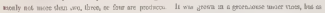

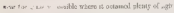

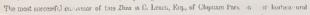

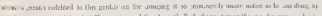

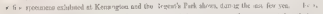

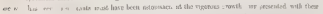

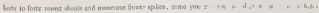

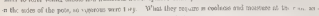

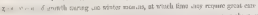

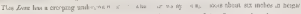

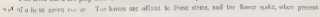




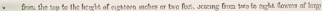

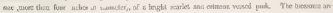

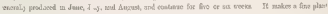

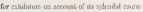

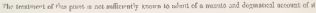

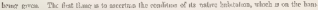

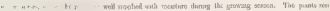

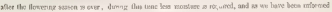

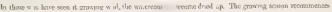

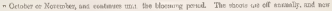

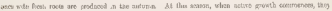

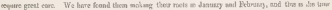

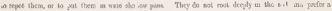

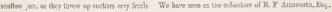

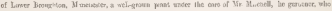

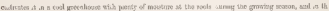

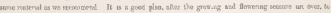

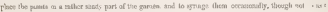

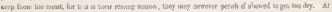

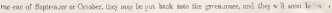

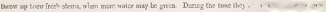

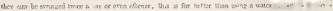

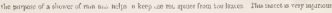

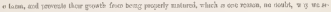

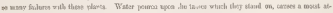

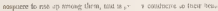

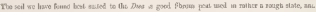

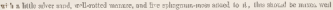

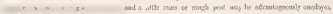

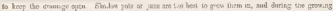

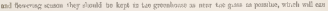

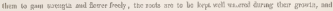

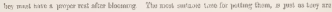

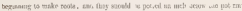

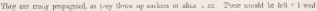

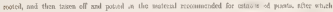

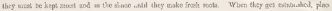

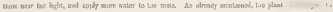

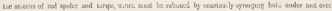
ina leten 



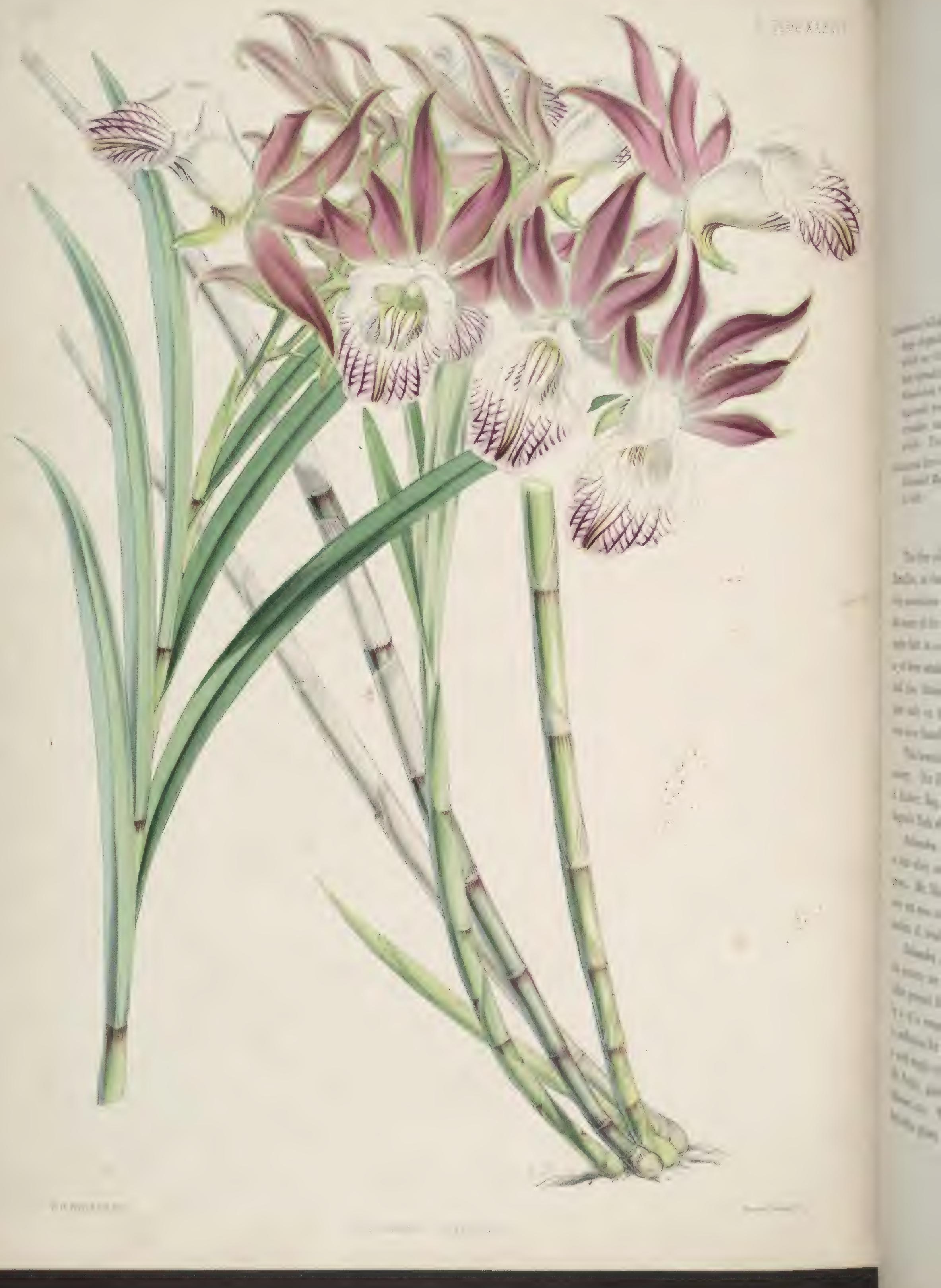


Prat $\lambda+\lambda 311$

G.ALANDRA DFVOYLAA

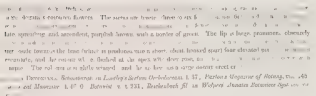

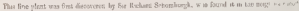

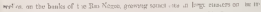

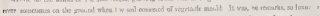

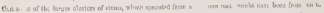

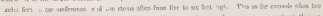

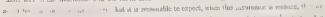

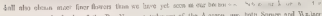

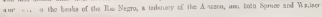

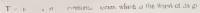

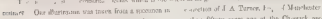

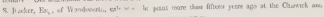

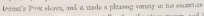

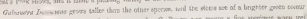

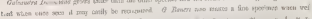

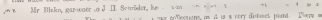

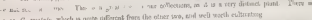

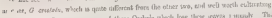

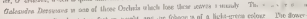

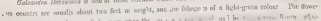

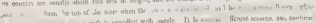

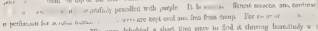

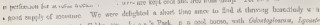

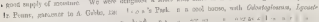

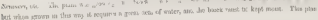




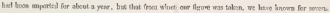

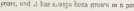

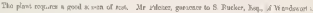

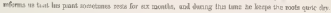

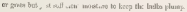

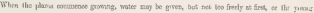

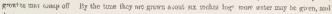

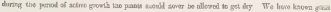

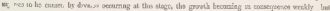

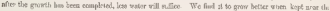

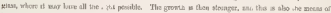

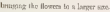

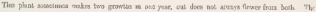

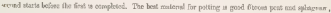

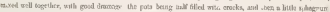

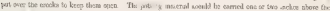

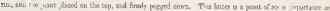

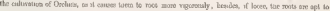
प्रes unueal

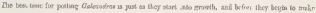

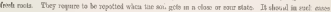

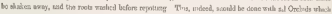

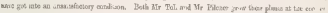

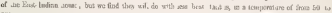

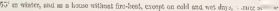

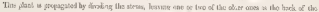

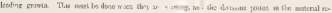

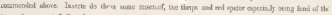

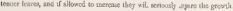





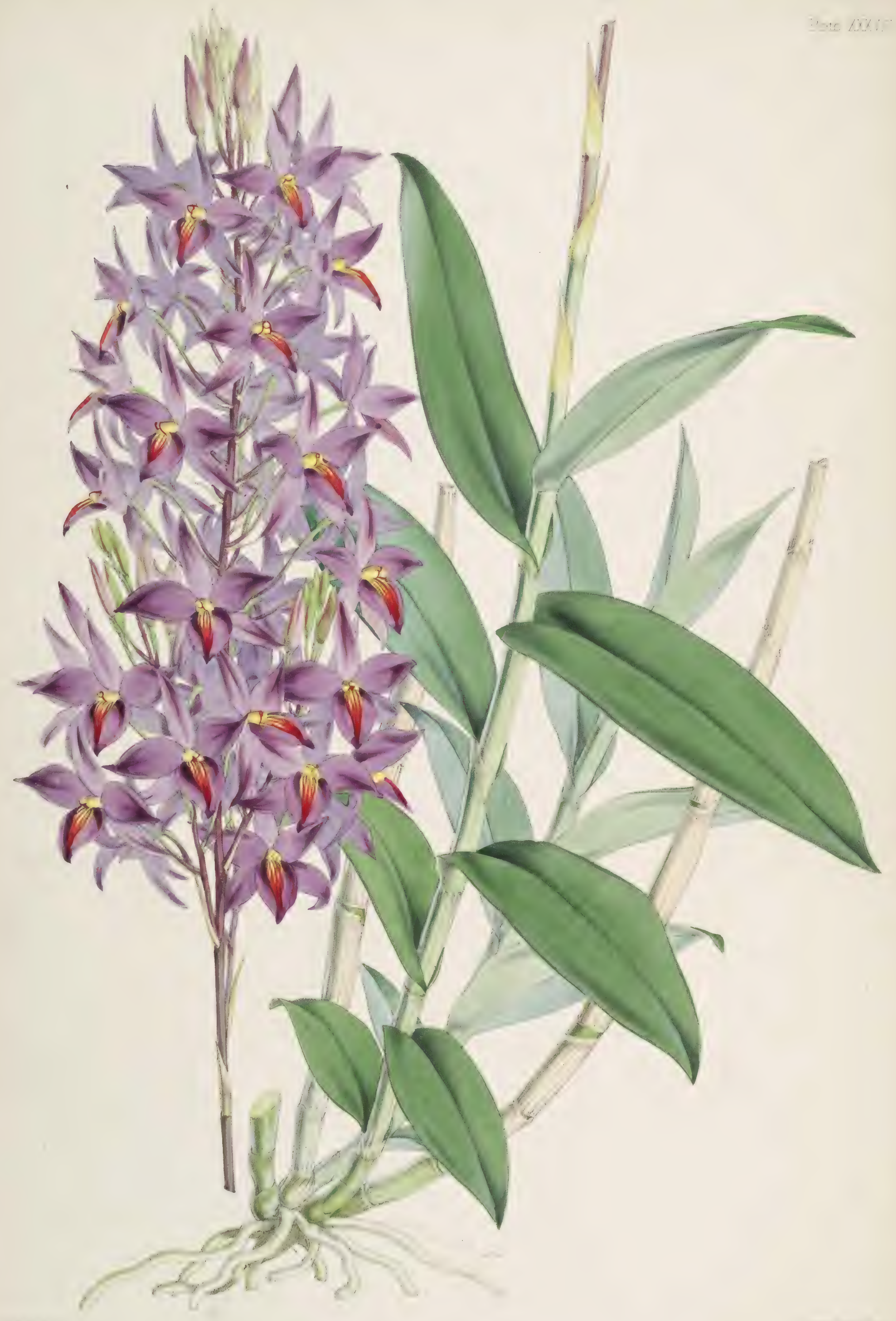

d 
Pinte XXXVנII

LPIDRNDRUM SKINKER SUPERBUM

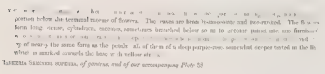

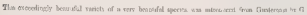

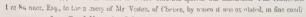

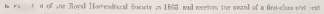

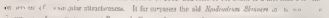

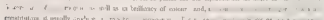

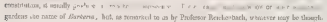

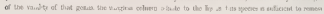

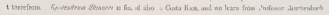

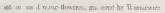

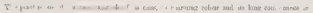

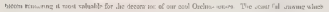

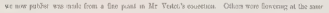

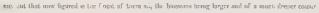

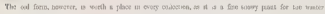

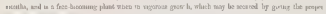

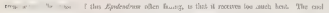

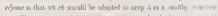

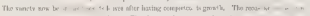

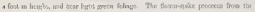

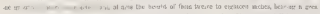

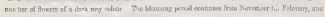

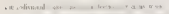

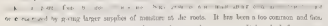

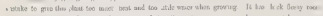

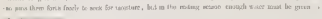

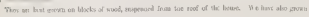




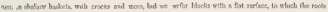

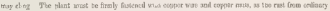

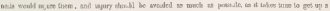

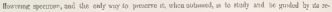

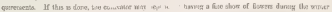

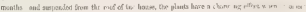

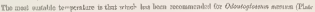

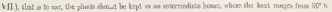

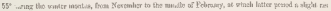

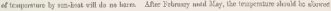

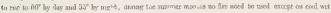

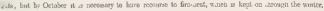

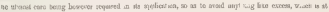

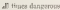

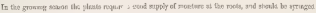

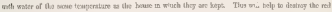

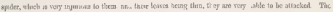

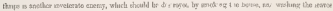

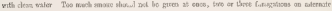

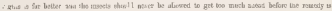
aprizal

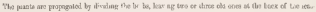

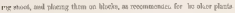




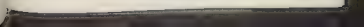




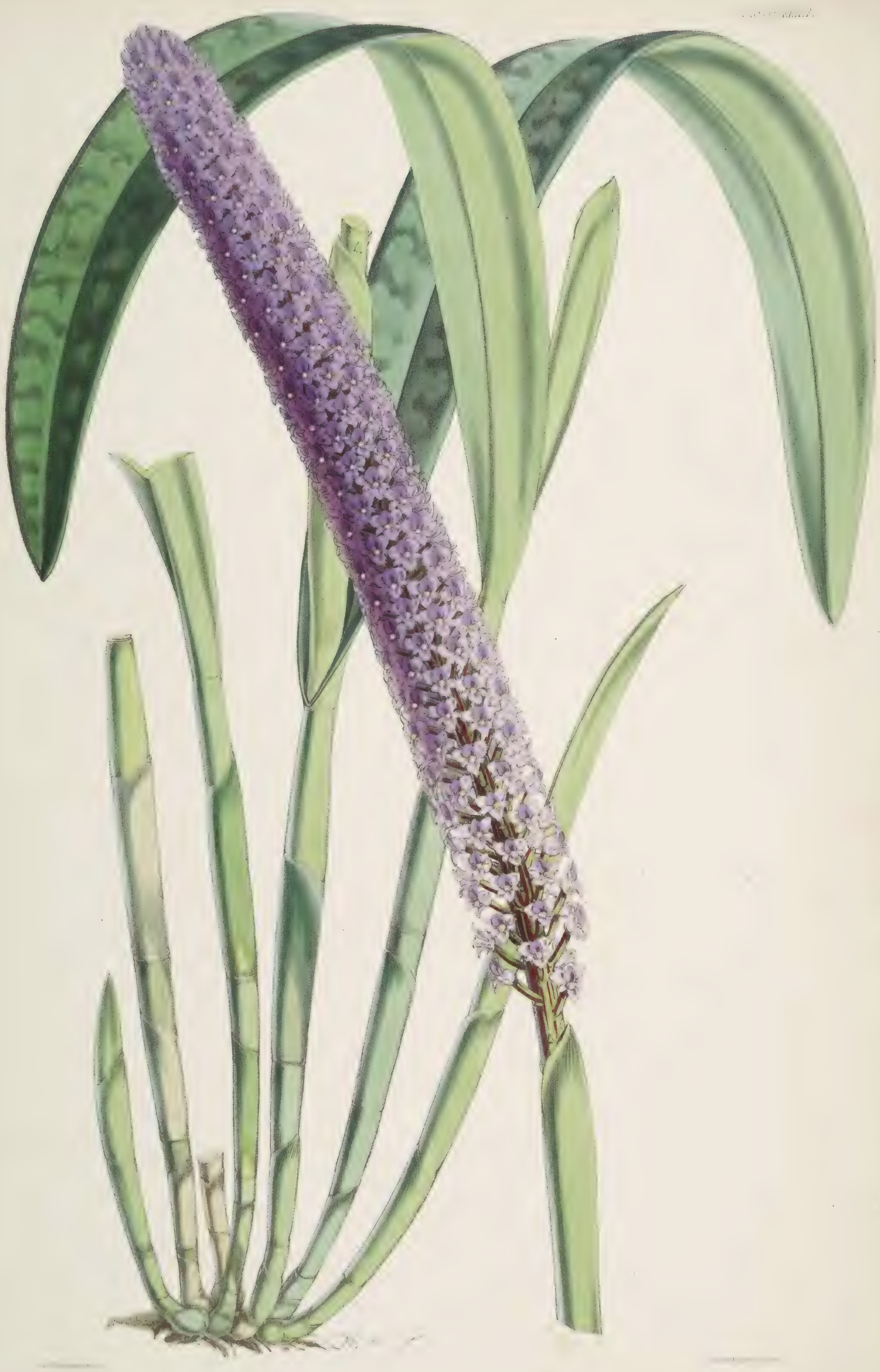

1 
Pusse $3 \times x \times 11$

IRPOPTYLLEX GIGANTERM

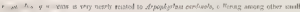

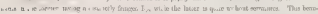

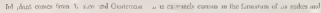

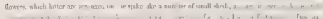

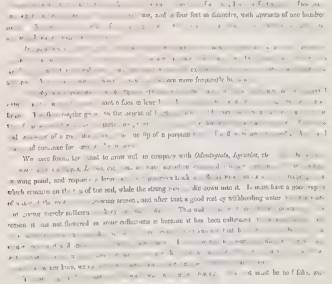




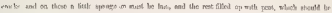

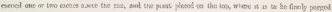

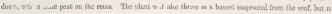

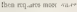

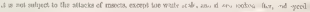

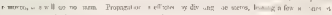

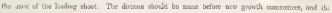

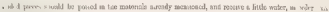

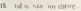




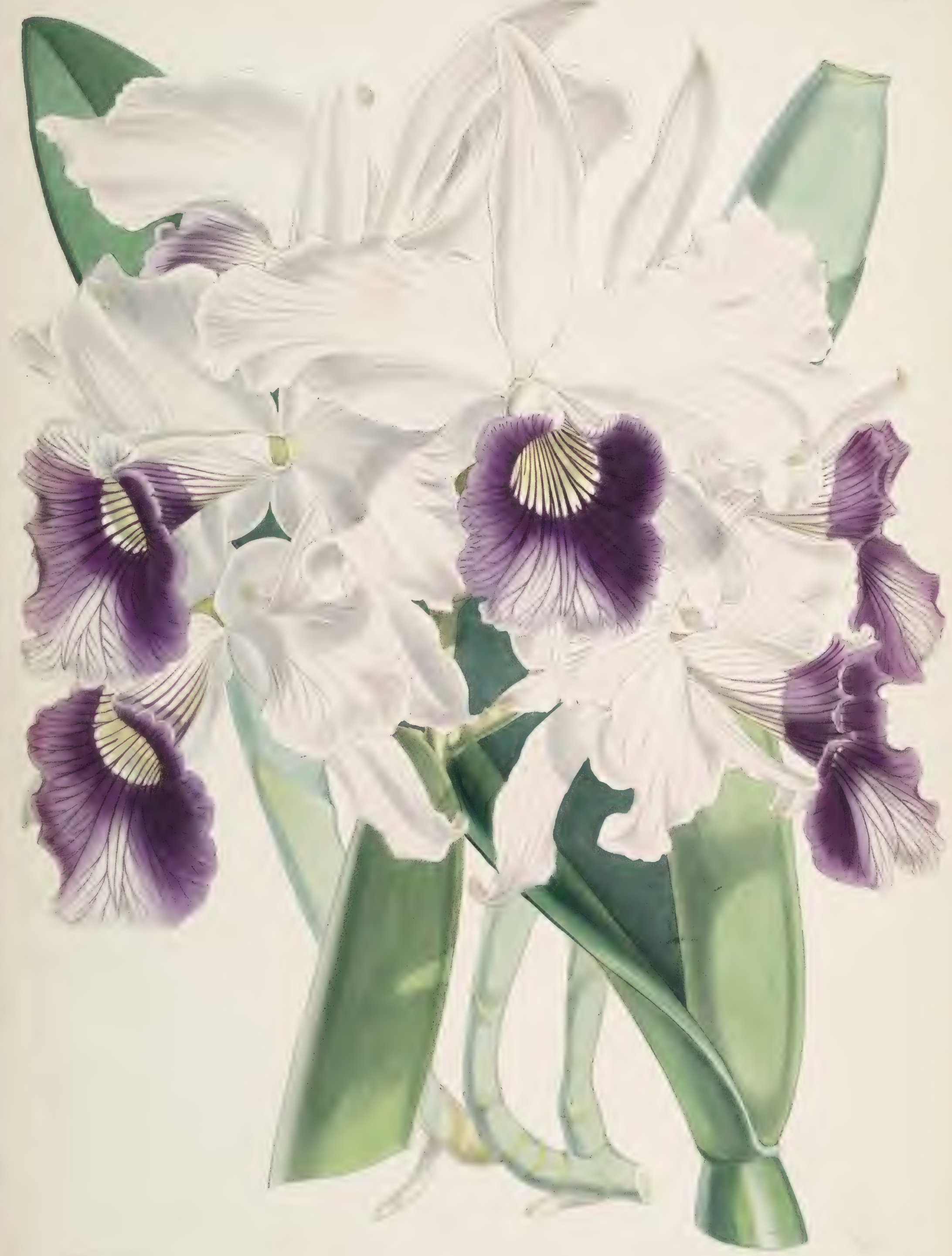
$1 \cdot 1+17 R \times 1$

L.AZLIA PTTPETATA

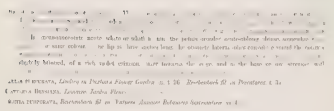

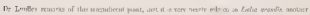

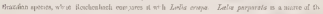

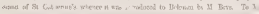

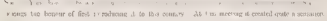

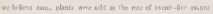

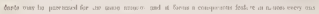

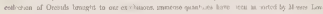

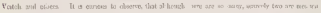

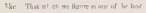

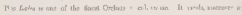

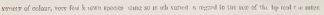

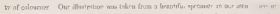

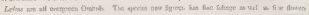

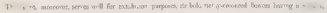

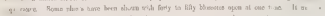

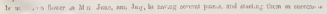

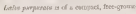

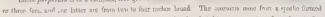

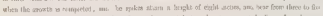

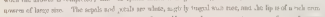

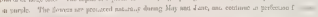

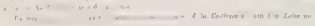





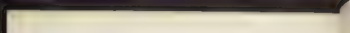




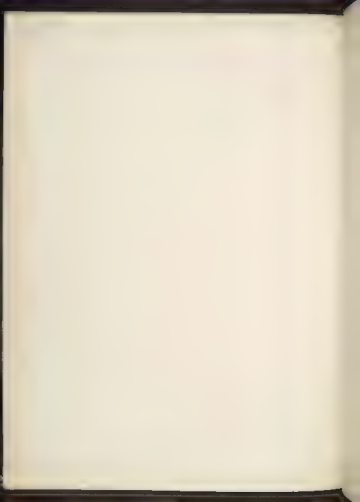





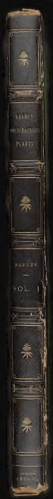

Spine

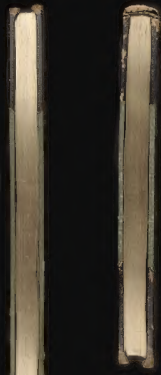

Foot

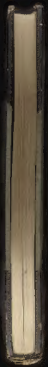

Top

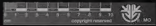

Fore 


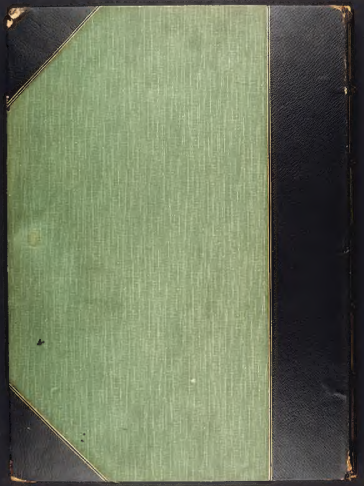




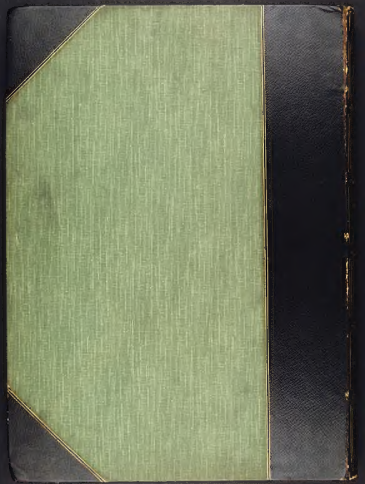

